\title{
XXVIII.
}

Aus dem hirnanatomischen Laboratorium der LandesIrrenanstalt in Wien.

\section{Zur Anatomie und Physiologie des Kleinhirns.}

\author{
Von
}

\author{
Dr. Moriz Probst, \\ Vorstand des Laboratoriums.
}

(Hierzu Tafel XVI-XVIII.)

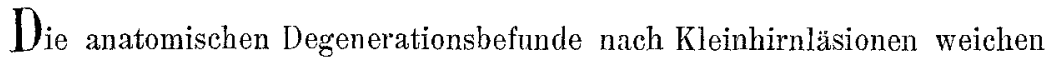
in der mannigfachsten Art bei den verschiedenen Autoren von einander ab. Um nun die verschiedenen Befunde nachzuprüfen, bedurfte es einer stattlichen Anzahl von mannigfaltigen Experimenten. Ich habe die im Folgenden geschilderten Thierversuche mit nachfolgender genauer histologischer Untersuchung auf lückenlosen Seriensehnitten unternommenen, um die anatomisehen Verhältnisse der zum und vom Kleinhirn führenden Bahnen genau darzulegen und ibre Endigungsstellen zu ermitteln. Die Thiere (Hunde und Katzen) lebten rerschieden lange Zeit; das Centralnervensystem wurde mittelst Osminmsäure nach Marchi nach der von mir beschriebenen Methode ${ }^{1}$ ) gefärbt.

Die Erscheinungen, welche die Thiere während und nach der Operation darboten, wurden genau beobachtet, so dass nicht nur die Läsion mit den davon abhängigen secundären Degenerationen, sondern auch die damit verbuudenen unmittelbaren und mittelbaren Erscheinungen festgestellt wurden.

\section{Halbseitige Rindenabtragung des Kleinhirns mit Verletzung des gezahnten Kernes und des Dachkerns.}

Bei erwachsenen Katzen wurden Rindenabtragungen vorgenommen, welche die Medianlinie nicht überschritten. Dabei wurden gewöhnlich

1) Probst, Archiv für Psych. Bd. 33. Heft 1. S. 6. 
die äusseren und oberen Antheile des gezahnten Kerns und des Dachkerns verletzt, in manchen Fällen hat anch der andere Dachkern etwas mitgelitten. Die. Entrindung wurde mit einem Löffelchen vorgenommen. Die Thiere lebten durchschnittlich drei Wochen.

Das Gehirn wurde in lückenlose Serienschnittreihen nach Osmiumsäurefärbung nach Marchi zerlegt.

Von den Versuchen wähle ich einen besonders hervorstechenden als Beispiel heraus, mit dem auch die übrigen Versuche illustrirt sind. Die Iückenlose Frontalschnittserie zeigt deutlich und genau die Verletzung und die secundären Degenerationen.

Beginnen wir mit einem Frontalschnitte, wie einen Figur 1 zeigt. Der Schnitt geht durch das Klejnhirn, Dachkern und gezahnten Kern, durch die Gegend des Facialiskernes, der oberen Olive und des Acusticusliernes. Wir sehen hier die Verletzung der Rindenabtragung auf der linken Hemisphäre des Kleinhirns. Die Rindenabtragung reicht ungefähr bis zur Medianlinie, die Tiefe der Rindenabtragung reicht bis zum äusseren und oberen Theile des gezahnten Kernes und des Dachkerns. Die Art und Grösse des Defectes zeigt die Figur (Photogramm).

Der gezahnte Kern ist nur in seinem äusseren and oberen Theil von der Verletzung erfasst. Sowohl dieser Kern als der Dachkern der Iinken Seite sind erfüllt von zahlreichen degenerirten Nervenfasern, die hier enden. Aber auch der Dachkern der rechten Seite ist von feinen degenerirten Nervenfasern durchsetzt, während der gezahnte Kern der rechten Seite frei von solchen ist. Von der Verletzungsstelle zieht ein Bündel stark degenerirter Fasern über dem Dachkern der rechten Seite und ist bis über den gezahnten Kern zu verfolgen; die Fasern dieses Bündels, das auch in Fig. 1a zu sehen ist, sind dickeren Calibers. Eine Menge feincalibriger Fasern zieht von der Verletzungsstelle in das Mark des Oberwurmes und das Mark der rechten Kleinhirnhernisphäre, wo sie in der Rinde mit Aufsplitterungen enden.

Sehen wir nun, welche degenerirten Fasern in die Medulla oblongata abgehen, so finden wir zahlreiche Fasern degenerirt, dic zu den Acusticuskernen hinziehen, zahlreiche degenerirte Fasern ziehen zam Deiters'schen Kern und ziehen von hier theils als innere Bogenfasern in die Substantia reticalaris, zum Theil als stärkeres Bündel (inneres Stricklörperbündel) an die Innenseite (inneren Abschnitt) des Strickkörpers. Diese degenerirten Fasern sind beiderseits im verlängerten Marke nachzuweisen (b Figur 1). Auf der Verletzungsseite sind im lateralen Theile des Strickkörpers degenerirte Fasern zu treffen, die sich aber bald verlieren und nicht auf längere Strecken hin verfolgbar sind. Im Strickkörper der gesunden Seite sind aber auch solche kurz verlaufende degenerirte Fasern nicht anzutreffen.

Die degenerirten Fasern an der Innenseite des Strickkörpers (b Fig. 1) bilden beiderseits sowohl auf der Verletzungsseite als auf der gesunden Seite ein kleines compactes Bündelchen (inneres Strickliörperbündel), das in dieser Form bis nahe an den Burdach'chen Kern zu verfolgen ist and während 
dieses Verlaufes stets Fasern als innere Bogenfasern an die Substantia reticularis abgiebt. Viele von diesen Fasern enden mit Aufsplitterungen daselbst. Manche der Fasern ziehen linapp an die Raphe, wo sie in die sagittale Richtung umbiegen (c Fig. 1). Von hier aus laufen einige wenige Fasern sowohl in proximaler Richtung gegen den hinteren Zweibügel hin als auch in caudaler Richtung in das Randzonenbündel der vorderen Fissur des Rückenmarkes. Sie sind im verlängerten Mark im Areal der Vierhügel-Vorderstrangbahn gelegen. Am Beginne des Halsmarkes sind diese Fasern noch längs der vorderen Fissur nachweisbar, während sie im mittleren Halsmark nicht mehr nachweisbar sind. Die vom Kleinhirn an die Innenseite des Strickkörpers ziehenden Fasern, welche als innere Bogenfasern in's Areal der Vierhügel-Vorderstrangbahn gelangen and hier proximalwärts ziehen, sind mit Sicherheit nur bis in die proximale Brückengegend verfolgbar, da sich hier bereits andere Kleinhirnfasern beimengen und von einander nicht zu unterscheiden sind. Viele dieser Fasern biegen seitlich in die Substantia reticularis, wo sie mit Aufsplitterungen enden.

Von den candalwärts ziehenden Faserzügen ist noch die von mir bereits als Kleinhirn-Vorderseitenstrangbahn beschriebene Bahn za erwähnen KVS, welche vom Deiters'schen Kern in der Richtung zum Facialiskern abwärts zieht und in die ventrale Randzone des Vorderstranges zu liegen kommt. Diese Bahn war hier nicht degenexirt. Die Fasern der Kleinhirn-Vorderseitenstrangbahn kommen von den Ganglienzellen des Deiters'schen Kerns. In diesem Falle, wo der Deiters'sche Kern ganz unverletzt ist, sehen wir nur sehr wenige einzelne Fasern der Kleinhirn-Vorderseitenstrangbahn degenerirt, die sich nur bis an die laterale Seite der Olive verfolgen lassen. Es beweist dies, dass die Kleinhirninde ganz sicher keine Fasern in die Kleinhirn-Vorderseitenstrangbahn entsendet. In diesem Falle ist aber auch der gezahnte Korn zerstört, es beweist dies, dass auch von diesem Theilo des gezahnten Kernes nur sehr wenige Fasern der Kleinhirn-Vorderseitenstrangbahn entspringen können. Für diese Bahn, die ich aus physiologischen Gründen mit dem Namen Kleinhirn-Vorderstrangbahn bezeichnet habe, kommt nur der Deiters 'sche Kern und Zellen, die zwischen eigentlichem Deiters'schen Kern und gezahntem Kern liegen, als Ursprungsganglienzellen in Betracht.

Die rom Deiters'schen Kern in das Rückenmark absteigenden Bahnen bilden zuerst zwei Bündel, von denen das eine die Kleinhirnvorderstrangbahn yon dem Deiters'schen Kern als innere Bogenfasern gegen die Raphe hinverlaufen, wo sie dann sagittal umbiegen am in das Fissurenrandbündel des Rückenmarkes zu gelangen, wo sie mit den Fasern des dorsalen Längsbündels zusammen verlaufen und bis ins Sacralmark verfolgbar sind. Das andere Bündel, die Kleinhirn-Vorderseitenstrangbahn geht rom Deiters'schen Kern durch die Substantia reticularis an die laterale Seite der unteren. Olive und gelangt von hier in die ventrale Randzone des Rückenmarkes und steigt hier, wo die vorderen Wurzeln des Rückenmarkes austreten, abwärts. Die Kleinhirn-Vorderstrangbahn und die Kleinhirnvorderseitenstrangbahn sind im Halsmark von einander getrennt durch die Vier- 
hügel-Vorderstrangbahn, welche letztere bis ins Brustmark reicht. Im unteren Halsmark und oberen Brustmark bilden die Kleinhirn-Vorderstrangbahn und die Kleinhirn-Vorderseitenstrangbahn bereits ein vereinigtes, geschlossenes Bündel, welches die Fissurenrandzone und die ventrale Randzone einnimmt, das ich kurzweg als Kleinhirn-Vorderseitenstrangbahn bezeichne. In dieser Weise ziehen die Fasern, wenn auch der Deiters'sche Kern verletzt ist, bis in's Sacralmark, Figur 15 (KVS), während ihres Verlaufes stets Fäserchen in die Vorderhörner entsendend. In diesom Falle war die Kleinhirn-Vorderstrangbahn nur zu eixem kleinen Theile degenerirt, und zwar bis an die laterale Seite der Olive.

Die Kleinhirn-Vorderstrangbahn dehnt sich längs der Fissurenrandzone des Rückenmarkes aus. Bie Kleinhirn-Vorderseitenstrangbahn liegt im oberen Halsmark nicht mit allen Fasern in der Peripherie der ventralen Randzone, sondern die lateralsten Fasern liegen von der Peripherie etwas weiter ab. (Figur 14 KVS.) Erst im unteren Halsmark und im Brustmark liegen alle Fasern der Kleinhirn-Vorderseitenstrangbahn ganz peripher. Nach rückwärts (dorsalwärts) dehnt sich die Kleinhirn-Vorderseitenstrangbahn bis dorthin aus, wo die Verbindungslinie der vorderen Antheile der Vorderhörner die Peripherie des Rückenmarkes trifft. Im Lenden- und Sacralmark reichen die Fasern aber nicht so weit nach hinten, sondern sie sind in die ventrale Randzone zusammengedrängt. Die Lage der Kleinhirn-Vorder- und Vorderseitenstrangbahn im unteren Halsmark habe ich in Figur 10 meiner Arbeit im Band XXX dieses Archivs gegeben; anch habe ich in Figur 6 u. 7 Band XV der deutschen Zeitschrift für Nervenheilkunde die Kleinhirn-Vorderseitenstrangbahn abgebildet in Bezug auf ihre Lage zur unteren Olive und im oberen Halsmark.

Ein anderes Bündel, das jch anderwärts ebenfalls schon! beschrieben babe, sehen wir im ventralen Theile der Substantia reticularis knapp an der Raphe, unmittelbar über der medialen Schleife degenerirt. Die Fasern dieses Bündels kommen von der linken Seite, der Verletzungsseite, des Kleinhins (gezabnten Kern), ziehen dorch den Deiters'schen Kern und gelangen als innere Bogenfasern durch den ventralen Theil der Substantia reticularis überschreiten die Raphe und biegen im Winkel zwischen Raphe und medialer Sehleife in die sagittale Rightung um. Sie behalten stets diese Lage inne und sind, wie wir noch sehen werden, bis in den Sehhügel verfolgbar, woselbst sie mit Aufsplitterungen enden. (Ventrales Kleinhirn-Thalamusbändel) Dieses ventrale Kleinhirn-Thalamusbündel wird von Fasern verstärkt, die von der Substantia gelatinosa der aufsteigenden Trigeminuswurzel und vom Monak:0 w' schen Kiern. komwen, wie ich das anderwärts durch Versuche mit Zerstörung der Substantia gelatinosa der aufsteigenden Trigeminuswurzel feststellte. $\left.{ }^{1}\right)$ Ausserdem erhält dieses Bündel in der hinteren Zweihügelgegend einen Zuwachs an Fasern vorn Bindearm, wio wir noch sehen werden.

1) Experimentelle Untersuchungen über die Schleifenendigung, die Hazbenbahmen, das dorsale Längsbündel und die bintere Commissur. Dieses 
In den Frontalsohnitten, die caudal vom Schnitte, den Figur 1 darstellt, gelegen sind, finden wir die Läsion des Kleinhirns stets ebenso einseitig; als auf den frontaler gelegenen Schnitten. Auf den eaudaleren Schnitten können. wir die Bündel b (inneres Strickkörperbündel) auf beiden Seiten weiter verfolgen, Sie liegen zwischen dem Strickkörper und der aufsteigenden Trigeminuswurzel und caudaler, wo der Fasciculus solitarius auftritt zwischen dem Stricklörper, der aufsteigenden Trigeminuswurzel und dem Fasciculus solitarius. Von hier aus geben sie im Verlaufe stets Fasern ab, die als innere Bogenfasern in der Substantia reticularis mit Aufsplitterungen enden, theils neben der Raphe in die sagittale Richtung umbiegen. Die Fasern der Bündel ziehen bis zu den Hinterstrangkernen.

Die Bündel b, welche den sogenannten inneren Antheil des Strickkörpers bilden, geben während ihres ganzen Verlaufes eine Nenge innerer Bogenfasern in die Substantia relicularis ab, die zum grossen Theile hier endigen. Einige wenige solcher Bogenfasern der Verletzungsseite überschreiten aber die Raphe und gehen zur gegenüberliegenden unteren Olve, wo sie endigen. Die Anzabl dieser Fasern ist eine geringe; sie stellen eine sehr spärliche Verbindung des Kleinhirns mit der gegenüberliegenden unteren Olive dar. (Der Hauptverbindungszug geht aber im umgekehrten Sinne von der unteren Olive zum Kleinhirn.) Die Bündeln b nenne ich das ,innexe Strckkörperbündel", welche zu einem Theile dem Tractus nucleo-cerebellaris von Edinger entsprchen. Diese austrahlende Kleinhirnbahn degenerirt nach einseitiger Kleinhirnabtragung beiderseits. Ein grosser Theil dieser ausstrahlenden Kleinhirnbahn endigt beim Deiters'schen Kern, ein Theil, das innere Strickkorperbündel, zieht aber längs der vierten Ventrikels caudalwärts im sogenannten inneren Antheil des Strickiörpers und gelangt bis zu den Burdach'schen Kernen, wo die Fasern, nachdem sie schon eine Menge innerer Bogenfasern abgegeben haben, endigen.

Ausserdem finden wir in Figur 1 auch den äussersten (lateralsten) Antheil des Strickkörpers auf der Verletzungsseite degenerirt. Es sind das Fasern, welche vom Dachkern und vom Mittellappen herkommen und duroh den äusseren Theil des Stricklkörpers gegen den Seitenstrangkern hin verlaufen; ausserdem geben diese Fasern auch innere Bogenfasern ab. Beiu Seitenstrangkern endigen die meisten dieser Fasern, einzelne scheinen aber auch als äussere Bogenfasern gegen die Pyramiden und in die Raphe zu verlaufen, obne mit Sicherheit zur gegenüberliegenden Olive verfolgt werden zu können.

Wenn wir in der Durchmusterung der lückenlosen Serienschnitte weiter frontalwärts schreiten, so finden wir die Degenerationsverhältnisse so vor, wie sie Figur 2 zeigt.

Den Frontalschnitt, den Figur 2 wiedergiebt, geht durch den Dachkern und gezahnten Kern, Abducenskern und das Facialislnie. Die Läsion der

Archiv. Bd. 33. H. 1 und Monatsschr. f. Psychiatrie 1901 and Archiv für Anatomie und Physiologie. 1902. 
Rindenabtragung erstreckt sich bis in die laterale Zone des Nucleus dentatus and die obere Seite des linken Dachkernes. Der linke Nucleus dentatus und beide Dachkerne sind erfüllt von zahlreichen feinen degenerirten Fäserchen, der rechte Nucleus dentatus ist davon frei.

Zahlreiche feine degenerirte Fasern gehen von der Verletzungsstelle in das Mark der rechten Hemisphäre über.

Von dem in seinen äusseren Theilen lädirten Nucleus dentatus sehen wir auf diesem Schnitte ein stärkeres degenerirtes Bündel gegen den linken Rand des vierten Ventrikels zu verlaufen - es sind das die ersten Fasern des degenerirten Bindearmes. (B A Figur 2.)

Von dem Dachkerne ziehen degenerirte Fasern (c Figur 2) ventralwärts und kreuzen sich im ventralen. Markantheile des Oberwurmes, um von hier aus in den proximaleren Schnitten in die oberen Theile des Bindearmes zu gelangen und in den caudaleren Schnitten an die mediale Seite des Strickkörpers (b Figur 1) zu kommen und von hier aus theils als innere Bogenfasern in die Substantia reticularis zu gelangen, theils bis zu den Hinterstrangkernen zu verlaufen.

Durch den Deiters'schen Kern ziehen eine Menge degenerirter. Fasern hindurch in die Substantia reticularis, wo sie im Areal der Vierhügel-Vorderstrangbahn in die sagittale Richtung umbiegen und hier weiter in die Brücke verlaufen. Fine Menge solcher Fasern endigen im Deiters'schen Kern.

Ausserdem ziehen von der Verletzungsstelle durch den Deiters'schen Kern Bogenfasern, welche die Raphe überschreiten und im Winkel zwischen Raphe und medialer Schleife in die sagittale Richtung ambiegen and hier bis zum Nucleus reticularis und dann in den Sehhügel verlaufen. (Ventrales Kleinhirn-Thalamusbündel).

Viele Bogenfasern, die vom Kleinhirn durch den Deiters'schen Kern ziehen, treten zum dreieckigen Acusticuskern.

Auf den folgenden Frontalschnitten proximalwärts sehen wir den Binde. arm als starkes Bündel aus dem gezahnten Kern treten, das von den Fasern aus dem gekreuzten und gleichseitigem Dachkern, die sich dorsal dem Bindearm auflegen, verstärkt wird. Die Fasern, welche wir auf Figur $2 \mathrm{c}$ aus dem Dachkern abgehen sehen, kreazen sich in der Raphe des Oberwurmes, die ebenso aussieht wie die Raphe im verlängerten Mark und der Brücke und legen sich dorsal gleichsam wie eine Haube auf den Hauptstamm der Bindearmfasern, die im gezahnten Kern entspringen. Dieses Bündel nenne ich das „aceessorische Bindearmbündel"1). In Figur 3 sehen wir bereits einen Frontalschnitt durch das distale Brückenende hinter dem Trigeminusausstritte. Hier sehen wir bereits die aus dem gekreuzten und gleichseitigen Dạchkern stammenden Fasern o einerseits den linken Bindearm im dorsalen Theil verstärken, andererseits sehen wir auch die Fasern c gleichsam als Haube auf dem gegenüberliegenden Bindearm aufsitzen, dessen Hauptzug, der

1) Probst. Zur Kenntniss des Bindearmes, der Haubenstrahlung und der Regio subthalamica. Monatsschrift f. Psychiatrie u. Neurologie. 1901. 
aus dem gezahnten Kern stammt, unversehrt ist. Daraus sehen wir, dass nicht nur der gezahnte Kern, sondern auch der Dachkern und zwar hauptsächlich der gegenüberliegende Ursprungszellen für den Bindearm abgiebt. Ausserdem sehen wir hier die Lage dieser verschieden entspringenden Fasern im Bindearm deutlich gekennzeichnet.

Der gezahnte Kern der gesunden Kleinhirnhälfte zeigt einstrahlende degenerirte Fasern.

Durch den Deiters'schen Kern ziehen noch viele degenerirte Fasern hindurch, um als innere Bogenfasern in die Substantia reticularis überzugehen und theilweise neben der Raphe in die sagittale Richtung umzubiegen. Zum Trigeminuskern treten ebenfalls welche vom Kleinhirn kommende Bogenfasern.

Dem ventralen Kleinhirn-Thalamusbündel laufen noch immer Fasern von der Verletzungsstelle zu, indem sie als innere Bogenfasern von der Gegend des Deiters'schen Kernes kommen und in der Raphe abwärts auf die andere Seite übergehen. Einzelne dieser Bogenfasern biegen aber nicht im ventralen Kleinhirn-Thalamusbündel in die sagittale Richtung um, sondern gehen weiter in den lateralen Antheil der gegenüberliegenden Substantia reticularis, etwa in die Gegend der oberen Olive.

Die Zahl dieser Fasern ist eine sehr spärliche. Mediale Schleife und Trapezkörper sind intact. Die Fasern des ventralen Kleinhirn-Thalamusbündels sind feincalibrig. Die Fasern, welche wie eine Haube dem Bindearm aufsitzen, accessorisches Bindearmbündel, gehen theils als innere Bogenfasern in die Substantia relicularis, theils bleiben sie im Areal des Bindearmes und gelangen proximal in die Gegend der Haubenfascikeln von Forel und in die innere Marklamelle der Sehhügel.

In den folgenden proximalen Schnitten sehen wir die Grösse und Art der Verletzung der linken Kleinhirnhemisphäre im Photogramme der Figur 4. Die Läsion reicht nicht mehr bis zur Medianlinie.

Zahlreiche degenerirte Fasern ziehen von der Verletzungsstelle zum Oberwurm und auch zur anderen Kleinhirnhemisphäre.

Wir sehen in Figur 4 den Frontalschnitt durch die Brückenarme und den Nucleus reticularis pontis gehen.

Von der Verletzungsstelle ziehen degenerirte Fasern, besonders im inneren (medialen) Antheil durch den Brückenarm abwärts, überschreiten die Mittellinie und endigen mit Aufsplitterungen im Brückengrau, das um die gegenüberliegende Pyramidenbahn angesammelt ist, theils steigen sie in der Raphe aufwärts zum gegenüberliegenden Nucleus reticularis pontis, wo sie sich zum Theil aufsplittern.

Den linken Bindearm seheri wir völlig degenerirt, im rechten Bindearm sehen wir die aus dem Dachkern kommenden Fasern "das accessorische Bindearmbündel" degenerirt, die hauptsächlich dorsal dem Bindearm aufsitzen, aber hier schon etwas zerstreut in das Innere des Bindearmes zu liegen kommen.

Noch immer ziehen Kleinhirnfasern von der Gegend der Bindearme als innere Bogenfasern gegen die Raphe, wo sie zum Theil im Areal der Vier- 
hügel-Vorderstrangbahn in die sagittale Richtang umbiegen und proximalwärts zu verfolgen sind.

Auch das ventrale Kleinhirn-Thalamusbündel wird noch immer durch Bogenfasern, die in die sagittale Richtung umbiegen, verstärkt. Auf dem Schnitte, den Figur 4 darbietet, sehen wir den Nucleus reticularis pontis auftreten. Dieser scheint für das Kleinhirn-Thalamusbündel dieselbe Bedeutung zu haben, wie der rothe Kern für den Bindearm. Im Nucleus reticularis pontis giebt das ventrale Kleinhirn-Thalamusbündel zahlreiche Collateralen $a b$, die sich hier aufsplittern; der Hauptzug des ventralen Kleinhirn-Thalamusbündel zieht weiter proximalwärts.

Der Brückenarm der gesunden Seite zeigt lauter intacte Fasern.

In den proximalwärts folgenden Schnitten sehen wir das ventrale Kleinhirn-Thalamusbündel dorsal vom Nucleus reticularis pontis durch neu zuwachsende Bogenfasern sich ausdehnen, bis es noch weiter proximalwärts mit den gekreuzten Bindearmfasern zusammen weiter gegen den Sehhügel zieht.

Einzelne Brückenarmfasern durchziehen die Pyramidenbündel der Verletzungsseite und gelangen bis zur Raphe, in welcher sis aufwärts steigen in die Substantia reticularis und wahrscheinlich im Nucleus reticularis pontis der gegenüberliegenden Seite endigen, da sie nicht weiter verfolgbar sind.

Die mediale Schleife erhält keine Fasern von dem Bezirke des zerstörten Kleinhirns. Der Theil, den ich als besonders ventrales Kleinhirn-Thalamusbündel beschreibe, gehört nicht zur medialen Schleife.

Wenn wir in der lückenlosen Serienschnittreihe weitergehen, so sehen wir ähnliche Verbältnisse in der proximalen Ponsgegend. In der hinteren Zweihügelgegend finden wir die degenerirten Fasern in der Anordnung wie es Figur 5 zeigt. Das Photogramm zeigt einen Frontalschnitt durch die Bindearmkreuzang etwas caudal vom Trochleariskern.

Von dem ventralen Theil des vollständig degenerirten Bindearmes löst sich ein geschlossenes Bündel ab, das in Gestalt von inneren Bogenfasern knapp über der medialen Schleife zur Mittellinie zieht, daselbst über das hier angesammelte Grau hinübersteigt und in das ventrale Kleinhirn-Thalamusbündel der gegenüberliegenden Seite einmündet und mit diesem vereint in den Sehhügel zieht, wo die Fasern mit Aufsplitterungen enden. Ich habe diesen ventralen Antheil des Bindearmes bereits sehon als besondere Verstärkung des ventralen Kleinhirn-Thalamusbündels beschrieben. Der Bindearm theilt sich also in der hinteren Zweihügelgegend in einen starken dorsalen und einen schwachen ventralen Arm.

Der Bindearm kreuzt in der Art und Weise auf die andere Seite, wie es die Figur 5 zeigt. Zuerst gelangen die dorsalsten Fasern des Bindearmes zur Kreuzung, dann allmählig die ventraler liegenden. Dadurch erhält der Bindearm ein breit gezogenes Aussehen.

Nach seiner Kreuzung biegen die Bindearmfasern knapp an der Raphe in die sagittale Richtang um, ähnlich wie die Fasern des ventralen KleinhirnThalamusbündels, nur dass die Fasern des Bindearmes dorsaler liegen und ein 
dorsales Kleinhirn-Thalamusbündel darstellen, zum Untersohied vom ventralen Kleinhirn-Thalamusbündel.

Beiderseits finden wir aber in dem Frontalschnitt, den Figur 6 darstellt noch degenerirte Fasern, die keine Kreuzung eingehen (Figur 8) und im dorsalen Theile der Substantia reticularis, knapp unter dem centralen Höhlengrau zwischem dorsalen Längsbündel und Innenrand des hinteren Zweihügels gelegen sind. Die Fasern kommen yon dem gegenüberliegenden Dachkern des Kleinhirns und stellen die scheinbar ungekreuzten Fasern des Bindearmes dar, sie sind die proximale Fortsetzung eines Theiles des accessorischen Bindearmbündels.

Während das dorsale Längsbündel nach meinen Untersuchungen mit Zerstörung des Deiters'schen Kerns viele Fasern von diesem erhält ${ }^{1}$ ), empfängt es keine Fasern vom Kleinhirn, wie wir es diesen Frontalschnitten entnehmen, wo der Deiters'sche Kern vollständig unversehrt ist.

Nach der Bindearmkreuzung finden wir die Faserzüge so angeordnet, wie es das Photogramm der Figur 6 zeigt.

Die scheinbar ungekreuzten Fasern c, welche gekreuzte Dachkernfasern sind, kommen ins Areal der Forel'schen Haubenfascikel zu liegen und scheinen hier bereits an Zahl geringer zu sein, nachdem fort feine Bogenfasern abgegeben warden.

Die Fasern des Bindearmes (das dorsale Kleinhim-Thalamusbündel) kommen in dem medialen Theil des rothen Kernes zu liegen und in der Gegend, die knapp dorsomedial dem rothen Kern anliegt. Die Fasern des ventralen Kleinhirn-Thalamusbündels liegen ventral und medial "vom rothen Kern. In der Folge ziehen nun das dorsale und ventrale Kleinhirn-Thalamusbündel gemeinsam als Kleinhirn-Thalamusbündel frontalwärts, bebalten aber ihre gegenseitige Lage bei.

Jene Fasern, die vom Kleinhirn als innere Bogenfasern ins Areal der Vierhügel-Vorderstrangbahn zogen und hier sagittal umbogen, sind hier nicht mehr zu erkennen.

Im rothen Kern werden zahlreiche Collateralen von dem KleinhirnThalamusbündel abgegeben, der Hauptzug der Fasern zieht aber dem Sehhügel zu.

Auch in die seitliche Strahlung des rothen Kerns werden einige Fäserchen entsendet. Diese Fäserchen, welche seitlich rom Kleinhirn-Thalamusbündel beim rothen Kern abgegeben werden, erhalten in proximaleren Schnitten fortwährend Zuwachs an Fasern, so dass eine ganze Strahlung entsteht, deren Fasern im bogenförmigen Verlaufe bis zur hinteren Commissur reichen, ähnlich wie die Schleifenfasern, die von den Goll'schen Kernen kommen und im Bogen vom rothen Kern zur hinteren Commissur gelangen. Eine Anzahl dieser seitlich abgehenden Fasern, wird in die hintere Com-

1) Probst, „Experimentelle Untersuchungen über die Schleifenendigung etc." Arch. f. Psych. Bd. 33. H. 1 and "Ueber das Monakow'sche Bündel etc." Deatsche Zeitschrift $f$, Nervenheilkunde. Bd, 15. 
missur entsendet. Diese im Kleinhirn-Thalamusbündel seitlich abgegebenen Fasern, welohe in die hintere Commissur gelangen, sind im proximalen Antheile des vorderen Zweihügels bis zum mittleren Marke verfolgbar und an der Uebergangsstelle des vorderen Zweihügels in den Sehhägel bis an die mediale Grenze des caudalsten Sehhügels. Die Anzahl der vom.Kleinhirn-Thalamusbündel in die hintere Commissur abgegebenen Fasern ist eine grössere als die von der medialen Schleife dahin abgegebenen Fasern.

Wenn wir mit unseren Schnitten noch proximaler gehen, finden wir die Faserzüge so angeordnet, wie es das Photogramm in Figur 7 wiedergiebt. Es ist dies ein Frontalschnitt durch die hintere Commissur und die äusseren Kniehöcker.

Die Hauptmasse des Kleinhirn-Sehhügelbündels verlauft in der frontalen Haubenstrahlung weiter frontalwärts (K Th Figur 7 ) und bildet die frontale Haubenstrahlung.

Jene Fasern, die seitlich vom rothen Kern abgegeben wurden und Zweige in die hintere Commissur sandten, sehen wir hier im candalen Theile der inneren Marklamelle des Sehhügels ansteigen.

Auch in der hinteren Commissur sehen wir hier noch degenerirte Fasern. Die Fasern steigen beiderseits vom Meynert'schen Bündel abwärts und eine Anzahl von Fasern scheint sich medial vom Meynert'sohen Bündel im centralen Höhlengrau zu verlieren.

Im grosszelligen Kern der inneren Marklamelle des Sehhügels endigen schon hier auf diesem Schnitte viele Fasern mit Aufsplitterungen.

Die Hauptmasse des Kleinhirn-Thalamusbündels zieht in der frontalen Haubenstrahlung weitex in dorsalen Mark der Regio subthalamica und erst weiter proximalwärts ziehen diese Fasern dorsalwärts in den Sehhügel zum Theil in die innere. Marklamelle, theils zwischen die innere und äussere Marklamelle. Es werden, je weiter wir proximalwärts kommen, immer mehr und mehr Fäserchen vom dorsalen Mark der Regio subthalamica dorsalwärts in die innere Marklamelle des Sehhügels entsendet, die alle mit Aufsplitterungen im Kern vent a endigen.

In Figur 8 sehen wir das Photogramm eines Frontalschnittes durch den Sehhügel und das Chiasma Nervi optici. Wir finden hier bereits alle Fasern des Kleinhirn-Thalamusbündels in die innere Marklamelle des Sehhügels aufgestiegen nnd sehen hier eine Fndigungsstätte jm Kern med c, wo sie zu einem kileinen Theil mit Aufsplitterungen enden. Die übrigen Fasern sind aber noch im medialen Antheil der äusseren Marklamelle des Sehhügels and zwischen beiden Sehhügellamellen zu sehen. Diese Fäserchen steigen nun in proximaleren Frontalschnitten dorsalwärts theils in die innere Marklamelle, theils in die äussere Marklamelle und splittern sich auf proximaleren Schnitten in der Kerngegend auf, die zwischen dem Kern lat $b$ und vent b und med c Monakow's gelegen sind, so dass die feinsten Aufsplitterungen des Kleinhirn-Thalamusbündels im centralventralen Kern vent a bis zur äusseren Marklamelle des Sehhägels hin sich ausdehnen. Jene Fasern die vom Dachkern zum gekreuzten 
Bindearm laufen und in die Gegend der Haubenfascikel Forels gelangen, ziehen ebenfalls in die innere Marklamelle des Sehhügels und enden theils hier, theils in vent a.

Wie gestalten sich nun, nach einer solchen Läsion des Kleinhirns, wie sie oben beschrieben ist und nach der Degeneration der oben beschriebenen Bahnen die physiologischen Wirkungen und wie reagirt ein solches verstümmeltes Gehirn auf elektrische Reizungen?

Während die linke Kleinhirntinde abgetragen wurde, erfolgte eine lebhafte Ablenkung beider Bulbi nach rechts; wenn mit dem Löffel gegen die Mitte des Oberwurmes hin Rinde abgetragen wurde, erfolgte vorübergehend eine Blickablenkung nach links. Die Ablenkung der Bulbi nach rechts war während der ganzen Operation andauernd.

Bei Abtragung tiefer gelegener Partien (siehe die Abbildung der Verletzungen) erfolgten Raddrehung der Bulbi, ohne aber dass der Deiters'sche Kern oder der Nervus trochlearis dabei verletzt worden wäre.

Während der Operation blieb die linke Pupille andauernd weiter als die rechte Pupille. Zwei Tage nach der Operation waren aber die Pupillen wieder gleich gross und reagirten beiderseits gut.

Unmittelbar nach der Operation wurde der Kopf des Thieres opisthotonisch zurückgeworfen, dabei machte die Katze Gehbewegungen nach rückwärts. Es machte sich dann sofort eine grosse allgemeine Schlaftheit geltend. Der Eingriff einer solchen Operation auf die Thiere ist ein ganz gewaltiger, indem sich eine allgemeine Consternation geltend macht.

An den Bulbi wurden unmittelbar nach der Operation nystagmusartige Zuckungen beobachtet. Während der Operation der Rindenabtragung wurden keine Bewegungen an den Extremitäten beobachtet.

Nach der Operation wird der Kopf wiederholt krampf haft nach rückwärts gezogen und machten sich tonische Streckungen in der rechten vorderen Extremität geltend, dann wieder in der linken vorderen Extremität. Anfallsweise stellt sich ein wilder Bewegsdrang ein, um gleich darauf einer vollständigen Erschlaffung Platz zu machen.

Der Kopf wird langsam tonisch, ähnlich wie beim epileptischen Anfall, nach rückwärts gezogen, dann, wenn er vollauf hinten ist, wird er nach der linken Seite gedreht, dabei dreht sich der ganze Körper zur Seite und es erfolgen Wälzbewegungen nach rechts, also Rotation von der gesunden Seite zur lädirten Seite, oder mit anderen Worten im Sinne des Uhrzeigers. In den linksseitigen Extremitäten sind dabei tonische Streckungen zu bemerken. Bei den Wälzbewegungen sind die Pupillen, die früher eng waren, auch maximal weit, nachher sind dic Pupillen wieder eng. Es besteht die Neigung nach rechts zn fallen. Zwei Stunden nach der Operation wird der Kopf noch immer stark zurüekgezogen gehalten, die vorderen Extremitäten sind aber völlig erschlafft. Die Wälzbewegungen werden bezüglich ihrer Richtung am besten im Sinne oder im entgegengesetzten Sinne des Uhrzeigers ausgedrückt, wenn die Uhr in der Querschnittsebene des Körpers liegt mit dem Zifferblatt gegen den Kopf hin. 
Die Katze nimmt keine Nahrung zu sich und muss mit der Pipette ernährt werden. Zwei Tage nach der Operation sind die Pupillen vollständig gleich und reagiren. Sie verdreht etwas den Kopf nach hinten zur verletzten Seite, die linke yordere Extremität erscheint bald spastisch bald sohlaff, wie paretisch und wird mit der Dorsalseite der Zehen aufgestellt (Muskelsinnstörung). Die Wirbelsäule wird etwas nach links gekrümmt. Das Thier taumelt, fällt nach rechts. Es erfolgen öfters tonisohe Streckungen der Extremitäten besonders der vorderen.

Drei Tage nach der Operation wird der Kopf bereits ganz ordentlich gehalten. Dio linksseitigen spastischen Extremitäten (Verletzungsseite) werden oft tonisoh weggespreizt, dabei fällt die Katze nach rechts. Das Thier vermag noch nicht zu gehen und fällt immer auf die rechte Seite und kriecht am Boden weitor, doch vermag es sich schon für einige Augenblicke zu erheben. Die Pupillen sind gleich, die Kniesehnenreflexe beiderseits erhöht. Die Ernährung geschieht mit der Pipette.

Am vierten Tage nach der Operation nimmt die Katze etwas Nahrung selbst zu sich und fängt sich etwas zu putzen an. Beim Gehen schwankt sie stark (oerebellare Ataxie) und fält auf die rechte Seite. Der Gang ist atactisch, die linksseitigen Extremitäten werden spastisch weggespreitzt und dabei fällt der Körper nach rechts.

Am fünften Tage nimmt die Katze selbst Nahrung. Sie vermag nicht zu gehen und fällt immer nach rechts. Die linksseitigen Extremitäten werden beim Gehen steif wie Stelzen gehalten (Spasmen). Der Körper wird über die rechte Seite gehalten, um sich auf den rechtsseitigen Extremitäten vollends zu stützen, so dass die Katze nach dieser Richtung umfällt. Auch wenn die Katze das Fell schüttelt, fällt sie nach der Seite und vermag nicht das Gleichgowicht zu erhalten.

Am achten Tage nach der Operation kann das Thier noch nicht gehen und taumelt dabei zur Seite. Die linksseitigen Extremitäten werden weggespreizt und die Katze fällt auf die rechte Seite. Hier und da fällt die Katze auch auf die linke Seite. Die Pupillen sind gleich und reagiren. Die Katze nimmt selbst Milch. Die rasche Ermüdbarkeit des Thieres ist auffallend und auch in der folgenden Zeit andauernd.

Am zehnten Tage geht das Thier noch immer sehr schlecht, aber sie vermag doch schon zu gehen, meist fällt sie nach rechts um. Das Thier ist stark abgemagert. Bei Bewegungen, die das Thier mit dem Kopfe machen will, wackelt es stark mit dem Kopfe. Wenn die Katze Milch lecken will, wackelt das Thier so heftig mit dem Kopfe und ist so atactisch, dass sie nur mit grösster Anstrengung und Mühe mit dem Kopfe zur Milch kommt; kaum hat sie mit Mühe den Kopf zur Milch gebracht, wird er atactisch wieder weggeschleudert. Immer geht der Kopf über der Oberfläche der Milch wackelnd hin und her und die Katze erwischt nur schnappender Weise etwas Milch.

Dieses Verhalten des Kopfes, wie wir es häufig bei multiplen Sklerosen, bei Paralysis agitans oder Sklerosen des Kleinhirns beim Menschen sehen, 
dauert bei der Katze an. Insbesondere kam es bei den intendirten Bewegungern zum Vorschein, wie beim Fressen.

Am 15. Tage konnte dieses seitliche Wackeln mit dem Kopfe noch immer beobachtet werden. Das Thier fält beim Gehen auf die linke Seite. Die Pupillen sind gleich und reagiren.

Am 15. Tage wurde in Narcose die Kleinhirnrinde elektriseh gereizt und die Wirkungen dabei beobachtet.

Bei schwächster Reizung des hintersten Antheils des Oberwarmes erfolgte ein starkes Zurückfahren des Kopfes. Die Elektroden an der Grenze zwischen gesunder Hemisphäre und Mittellappen, etwa in der Mitte angesetzt, erzeugte eine Drehung der Augen nach rechts unten. Am Oberwarm gereizt erfolgten an verschieden Stellen Beuteln des Kopfes, Augenzwinkern, Drehung des Kopfes, in der seitlichen Gegend des Oberwurmes erfolgte Zwinkern der Augen, Bewegung der Ohren und Kieferbewegungen.

Nach Reizung der Kleinhirnrinde wurde das rechte motorische Centrum der Grosshirnrinde freigelegt. Daselbst konnte kein epileptischer Anfall ausgelöst werden, sondern nur eine Drehung des Kopfes nach links und Bewe* gungen in den linksseitigen Extremitäten.

Bezüglich dor Reizung der rechten Kleinhirnhemisphäre wurden ganz schwache Ströme verwendet. Dabei konnten hier und da ganz leichte Bewegungen in der rechtsseitigen vorderen Extremität sowie im rechten Facialisgebiete beobachtet werden. Bei stärkeren Strömen konnte divergirende Stellung der Bulbi beobachtet werden, die vielleicht auf Stromschleifen, die tiefer eindrangen, bedingt war. Kieferbewegungen konnten bei Reizung des hinteren Theiles des Mittellappens beobachtet werden. Rechts vorne seitlich an der rechten Kleinhirnhemisphäre wurden auf elektrische Reizung Raddrehungen der Bulbi beobachtet.

Die Wirkungen bloss faradischer Reizung der Hirnrinde müssen immer sehr skeptisch beobachtet werden, da wir keine sichere Controlle den faradischen Reizversuchen gegenüber haben. Im Verein mit mechanischen Reizversuchen, die hier bei Ausführung der Rindenabtragung beobachtet wurden, sind die Resultate etwas sicherer. Reizungen mit chemischen Substanzen (Kreatin etc.) geben auch keine sicherere Resultate als die faradische Reizung.

In dieser Weise babe ich mehrfache Experimente bei Hunden und Katzen ausgefübrt und bin dabei zu ganz gleichen Resultaten gekommen. Einige Thiere lebten längere Zeit bis zu zwei Monaten, um die pathologischen Erscheinungen nach dieser Art von Kleinhirnläsionen längere Zeit zu verfolgen. Ich werde weiter unten die Erscheinungen, welche die verschiedenen Kleinhirnläsionen bieten, und deren Verlauf zusammenfassend schildern.

Bezüglich der anatomischen Resultate dieser Versuchsreihe, sehen wir zunächst, dass die Kleinhirnrinde keine Fasern in's Rückenmark entsendet, wie dies auch Versuche mit Kleinhirnrindenabtragungen bewiesen. In dem oben geschilderten Falle war aber auch der gezahnte Kern, von dem Thomas 
alle Fasern der Kleinhirn-Vorderseitenstrangbahn entspringen lässt, zerstört, nur die Partie desselben, welche dem Deiters'schen Kern angelagert ist, war gut erhaiten, trotzdem degenerirten nur einzelne Fasern der Kleinhirn-Vorderund Kleinhirn-Vorderseitenstrangbahn bis an die laterale Seite der Olive. Es kann somit die Annahme von Thomas nicht richtig sein, da wir ja auch zum Theil bei diesen Läsionen auf die Fernwirkung Rücksicht nehmen müssen. Doch muss ich zugestehen, dass Ganglienzellen, die lateral von der eigentlichen Masse des Deiters'schen Kernes liegen, ebenfalls Ursprungsganglienzellen der Kleinhirn-Vorderseitenstrangbahn sind, aber zum Deiters'schen Kern gehören. Sicher ist es aber, dass der Deiters'sche Kern in seiner Gesammtheit der Ursprungskern der Kleinhirn-Vorder- und Vorderseitenstrangbahn ist. Ich habe diese vom Deiters'schen Kern absteigende Bahn als Kleinhirnvorderstrangbahn hauptsächlich aus physiologischen Gründen so benannt, weil ja hier hauptsächlich Kleinhirnreize durch den Knotenpunkt des Deiters'schen Kerns peripher entsendet werden. Der Deiters'sche Kern spielt gegenüber dem Kleinhirn eine ähnliche Rolle, wie der rothe Kern gegenüber dem Sehhügel. Der Deiters'sche Kern muss in einem gewissen Sinne als Kleinhirnantheil betrachtet werden.

Die im Rückenmark absteigende Kleinhirn-Vorderstrangbahn bildet im verlängerten Mark und im obersten Halsmark zwei getrennte Bündel, die Kleinhirn-Vorderstrangbahn und die Kleinhirn-Vorderseitenstrangbahn. Im unteren Halsmark und im weiteren caudalen Verlaufe berühren sich beide Bündel und erfüllen die Peripherie der Fissurenrandzone and der ventralen Randzone des Rückenmarkes. Sie geben während ihres Verlaufes Fäserchen an die Vorderhörner ab. Die vereinigte Kleinhirn-Vorderstrangbahn und Kleinhirn-Vorderseitenstrangbahn habe ich kurz als Kleinhirn-Vorderstrangbahn bezeichnet ${ }^{1}$ ). Den Verlauf dieser vom Deiters'schen Kern absteigenden Kleinhirnbahn habe ich oben und in früheren Arbeiten genauer beschrieben.

Durch das Corpus restiforme und zwar dessen lateralen Antheil sehen wir ebenfalls absteigende Kleinhirnfasern gehen, doch endigen diese bereits beim Seitenstrangkern und nur wenige sehr spärliche scheinen noch als Bogenfasern zu den Pyramiden und Oliven hin zu verlaufen. Die im lateralsten Antheil des Strickkörpers absteigend degenerierenden Fasern kommen von der Rinde des Wurmes und entsenden auch einzelne innere Bogenfasern in die Substantia reticularis. Zur medialen Schleife werden keine Kleinhirnfasern entsendet. Dagegen sehen wir im medialen Antheil des Strickkörpers degenerirte Fasern bis zu den Hinterstrangkernen verlaufen.

Vom Dachkern und vom Mittellappen wird ein grösseres Fasersystem entsendet, die "ausstrahlende Kleinhirnbahn," welche aus dem accessorischen Bindearmbündel, dem inneren Strickkörperbündel und andere oben beschriebenen Fasern besteht. Die Fasern kreuzen sich grösstentheils in der Raphe

1) Probst, Ueber die Kleinhirn-Vorderstrangbahn eto. Deutsche Zeitschrift für Nervenheilkunde. XV. Bd. - Probst, Archir für Psychiatrie. Bd. XXXIII. 
des Mittellappens und strahlen dann fächeriörmig ventralwärts in die Substantia reticularis als innere Bogenfasern, proximalwärts als accessorisches Bindearmbündel in den Bindearm und Sehhügel und caudalwärts als inneres Strickkörperbündel in den lateralen Theil des sogenannten inneren Abschnittes des Strickkörpers bis zu den Hinterstrangkernen. Viele Fasern des inneren Strickkörperbündels biegen hakenförmig um den Bindearm herum und gelangen in den inneren Antheil des Stricklörpers.

Viele Fasern dieser vom Dachkern und Mittellappen ausgehenden Fasern endigen zugleich mit vom gezahnten Kern ausgehenden Fasern im Deiters'schen Kern.

1. Der caudale Abschnitt dieses Fasersystems, das innere Strickkörpebündel, verläuft über dem Deiters'schen Kern hinaus im lateralen An. theil des sogenannten inneren Abschnittes des Strickkörpers zwischen dem Stricklörper, der aufsteigenden Trigeminuswurzel und dem Fasciculus solitarius und endigt bei den Hinterstrangkernen. (Monakow'schen Kern und Burdach'schen Korn.) Während seines Verlaufes giebt es stets innere Bogenfasern $a b$, die theils durch den dreieckigen Acusticuskern laufen und auch zum Theil hier endigen, theils in die Substantia reticularis, theils in sehr geringer Zahl zur gegenüberliegenden unteren Olive. Aehnlich verlaufende innere Bogenfasern, die aber rom Deiters'schen Kern und vielleicht von der medialen Partie des gezahnten Kernes kommen, biegen knapp neben der Raphe in die sagittale Richtung um und verlaufen proximalwärts in die Brücke, caudalwärts in das ventrale Randzonenbündel des Rückenmarkes.

2. Der mittlere Antheil der (ausstrahlenden Kleinhirnbahn) vom Dachkern und Mittellappen ausgehenden absteigenden Kleinhirnfasern treten zum dreieckigen Acusticuskern und verlaufen zugleich mit vom gezahnten Kern ausgehenden inneren Bogenfasern gegen den Abducenskern in die Substantia reticularis.

Die vom Dachkern kommenden Fasern kreuzen sich in der Raphe des Wurmes und gelangen auf die dorsale Seite des Bindearmes, dem sie wie eine Haube aufgesetzt sind. Die Fasern biegen dann an der vorderen Seite des Bindearmes hakenförmig um, (beide Bündel, der Bindearm, das accessorische Bindearmbündel und das innere Strickkörperbündel sind gleichsam in einander eingehängt) und gelangen zum Theil als die oben beschriebenen inneren Bogenfasern in die Substantia reticularis, zum Theil in den sogenannten inneren Abschnitt des Stricklörpers.

3. Der proximale Antheil der vom Dachkern und Mittellappen ausgehenden Fasern gelangt nach Kreuzung der Raphe in das sogenannte accessorische Bindearmbündel und von diesem in das Innere des Bindearmes. Mit den Bindearmfasern ziehen diese Dachkernfasern weiter, gehen aber nicht die Bindearmkreuzung ein, sondern bleiben nun auf dieser Seite und bilden die von mir bereits beschriebenen ungekrenzten Bindearmfasern. Diese Fasern des Bindcarms sind aber nur scheinbar ungekreuzt, da sie ja im Mittellappen des Kleinhirns bereits die Kreuzung eingegangen sind. Diese Fasern bilden also die scheinbar ungekreuzten Bindearmfasern (s. Arch. f. Psych. Bd. 33, 
S. 30 u. Monatsschr. f. Psych. 1901) und gelangen im dorsalen Theil der Substantia reticularis zwischen Trochleariskern und hinteren Zweihügel weiter proximalwärts in die Gegend der Forel'schen Haubenfascikeln. Von hier aus gelangen die Fasern in die innere Marklamelle des Sehhügels, woselbst sie im Kern med $c$ und vent a mit Aufsplitterungen endigen. Während des Verlaufes durch die Brücke werden stets feine innere Bogenfasern entsendet, so dass nur: eine sehr kleine Zahl von Fasern in den Sehhügel gelangt. In der Brücke werden hauptsächlich beim Trigeminuskern feine Bogenfasern entsendet.

Das ventrale Kleinhirn-Thalamusbündel kommt vom gezahnten Kern, von wo aus innere Bogenfasern durch die Substantia reticularis ziehen etwa auf Frontalschnitten, die durch den austretenden Nervus facialis gehen.

Diese vom gezahnten Kern kommenden Bogenfasern überschreiten die Raphe und biegen im Winkel, den die mediale Schleife mit der Raphe bildet in die sagittale Richtung um und verlaufen proximalwärts zum Nucleus reticularis pontis, wo viele Collateralen entsendet werden. Die Mehrzahl der Fasern zieht aber weiter proximalwärts zum rothen Kern und gelangt ins dorsale Mark der Regio subthalamica und endigt in den Kernen der inneren Marklamelle des Sehbügels und im Kern vent a. Dieses ventrale Kleinhirnbündel wird durch Fasern verstärkt, welche, wie andere Versuche von mir lehren, von der Substantia gelatinosa kommen ${ }^{1}$ ). Ausserdem wird das ventrale Kleinhirn-Thalamusbündel in der hinteren Zweihügelgegend durch einen ventralen Ast des Bindearms verstärkt. Das ventrale Kleinhirn-Thalamusbündel muss von den Antheilen der medialen Schleife getrennt werden, wenngleich es derselben knapp dorsal aufliegt.

Der Bindearm ist nach meinen Untersuchungen ein Kleinhirn-Sehhügelbündel, keine einzige Faser dieses Bündels geht in die innere Capsel über.

Bezüglich des Bindearmes lehren meine Versuche, dass die scheinbar ungekreuzten Bindearmfasern (accessorische Bindearmbündel) im Dachkern entspringen, in der Raphe des Mittellappens kreuzen und durch den Bindearm in den Sehhügel gelangen, wo sie beim Kern medb, medc und venta endigen.

Die übrigen Fasern des Bindearmes entspringen im vorderen und inneren Theil des gezahnten Kerns und gehen eine vollständige Kreuzung ein. Im Bindearm verlaufen nach meinen Untersuchungen nur centrifugale Kleinbirnbahnen, er ist also ein Kleinhirn-Sehhügelbündel, wenn wir in der Bezeichnung Ursprung und Endigung ausdrücken wollen.

In der hinteren $Z$ weihügelgegend theilt sich der Bindearm in einen mächtigen dorsalen und einen dünnen ventralen Ast, welcher letzterer das ventrale Kleinhirn-Thalamusbündel verstärkt.

Der ventrale Ast des Bindearmes, den ich in einer früheren Arbeit als ventrales Kleinhirn-Thalamusbündel beschrieb, geht in der hinteren Zweihügelgegend vom Stamme des Bindearmes ab, indem die Fasern ventral auf mie. 1902.

1) Probst, Archiv für Psychiatrie. Bd. XXXIII. und Archiv für Anato- 
die dorsale Fläche der medialen Schleife verlaufen, die Raphe übersohreiten und ventral vom Areal der Vierhügel-Vorderstrangbahn proximalwärts mit den Fasern des ventralen Kleinhirn-Thalamusbündels in das dorsale Mark der Regio subthalamica verlaufen und bei den Kernen med $b$, med $c$ und vent a mit Aufsplitterungen endigen.

Der dorsale mächtigere Ast des Bindearmes kreuzt in der bekannten Weise die Raphe und gelangt zum rothen Kern, wo zahlreiche Collateralen abgegeben werden. Daselbst vereinigt sich der dorsale Ast, (dorsales Kleinhirn-Thalamusbündel) wieder mit dem ventralen Ast und mit dem ventralen Kleinhirn-Thalamosbündel und zieht als vereinigtes Kleinhirn-Thalamusbündel zum Sehhügel.

Das Kleinhirn-Thalamusbündel kommt in den medialen Theil des rothen Kernes zu liegen and in die Gegend, die medial, dorsal und ventral dem rothen Kern knapp anliegt.

Im weiteren Verlaufe des Kleinhirn-Thalamusbündels werden Fasern im Bogen seitlich vom rothen Kern entsendet, die zum Theil in die hintere Commissur abgegeben werden. Die seitlich rom rothen Kern abgegebenen Fasern gelangen in die innere Marklamelle des Sehhügels und durchziehen zum Theil medial vom Meynert'schen Bündel des centrale Höhlengrat. Die Hauptmasse des Kleinhirn-Thalamusbündels gelangt ins dorsale Mark der Regio subthalamica, bildet die sogenannte Haubenstrahlung und zieht von bier in die innere Marklamelle des Sehhügels und endigt zum Theil bei den Kernen med $b$, med $c$ und bei den Ganglienzellen, die zwischen med $\mathrm{c}$ und vent a gelegen sind, mit zahlreichen Aufsplitterungen im Kern vent a.

Bezüglich des Brückenarmes haben wir gefunden, dass hauptsächlich in seinem inneren (medialen) Antheil centrifugale Kleinhirnfasern verlaufen, die in der Kleinhirnrinde ihren Ursprung nehmen und im gegenüberliegenden Brückongrau mit Aufsplitterungen endigen. Ein Theil dieser Fasern ziehen in der Raphe aufwärts und endigen mit Aufsplitterungen beim gegenüberliegenden Nucleus reticularis pontis. Die Hauptmasse des Brückenarmes ist nicht degenerirt und besteht aus Brücken-Kleinhirnfasern.

Eine Kleinhirn-Rückenmarksbahn, die, wie Marchi und Biedl annehmen, durch den mittleren Kleinhirnsohenkel zum Rückenmark gehen soll, giebt es auf Grund meiner Untersuchungen nicht.

Nach halbseitiger Rindenverletzung des Kleinhirns sind, wie wir gesehen haben, zahlreiche degenerirte Fasern in die Rinde der gesunden Hemisphäre zu verfolgen, ausserdem ein stärkeres Bündel über beiden Dachkernen bis zum gegenüberliegenden gezahnten Kern. Im letzteren endigen viele degenerirte Fasern mit Aufsplitterungen.

In einer weiteren Thierversuchsreihe wurde der Dachkern des Kleinhirns einseitig isolirt zerstört und die von diesem Kern ausgehenden, degenerirten Faserzüge genauestens auf lückenlosen Serienschnitten verfolgt. 


\section{Einseitige Zerstörung des Dachkerns.}

Bei erwachsenen Thieren, Katzen und Hunden wurde am hintersten Abschnitte des Oberwurmes mit der Hakencanüle in der Mittellinie eingegangen und der Haken in der Höhe des Dachkerns seitlich oder nach vorne vorgeschoben und das Instrument als Ganzes etwas emporgezogen. Hier und da wurden durch diese Operation beide Dachkerne zerstört, in einigen Fällen betraf aber die Verletzung nur einen Dachkern. Die Thiere wurden 3 Wochen am Leben gelassen und das Gehirn hernach mit Osmiumsäure behandelt und in eine lückenlose Serienschnittreihe zerlegt.

In den Fällen mit einseitiger Zerstörung des Dachkernes konnte ich stets Fasern von ziemlicb dicken Caliber, die in den Ganglienzellen des Dachkemes entspringen, verfolgen. Sie verlaufen vom Dachkern ventralwärts bis nahe an das Ventrikeldach und kreuzen in der Raphe des Oberwurmes in dessen ventralsten Antheil auf die andere Seite hinüber, ganz so wie wir es in der früheren Thierversuchsreihe sahen, wo in Figur 2, die'Fasern c und $c^{\prime}$ ventralwärts verlaufen und dann auf die andere Seite laufen.

Die Dachkernfasern kommen, nachdem sie die Mittellinie des Oberwurmes überschritten haben, in die dorsale Partie des Bindearmes zu liegen, wo sie gleichsam eine dorsale Haube über den Hauptfaserzug des Bindearmes, der aus dem gezahnten Kern kommt, ganz so wie es 0 in Figur 3 der früheren Thierversuche zeigt. Einzelne dieser Fasern kommen vielleicht auch vom gleichseitigen Dachkern. (Accessorisches Bindearmbündel.)

Beständig im weiteren proximalen Verlaufe werden von diesen feine innere Bogenfasern durch den Deiters'schen Kern hindurch zur Substantia reticularis abgegeben, ebenso wie es die Fasern z in Fig. 3 der früheren Versuchsanordnung zeigen. Diese Fasern $z$, die vom gegenüberliegenden Dachkern kommen, gehen bis zum sensiblen Trigeminuskern und sind auch bis gegen die Raphe hin zu verfolgbar. Die meisten splittern sich in der Substantia reticularis der Brücke auf.

Auch zum Acusticuskern treten solche Dachkernfasern hin. Vielleicht sind auch einige Fasern von der Rinde des Mittellappens dabei im Sptele. Dort, wo der Trochleariskern und dieBindearmkreuzng auftritt, kommen diese Dachkernfasern, welche die dorsale Partie desBindearmes ansmachen, medialer zwischen Trochleariskern und absteigender Trigeminuswurzel zu liegen und verlaufen an dieser Stelle aufwärts gegen den Sehhügel.

Diese Daehkernfasern (accessorisches Bindearmbündel) gehen nicht mit der Bindearmkrenzung auf die andere Seite, da sie bereits im Kleinhirn selbst die Kreuzung eingegangen sind, während die Bindearmfasern des gezahnten Kernes in der bekannten Bindearmkrenzung auf die andere Seite gelangen. Diese Dachkernfasern sind identisch mit den Fasern $\mathrm{c}$ in Figur 5 der früher beschriebenen Versuchsreihe. Sie kommen sowohl dem Trochleariskern als dem Oculomotoriuskerne sehr nahe zu liegen und wäre es möglich, dass sie an die laterale Seite dieser Kerne Collateralen abgeben. Die Hauptverbindung des. Kleinhirnes mit den Augenmuskel-Nervenkernen geschieht aber, wie an- 
dere Versuche von mir klarlegten, durch Fasern vom Deiters'schen Kern, die in die hinteren Längsbündel gelangen, und mit feinen Aufsplitterungen in den Kernen der Augenmuskelnerven enden.

Im weiteren proximalen Verlaufe kommen diese Dachkernfasern in die Gegend der Faubenfaseikel Forel's zu liegen, wie es die Fasern a der Figur 6 der früheren Versuchsreihe zeigt.

Von hier aus ziehen feine Abweigungen der Dachkernfasern in den ventralen und dorsalen Antheil der hinteren Commissur und können hier weiter auf die andere Seite verfolgt werden, bis in die Gegend des mittleren Markes an der Uebergangsstelle zwischen vorderem Zweihügel und Sehhügel.

Wenn wir die Dachkernfasern noch weiter stirnwärts verfolgen, so finden wir sie von der Gegend der Haubenfascikel Forel's in die frontale Haubenstrahlung uud das dorsale Mark der Regio subthalamica übergehen, ähnlich wie es die Figur 7 der früheren Versuchsordnung zeigt, in dem die Fasern das Gebiet des Kleinhirn-Thalamusbündels innehaben. Von hier aus strahlen feine Fäserchen durch das centrale Grau medial vom Meynert'schen Bündel und in die innere Marklamelle ein.

Die im ventralsten Areal des Kleinhirn-Thalamusbündels verlaufenden Kleinhirn-Sehhügelfasern laufen am weitesten proximalwärts.

Alle diese Dachkernfasern endigen mit Aufsplitterungen in den Kernen der inneren Marklamelle des Sehhügels, med $b$ und med $c$ und lateral von der inneren Sehhügellamelle im Kern vent a. Weiter proximalwärts verlaufen die Dachkernfasern nicht mehr. In keinem einzigen Yersuche sind Kleinhirnfasern über den Sehhügel hinaus zu verfolgen, sondern alle endigen im Sehhügel.

Caudaler verlaufende Fasern der Dachkerne (inneres Striokkörperbündel) kommen an die mediale Seite des Strickliörpers zi liegen und entsenden von hier aus, ebenso wie die Fasern z in Figur 1 der früheren Versuchsordnung feine Fäserchen gegen den Acusticuskern und in die Substantia reticularis gegen den Nucleus centralis inferior hin. Die im medialen Strickkörperantheil verlaufenden Kleinhirnfasern können bis zu den Hinterstrangkernen verfolgt werden.

Nach einseitiger Zerstörung degeneriren in Folge der Kreazung diese Fasern beiderseits.

Bei der Operation wurde meist auch der mittlere Theil des hintersten Abschnittes des Oberwurmes etwas mitverletzt.

Die Pupillen waren nach solchen Operationen stets gleich und reagirten gut. Beim Sitzen sinken die Thiere auf der verletzten Seite mehr ein, beim Zusammenklatschen fährt das Thier zusammen. Das Thier vermag vom Boden auf den Tisch zu springen. Beim Gehen versucht die Katze mit den Krallen in den Boden einzusetzen, um das Gleichgewicht zu erhalten. Es wurden auch tonische Streckungen in den Extremitäten beobachtet. Die Sehnenreflexe sind sehr lebhaft. Der Kopf wird gesenkt gehalten. Die Augenlidspalten sind gleich. Die Hautreflexe sind vorhanden.

Die Katzen müssen mit der Pipette genährt werden und magern sichtlich ab. Die Pupillen sind gleich und reagiren einzeln und consensuell. Die eine 
Körperbälfte bleibt auch in der Folgezeit mehr eingesunken. Das Hervorstechendste ist die cerebellare Ataxie und Spasmen.

Die Fälle dieser Versuchsreihe lehren deutlich, dass ein Theil der Bindearmfasern vom gegenüberliegenden Dachkern kommen (accessorisches Bindearmbündel) und die Bindearmkreuzung nicht eingehen und die scheinbar ungekreuzten Fasern des Bindearmes darstellen. Sie endigen, wie wir gesehen haben, in den Kernen der inneren Marklamelle des Sehhügels und im Kern vent a mit Aufsplitterangen. Eine kleine Zahl von Fasern wird zur hinteren Commissur entsendet.

Ausserdem sehen wir, dass die ausstrahlende Kleinhirnbahn einen grossen Theil ihrer Fasern aus dem gegenüberliegenden Dachkern und zum Theil aus der Rinde des Mittellappens erhält. Das accessorische Bindearmbündel, welches einen vorderen Theil der ausstrablenden Kleinhirnbahn bildet, erhält ebenfalls seine Fasern aus dem gegenüberliegenden Dachkern und ebenso die Kleinhirnbahn (inneres Strickkörperbündel), welche durch den sogenannten inneren Antheil des Strickkörpers gegen den Burdach'schen Kern verläuft und auf diesem Wege zahlreiche feine innere Bogenfasern zum dreieckigen Acusticuskern und der Substantia reticularis entsendet. Die Zahl der degenerirten Bündel im sogenannten inneren Antheil des Strickkörpers (inneres Strickkörperbündel) ist aber bedeutend grösser, wenn auch der gezahnte Kern verletzt wordén war.

Wir sehen auch aus den Versuchen, dass der grösste Theil der Fasern, welche die Forel'schen Haubenfascikeln bilden, aus dem Dachkern stammen.

Vom Mittellappen und vom Dachkern gelangen ebensowenig Fasern in's Rückenmark wie vom gezahnten Kern.

Die Dachkernfasern, welche zum gegenüberliegenden Bindearm ziehen (accessorisches Bindearmbündel), liegen diesem erst dorsal an, gelangen aber weiter proximal in's Areal des Bindearmes und ziehen durch die Haubenfaseikeln Forel's in die innere Marklamelle des Sebhügels und lateral von dieser, wo sie im Kern a endigen.

Nach Verletzung des einen Dachkernes degeneriren viele Fasern auch in die Rinde des Kleinhirns (Mittel- und Seitenlappen), ausserdem ziehen Fasern zum gegenüberliegenden gezahnten Kern, woselbst diese mit feinen Ausstrahlungen endigen.

\section{Versuche mit Zerstörung des Deiters'schen Kernes.}

Ich habe den Deiters'schen Kern nach Wegnahme des untersten Theiles des Hinterhauptknochens, indem der Mittellappen des Kleinhirns mittelst eines stumpfen Hakens, der in den vierten Ventrikel 
eingeschoben war, aufwärts gehoben wurde, vom vierten Ventrikel aus zerstört. In anderen Versuchen habe ich diesen mittelst der Hakencanüle zerstört, indem diese ins Kleinhirn bis zum Deiters'schen Kern eingeführt wurde und daselbst der Stahlhaken hervorgeschoben und umgedreht wurde.

Bei Zerstörung des Deiters'schen Kernes werden aber auch die Faserzüge zerstört, welche diesen einfach durchziehen, daher auch anderweitig vom gezahnten Kern und Dachkern herkommende Fasern zur Degeneration gebracht wurden.

Nach Zerstörung des Deiters'schen Kernes konnte ich sowohl die Fasern degenerirt finden, die ich in den obigen Versuchen nach Kleinhirurindenabtragung und Verletzungen des gezahnten Kernes beschrieben habe. Ich konnte bei diesen Versuchen denselben Verlauf der Fasern constatiren.

Bei Zerstörung des Deiters'schen Kernes werden auch die vom Tuberculum acusticum kommenden Fasern durchschnitten und zur Degeneration gebracht. Diese Fasern gehen als Bogenfasern über die Raphe und biegen an der dorsalen Seite der oberen Olive durch das Areal des Monakow'schen Bündels in den inneren Antheil der lateralen Schleife ein, um beim lateralen Schleifenkern und im ventralen Theil der hinteren Zweihügelkuppe mit Aufsplitterungen zu endigen. Es sind das die Striae acusticae, die einen Theil der weiter unten zu schildernden centralen Hörbahn bilden.

Vom Deiters'schen Kerne ziehen nach meinen Befunden Fasern als Bogenfasern zum hinteren Längsbündel und zwar sowohl zum gleichseitigen als zum gegenüberliegenden. Die Mehrzahl der Fasern läuft zum gleichseitigen hinteren Längsbündel. Diese Fasern geben zahlreiche Collateralen ab zum Abducenskern, besonders aber zum Trochleariskern und Oculomotoriuskern, woselbst sie endigen.

Caudalwärts degeneriren vom Deiters'schen Kerne aus die von mir bereits beschriebene Kleinhirn-Vorderstrangbahn, deren Fasern als Bogenfasern vom Deiters'schen Kern gegen die Raphe ziehen und hier neben der Raphe caudalwärts in die sagittale Richtung umbiegen, um hier weiter in das Fissurenrandbündel des Rückenmarkes zu gelangen.

Ausserdem degenerirt caudalwärts vom Deiters'schen Kern die Kleinhirn - Vorderseitenstrangbahn. deren Fasern vom Deiters'schen Kern herkommen und durch die Substantia reticularis gegen die dorsale und laterale Fläche der Olive ziehen, um von hier aus in das ventrale Randzonenhündel des Rückenmarkes überzugehen, von wo aus feine Einstrahlungen in die Vorderhörner des Rückenmarkes stattfinden. Die Kleinhirn-Vorderseitenstrangbahn ist bis ins Sacralmark ver- 
folgbar. Ich verweise hier auf die gelegentlich des ersten Versuches gegebene Schilderung der Kleinhirn-Yorderseitenstrangbahn.

Nach der Zerstörung des Deiters'schen Kernes degeneriren ausserdem die hier durchziehenden Fasern des Dachkernes caudalwärts an der Imnenseite des Corpus restiforme, zwischen diesem und dem Fasciculus solitarius, die bis zu den Burdach'schen Kernen verfolgbar sind. (Inneres Strickkörperbündel.). Von diesen Fasern gehen während des caudalen Verlaufes stets Fäserchen als innere Bogenfasern in die Substantia reticularis ab.

Nach Zerstörung des Deiters'schen Kernes, aber nicht von diesem, sondern vom gezahnten Kern kommend, degenerirt auch das oben beschriebene ventrale Kleinhirn-Thalamusbündel und bietet dieses Bündel auch in diesen Versuchen denselben Verlauf dar.

In die mediale Schleife, von welcher ich das ventrale KleinhirnThalamusbündel trenne, werden weder vom Kleinhirn noch vom Deiters'schen Kern Fașern abgegeben.

Vom zerstörten Deiters'schen Kern lassen sich degenerirte Fasern auch in den lateralen Antheil des eigentlichen Strickkörpers verfolgen von wo sie als äussere Bogenfasern zum Seitenstrangkern ziehen, woselbst sie zum grossen Theil endigen, einige sehr wenige Fasern ziehen zur Pyramide and steigen in der Raphe zur gegenüberliegenden Olive auf. Diese Fasern kommen aber nicht vom Deiters'schen Kern, sondern durchziehen denselben nur. Von den degenerirten Fasern im äusseren Theil der Strickkörpers werden auch innere Bogenfasern in die Substantia reticularis entsendet, doch ist ihre Zahl keine grosse.

Nach Zerstörung des Deiters'schen Kernes degeneriren viele Fasern aufwärts zur Rinde des Kleinhirns (Mittel- und Seitenlappen) eine Menge dieser Fasern endigen im gezahnteu Kern und im Dachkern.

Im Deiters'schen Kerne endigen einerseits viele Kleinhirnfasern, die von der Rinde, dem Dachkern und dem gezahnten Kern kommen, anderseits gelangen viele Fasern, die vom Deiters'schen Kern ausgehen, zur Kleinhirnrinde, dem gezahnten Kern und dem Dachkern.

Meine Versuche mit Zerstörung des Deiters'schen Kernes bestätigen alle in den früheren Versuchsreihen gefundenen Ergebnisse. Nach der Verletzung wurde durch einige Tage taumelnder Gang beobachtet, am 1. Tage Wälzbewegungen.

\section{Rindenabtragung der caudalsten seitlichen (rechten) Partie des Oberwurmes mit Zerstörung des rechten Dachkernes und Rinden- abtragung der rechten Kleinhirnhemisphäre.}

Bei einer erwachsenen Katze wurde die caudalste rechte Partie desOberwurms mit dem Dachkern zerstört und die angrenzende Rinde der rechten Klein- 
hirnhemisphäre abgetragen, welehe Läsion sehr oberfächlich nach vorne reichte. Die Läsion erreichte nur anf kleinen caudalen Partien die äussere Begrenzung des gezahnten Kerns.

Vom rechten Dachkern, der zerstört war, degenerirte nur jenes Bündel, das ich schon früher beschrieben und abgebildet habe (o in den Figuren), accesssorisches Bindearmbündel.

Die Dachkernfasern (in diesem Falle wurden nur die caudal gelegenen Ganglienzellen des Dachkernes zerstört) degenerirten und waren mit der grössten Sicherheit zu verfolgen. Sie ziehen erst vom Dachkern ventralwärts, übersohreiten dann ventralst die Raphe des Oberwurmes und gelangen an die medialste Seite des gegenüberliegenden Bindearmes. Ueber dem gegenüberliegenden Bindearm bilden die Dachkernfasern eine dorsale Haube, wie $c^{\prime}$, in Figur 4.

Die Dachkernfasern gehen die Bindearmkreuzung nicht ein und sind am selben Platze im dorsalsten Theil der Substantia reticularis zwischen Trochleariskern und Medialrand des hinteren $Z$ weihügels weiter, wie $c$ und $c^{\prime}$ Fig. 5 in die Gegend der Haubenfascikel Forel's verfolgbar, von wo aus sie Collateralen in die hintere Commissur abgeben, die bis zum gegenüberliegenden mittleren Mark an der Uebergangsstelle des vorderen Zweihügels zum Sehhïgel verfolgbar wird.

Weiter proximalwärts geben sie Fäserchen dorsal vom Oculomotoriuskern zum centralen Höhlengraa $a b$ und gelangen in die innere Marklamelle des Sehhügels, wo sie sich im Kern med $b$ und $c$ und vent a aufsplittern und enden, sowie es Fig. 7 und 8 der früheren Versuchsreihe zeigt. Einige Fasern ziehen im Kleinhirn-Thalamusbündel, im dorsalen Mark der Regio subthalamica weiter proximalwärts, gehen aber endlich auch in die innere Marklamelle des Sehhügels und lateral von dieser und endigen mit Aufsplitterungen im centralventralen Sehhügelkern vent a.

Während des Verlaufes durch die Brücke werden beständig feine Fasern als innere Bogenfasern abgegeben, sowie es die Fasern $c$ und $z$ in Fig. 2 der früheren Versuchsreihen zeigen, namentlich auch beim Acusticuskern und beim Trigeminuskern, welche die Mittellinie zu überschreiten scheinen.

Da der äussere Rand des gezahnten Kerns etwas von der Verletzung tangirt wurde, degenerirten auch einige Bindearmfasern des gezahnten Kerns auf der rechten Seite, die durch die Bindearmkreuzung hindurch, als KleinhirnThalamusbündel in die innere Marklamelle des linken Sehhügels bis zum Kern med $c$ und vent a verfolgbar sind, wo sie sich aufsplittern.

Caudal konnten nur die Fasern am Innenrande beider Strickkörper (inneres Strickkörperbündel) degenerirt verfolgt werden, die bis zu dem Burda ch'schen Kernen reichen. Während des Verlaufes werden innere Bogenfasern entsendet, die nicht weiter verfolgbar sind.

Weiter waren keine caudal verlaufende Degenerationen zu sehen, namentlich degenerirte keine Faser der Kleinhirnvorder- und Vorderseitenstrangbahn, was beweist, dass diese Bahn keine Fasern von der Kleinhirnrinde erhält.

Jene Fasern, die in Ganglienzellen der abgetragenen Kleinhirnrinde ent- 
springen, waren durch den inneren Theil des Brïckenarmes in's gegenüberliegende Brückengrau zu verfolgen, wo sie sich um diese Ganglienzellen aufsplittern; zum Theil ziehen sie in der Raphe aufwärts zum gegenüberliegenden Nucleus retionlaris pontis.

Die degenerirten Fasern des Oberwurmes waren zwischen Dachkern und gezahntem Kern als feincalibrige Fasern bis zum Deiters'schen Kern verfolgbar, woselbst eine grosse Zahl endigen. Andere feincalibrige degenerirte Fasern waren in den gegenüberliegenden Dachkern und gezahnten Kern zu verfolgen und ebensolche in den gleichseitigen Dachkern und gezahnten Kern. Ausserdem degenerirten Fasern in der Richtong zur Rinde der unverletzten Seite.

Bei dieser Katze war also die caudale seitliche Partie des Oberwurmes und eine angrenzende Partie der rechten Kleinhirnhemisphäre entfernt worden. Die Rindenabtragung war ganz oberflächlich und berührtc nur die caudalsten Zellen des rechten Dachkernes und einige ganz lateral gelegene Zellen des gezahnten Kerns. Die anatomischen Ergebnisse dieser Versuchsreihe bestätigen die oben gefundenen Ergebnisse.

Nach dieser Verletzung nun degenerirten die oben geschilderten Leitungsbahnen; unter diesen Verhältnissen machten sich die folgenden physiologischen Erscheinungen geltend.

Während die Rinde des rechten Oberwurmes und der rechten Kleinhirnhemisphäre mit einem Löffelchen entfernt wurde, erfolgten Kieferbewegungen und Bewegungen im Facialisgebiete, es wurde der Kopf nach rückwärts bewegt; auch conjugirte Bulbusbewegungen erfolgten nach der entgegengesetzten Seite.

Die rechte vordere Extremität wird gleich nach der Operation so auf den Boden gesetzt, dass die Dorsalseite der Zehen auf den Boden aufruhen (Störung des Muskel- und Lagesinnes). Die Katze sucht sich aufzurichten, fällt aber dabei nach links, auch wird der Kopf nach links hin gezogen. Die hinteren Extremitäten lö̈nnen gut bewegt werden, während die vorderen Extremitäten noch nicht zum Aufstellen verwendet werden. Die vorderen Extremitäten werden ruhig gehalten und der ganze Körper wird duroh die Bewegungen der Hinterbeine vorwärts geschoben. In der rechten vorderen Extremität macht sich starke Ataxie geltend. Sie vermag nach kurzer Zeit sich anf die rechte vordere Extremität aufzusetzen, aber die Pfote wird umgekehrt (dorsal) aufgesetzt und das Thier schwankt stark.

Der Kopf wird nach rückwärts in den Nacken gezogen und die Katze geht eine Zeit lang so nach rückwärts. Die Bulbi stehen nicht abnorm, die Pupillen sind gleich, ziemlich weit. Die Katze macht Kieferbewegungen; der Kopf wird hernach stark nach links gegen den Rumpf gezogen nach rückwärts und später auch nach rechts u⿰氵 rückwärts. Die rechte vordere Extremität wird ähnlich mit dem Dorsum auf den Boden gestellt, wie es bei Katzen mit Abtragung der motorischen Zone des Grosshirnes erfolgt.

Am Abend des Operationstages aus dem Käfig genommen, wo das Thier bisher ruhig lag, wird es unruhig. Auf den Boden gestellt macht das Thier lebhafte Wälzbewegungen nach links, also von der gesunden nach der 
verletzten Seite oder in entgegengesetztem Sinne des Uhrzeigers and muss dabei aufgehalten werden, um sich nicht zu beschädigen. Die Katze vermag nicht zu gehen, liegt am Boden auf der verletzten Seite.

Am Tage nach der Operation ist die Katze ruhig und wird init der Pipette gefüttert. Sie schluckt dabei die Milch. Die rechte vordere Extremität wird noch mit dem Dorsum aufgesetzt, wenn man die Katze passiv aufstellt. Der Kopf wird aufrecht gehalten, die Pupillen sind weit und gleich gross. Das Thier macht keine Wälzbewegungen mehr und liegt beständig auf der Seite. Eine weitere Untersuchung wurde unterlassen, um das Thier vor den Folgen wilder Bewegungen zu schonen.

Am zweiten Tage nach der Operation hatte sich das Thier durch die ganze Länge des Zimmers fortbewegt und wurde hier ruhig liegend gefunden. Die Katze liegt beständig auf der Seite und athmet ruhig. Das Thier verdreht häufig krampfhaft den Kopf nach links; es ist wieder munterer, schmeichelt und drückt den Kopf der annähernden Hand entgegen. Beim Aufstellen des Thieres wird die rechte vordere Extremität mit dem Dorsum aufgestellt, wie nach einer Abtragung der motorischen Zone des Grosshirns. Bei der Fütterang mit der Pipette wehrt sich die Katze heftig, schluckt aber doch die Milch. Die Pupillen sind gleich und reagiren. Das Thier vermag bereits einige Schritte zu gehen, fällt aber dabei auf die ]inke Seite. Sie ermüdet äusserst rasch. Auf ibrem Lager ist die Katze ruhig.

Am fünften Tage nach der Operation vermag das Thier etwas besser zu gehen, doch fällt es dabei stets auf die linke Seite; die rechte vordere Extremität wird noch immer mit der Dorsalfläche wie paretisch aufgesetzt. Aus ihrem Käfig genommen, sucht sie diesen wieder selbst auf. Sie muss stets mit der Pipette gefüttert werden, trotzdem magert sie zusehends ab. Wenn das Thier sitzt, ist der Kopf meist nach einer Seite gedreht. Zn sitzen vernag die Katze erst seit dem dritten Tage. Wenn das Thier zu gehen versucht, schwankt es sehr stark und fällt nach links. Es geht dabei ganz ähnlich, wie Thiere, denen die Hinterstrangkerne zerstört wurden. Die rechte vordere Extremität wird noch immer umgekehrt mit der Dorsalseite der Zehen auf den Boden gestellt. Die Pupillen sind gleich und reagiren.

Am sechsten Tage nach der Operation vermag das Thier bei grosser Vorsioht sehrittweise zu gehen, sie schwankt dabei nach links und fällt schliesslich nach der linken Seite. Die rechte vordere Extremität wird noch immer mit der Dorsalseite der Zehen aufgesetzt. Die Bulbi stehen nicht abnorm, die Pupillen sind gleich und reagiren, kein Nystagmus. Die Katze ist stark abgemagert.

Am achten Tage muss das Thier noch mit der Pipette gefüttert werden, es vermag nur vorsichtig Schritt für Schritt zu gehen, setzt dabei die rechte vordere Extremität mit der Dorsalfläche der Zehen auf, dabei schwankt es stark.

Am neunten Tage nimmt die Katze selbst Nahrung zu sich; am elften Tage vermag es schon besser zu gehen, schwankt aber immer noch stark, setzt aber beim Gehen schon etwas besser die rechte vordere Extremität auf, wenngleich noch immer mit der Dorsalfläche der Zehen, 
Die folgenden 'Tage geht das Thier wieder etwas besser, stets aber vorsichtig, langsam, mübsam.

Am 14. Tage warde in Narcose die Kleinhirmrinde freigelegt und elektrisch gereizt. Auf der linken Kleinhirnhemisphäre erfolgten auf faradische Reizung conjugirte Bewegungen der Bulbi nach links, nach Reizung der rechten Kleinhirnhemisphäre erfolgten conjugirte Ablenkung der Bulbi nach rechts. Auch Rotationsbewegungen der Bulbi und Nystagmus konnte auf faradische Reizung der Kleinhirnrinde beobachtet werden. Auf der linken Hälfte des Mittellappens wurden bei stärkeren Strömen auch Bewegungen im linken Facialis und ganz leichte Bewegungen in der linken, vorderen Extremität erzielt. Der Kopf wirde dabei nach links und hinten gezogen.

Bei anderev auf ähnliehe Weise operirten Katzen und Funden mit Jängerer Lebzeit wurden ähnliche Erschemungen constatirt. Ich elwähne nur vorïbergehend noch einen Fall, wo bei einer Katze die Oberfläche des rechten seitlichen Oberwurmes und eine grössere angrenzende Partie der rechten Kleinhirnhemisphäre exstirpirt wurde. Die vordersten Antheile des Oberwurmes blieben unversehrt.

Bei der Auslöffelung der erwähnten Partie des rechtsseitigen Oberwuímes und der rechten Kleinhirnhemisphäre entstanden Zwinkern der Augen, Oeffnen der Kiefer, Bewegungen im Facialisgebjete, Zurücliziehen des Kopfes.

Nach der Operation erwies sich das Thier ganz ataotisch, fällt, weun man es aufstellt, sofort zur Seite, das Vorderbein wird mit dem Dorsum aufgesetzt. Es machen sich tonische Streckungen der Muskeln der vorderen Extremitäten und des Kopfes geltend. Das Thier geht einige Schritte nach rückwärts. Die Kniesehnenreflexe sind gesteigert.

Am Tage nach der Operation macht sich eine allgemeine Schlaffheit der Muskeln geltend, hier und da treten dann wieder tonische Streckungen auf. Die Katze vermag weder zu gehen, noch zn sitzen, muss künstich mit der Pipette ginährt werden. Die A taxie besserte sich ime Verlaufe der nächsten Tage, ebenso wie im oben geschilderten Falle.

\section{Abtragung des ganzen rechten Kleinhirnseitenlappens und des angrenzenden caudalen Theiles des Oberwurmes.}

Bei einem erwachsenen Hunde wurde die Rinde der ganzen rechten Kleinhirnhemisphäre entfernt, wobei auch der angrenzende hintere Theil des Oterwurmes mitverletzt wurde. Nach dieser Operation machten sich sehwere Allgemeinerscheinungen geltend. Der Hund lag schlaff da, vermochte sich nicht zu erheben und der Kopf des Thieres wurde zur Seite gezogen.

Gleich bei der Operation machte sich eine dauernde conjugirte Ablenkung der Bulbi nach links geltend bei Auslöffelung der Rindenpartien der rechten Kleinhirnhemisphärea, welche knapp an die rechte Seite des Oberwurmes stossen. Bei Auslöffelung der Rindenpartien der rechten Kleinhimbemisphäre, die weiter seitlich gelegen sind, werden die Bulbi conjugirt nach rechts abgelenkt, Ausserdem warden conjugirte Ablenkung der Bulbi nach oben, Rad- 
drehung dieser, Nystagmus, Bewegungen des Unterkiefers, Zuckungen im Facialisgebiete leichte Adductionsbewegungen der rechten vorderen Extremität während der Auslöffelung beobachtet. Es erfolgten Bewegungen des Kopfes nach aufwärts und rückwärts und Angenzwinkern. Das Thier liegt schlaff da und vermag sich nicht aufzurichten. Das rechte Vorderbein (Spasmen) wird stark flectirt gehalten und kann nur mitKraftanwendung passiv gestrecktwerden. Der Hund vermag sich nicht aufzusetzen und fällt, passiv in diese Lage gebracht, zur Seite. In der Zunge werden oft Krämpfe beobachtet, so dass er diese nicht dirigiren kann und zwischen den Zahnreihen bleibt; ist der Krampf vorüber, kann er die Zunge wieder gut gebrauchen. In der rechten vorderen Extremität wechseln tonische Muskelspannung mit folgender Erschlaffung ab. Wird der Hund passiv aufgerichtet, so wird die rechte Vorderpfote mit dem Dorsum aufgesetzt, der Kopf und Rumpf wird nach rechts verdreht und er fällt zur Seite um und vermag auch nicht zu. sitzen. Die Pupillen sind gleich und reagiren.

In der Folgezeit machten sich die atactischen Störungen in den Extremitäten, in der Haltung des Kopfes, in den Zungenbewegungen lebhaft geltend. Der Hund vermochte nur in der Bauchlage oder Seitenlage zu liegen. Tonische Muskelspannungen der Extremitäten traten beständig auf. Zu gehen vermochte der Hund nicht.

Bei dem Hunde erfolgten die ersten Tage keine Wälzbewegungen, sondern er lag ganz schlaff, erschöpft da.

In der folgenden Zeit macbten sich Wälzbewegungen um die Längsachse geltend, d. h. bei Abtragung der rechten Kleinhirnhemisphäre im umgekehrten Sinne des Uhrzeigers, wenn die Uhr mit dem Zifferblatt capital wärts gehalten wird. Während der Rotationsbewegungen werden die Augen conjugirt nach der gesunden Seite abgelenkt. Der Hund liegt gewöhnlich ruhig auf der Seite, bei Annähernng und beim Versuch ibn zu untersuchen erfolgen heftige Wälzbewegungen.

Die rechtsseitige rordere Extremität bleibt während der ersten Zeit immer stark flectirt, contracturirt. Mitunter treten heftige Streckbewegungen in den vorderen Extremitäten ein. Der Kopf des Thieres wird nach der verletzten Seite nach rückwärts gezogen; dabei ist auch die Wirbelsäule nach der Seite verkrümmt. Das Thier muss künstlich mit derPipette genährt werden, schluckt dabei schlecht und magert zusehends ab. Ganz erschlafft liegt das Thier ruhig, apathisoh da. Am Ende der ersten Woche hat die abnorme Stellung des Kopfes und der Wirbelsäule nachgelassen, während die Wälzbewegungen schon am vierten Tage aufhörten. Das Thier vermag sich nun schon aufzusetzen, nicht aber sich aufzurichten. Die Sehnenreflexe sind anfangs erheblich gesteigert.

Der Muskel- und Lagesinn erweist sich gestört, indem die erste Zeit die rechte Vorderpfote mit dem Dorsum aufgesetzt wird.

Erst nach zwei Wochen vermochte der Hund zu stehen, dabei werden die Beine stark weggespreizt, um eine grössere Unterstützungsfläche zu haben, doch fällt er beim Versuche sich aufzurichten oft zur Seite. In der dritten Woche macht das Thier die ersten Gehversuche. Diese erscheinen für das Thier äusserst mühevoll und kosten ihm viele Anstrengung, kaum ist es einige Schritte tau- 
melnd gegangen, fällt es atactisch oft schleudernd zur Seite. Der Kopf und der Körper wackelt beständig, was sich namentlich bei intendirten Bewegungen zeigt, besonders bei der Nahrungsaufnahme wackelt der Kopf über der Oberfläche der Milch hin and her, ohne zur Nahrungsaufnahme zu kommen; dabei. schwankt auch der Körper und der Hund fällt oft zur Seite.

Beim Versuche zu gehen balancirt der Hund mit Anstrengung hin und her und fällt schliesslich zur Seite odèr nach rückwärts. Der Hund geht mit weit gespreizten Beinen und ist bald sehr ermüdet. Bei allen intendirten Bewegungen besteht Ataxie und Schwanken, der Kopf wackelt hin und hor, der Körper schwankt nach allen Seiten.

Alle Erscheinungen besserten sich in der fünften and sechsten Woche, nur das Wackeln des Kopfes und eine gewisse Schwäche und leichte Ermüdbarkeit blieb noch bestehen, welche die ersten zehn Wochen andauerten.

Störungen im Intellect, im Hören und Sehen wurden nicht beobachtet.

Bei der Obduction wurde die totale Entfernung der rechten Kleinhirnhemisphäre und des caudalen Antheils des Wurmes constatirt.

Die Juntersuchung der Frontalschnitte ergab gegenüber der früheren Versuchsreihe nichts Neues. Die Untersuchung ausgedehnter Verletzungen und Abtragungen des Kleinbirns sind für die Anatomie weniger ergiebig als kleine circumscripte Verletzungen des Kleinhirns, wie sie in den vorigen Versuchsreihen geschildert wurden.

\section{Abtragung einer Kleinhirnhälfte.}

Die Operation wurde an erwachsenen Hunden und Katzen in ähnlicher Weise ausgeführt wie sie von L n ciani beschrieben wurde. Gleich nachdem die Operation ausgeführt wurde, wurde das Thier auf den Boden gelegt, wo es ruhig und schlaff ganz passiv liegen blieb.

Nach einigen Stunden macht der Hund heftige Walzbewegungen von der gesunden zur kranken Seite, oder richtiger ausgedrückt, nach linksseitiger. Entfernung der Kleinhirnhälfte macht der Hund Wälzbewegungen im Sinne des Uhrzeigers, wenn die Uhr in der Querschnittebene des Körpers liegt und mit dem Zifferblatte gegen den Kopf sieht. Auf Schallund Berührung werden die Wälzbewegungen wiederholt ausgelöst. Der Hund liegt auf der operirten Seite mit nach links zurückgebeugtem Kopfe und ausgestreckten vorderen Extremitäten. Ausserdem konnte Nystagmus und conjugirte Augenablenkung pach der gesunden Seite constatirt werden. Der Hund muss durch Eingiessen von Milch ernährt werden, dabei zeigen sich keine erheblichen Schluckbeschwerden.

Die Wälzbewegungen dauern durch einige Tage an. Wenn sich der Hund aufzurichten versucht, fällt er sofort auf die operirte Seite. Der ganze Körper, der Kopf und die Beine zeigen ein Zittern und Schwanken. Der Hund liegt beständig am Boden und vermag weder zu sitzen noch za stehen. Die Vorderbeine sind ansgestreckt und besonders wird das linke steif gehalten.

Die Augenablenkung und der Nystagmus schwinden in den nächsten Tagen. Später versucht das Thier sich auf die Beine zu erheben, fällt aber 
sofort auf die linke Seite. Um das Schwanken und Schütteln des Kopfes und und Rumpfes zu verhindern stützt er sich gegen die Wand. Wenn er in den folgenden Tagen die Milch aus der Schüssel lecken will, schwankt der Kopf so hin und her und zurück, dass er nicht zum Ziele gelangt und ihm der Kopf gehalten werden muss.

Nach zwei Wochen vermag sich der Hund zu erheben und sucht dabei eine grosse Stützfläche durch das Ausspreitzen der Beine zu gewinnen, dabei fällt er aber oft auf die linke Seite. In den ersten Wochen magerte der Hund zusehends ab. Die Pfote der operirten Seite zeigt Muskelsinnstörungen and wird durch kurze Zeit mit dem Dorsum aufgesetzt,

Nacb drei Wochen geht der Hund schon einige Schritte, schwankt aber dabei heftig, spreizt die Beine weg und fällt. Bei der Nahrungsaufnahme schwankt der Kopf des Thieres stark und jedesmal wenn er eine Bewegung intendirt, werden diese Schwankungen stärker. Die Kniesehnenreflexe sind sehr gesteigert, besonders links.

Nach vier Wochen geht der Hund schon viel besser, er erfasst besser die Nahrung und schwankt nur wenig. Die Erscheinungen, welche die halbseitige Kleinhimabtragung hervorgerufen, bessern sich im Laufe des zweiten Monats noch mehr, so dass die meisten Erscheinungen nur mehr durch Kunstgriffe hervorgerufen werden können. Die Kniesehnenreflexe bleiben gesteigert. Der Hund ermüdet sehr rasch. Bei der Obduction lronnte die vollständige Entfernung der linken Kleinhirnhälfte constatirt werden.

Die wichtigsten Erscheinungen nach halbseitiger Abtragung des Kleinhirnes bestehen nach meinen wiederholten Versuchen in der cerebellaren Ataxie, im Wackeln des Kopfes, im Schwanken des Körpers, der Hund geht wie ein Betrunkener; besonders bei intendirten Bewegungen, beim Erfassen der Nahrung tritt diese Ataxie auf; bei linksseitiger Abtragung entstehen bäufig in den ersten Tagen Wälzbewegungen im Sinne des Uhrzeigers, bei rechtsseitiger im entgegengesetzten Sinne des Uhrzeigers. Die Bulbi sind meist nach der gesunden Seite abgelenkt, die vordere Extremität der Operationsseite zeigt starke Spasmen, diese Extremität zeigt auch Muskelsinnstörungen, indem sie mit dem Dorsum aufgesetzt wird. Der Intellect ist nicht geschädigt, der Hund ist sehr deprimirt, bellt nicht und ermüdet rasch. Oft bestehen Schluckbeschwerden und Erbrechen. Die Wirbelsäule ist oft verbogen mit der Concavität zur Operationsseite. Die Kniesehnenreflexe sind immer beiderseits sehr gesteigert. Der Hund vermag erst nach zwei oder drei Wochen zu stehell, bei den Gehversuchen fällt er taumelnd zur Seite, sobald er ein Bein erhebt. In der Folge schwinden diese Störungen und das Thier vermag wieder über Stiegen zu laufen. Das Gehör und das Gesicht ist nie gestört. Sind die Spasmen und Contracturen in den Extremitäten der Operationsseite geschwunden, so lässt sich eine ge- 
wisse Schwäche und Schlaffheit in den Muskeln dieser Extremitäten nachweisen.

\section{Vollständige Kleinhirnabtragung.}

Nur wenige Thiere überlebten die vollständige Kleinhirnabtragung längere Zeit; meist gehen sie schon innerhalb der ersten Wochen zu Grunde, nur wenige sind länger am Leben zu erhalten.

Nach der Operation wurden bei einem Hunde, der längere Zeit am Leben blieb, Wälzbewegungen constatirt, die aber nur gering waren und bei den übrigen Thieren fehlten. Das Thier liegt hernach ganz passiv und schlaff da. Einige Stunden später werden die Vorderbeine tonisch gestreckt und der Kopf wird nach rückwärts in den Nacken gezogen.

Es zeigt sich keine Augenablenkung. Das Thier muss künstlich ernährt werden.

Der Kopf des Thieres wird oft nach hinten und nach links verzogen. Die Sehnenreflexe an den hinteren Extremitäten sind lebhaft gesteigert. Die Wälzbewegungan dauern nur die ersten Tage an. Der Kopf schwankt aber beständig hin und ber, so dass er lieine Nahrung erfassen kann. Wenn das Thier mit dem Kopfe zu dem vorgehaltenen Stück Zucker kommt, macht es noch stärkere Schwankungen.

Der Hund liegt beständig auf der linken Seite, unterstüzt den Kopf, um das Wackeln zu verhindern.

Nach zwei Wochen werden die ersten Gehversuche gemacht, doch vermag er erst nach vier Wochen sich ein wenig zu stützen, indem er die Vorderbeine auseinanderspreitzt. Das Thier ist apathisch; das Wackeln des Kopfes hält an, besonders bei intendirten Bewegungen. Die Kniesehnenreflexe sind gesteigert.

Nach vier Wochen vermag der Hund einige Schritte zu gehen, doch geht es dabei mit den Hinterbeinen noch sehlecht. Dabei fallt der Hund oft zur Seite. Die heftigen Schwankungen des Körpers und das Wackeln des Kopfes bringen ihn zum Falle. Meist liegt das Thier apathisch da, bellt nicht, nimmt keine Nahrung. Die Extremitäten zeigen sich stark spastisch und zeigen für kurze Zeit Muskelsinnstörungen.

Der: Hund geht in den folgenden Tagen besser, geht aber bei seiner starken Abmagerung nach 5 Wochen zu Grunde.

Aebnlich verhielten sich die übrigen Thiere.

\section{Abtragung des ganzen Kleiuhirnmittellappens.}

Die Operation wurde nach Luciani durchgeführt. Sofort nach der Operation treten bei dem Hunde Streckbewegungen in den Vorderbeinen ein, während der Kopf heftig in den Nacken zurückgezogen wird, dabei besteht Nystagmus und Blick nach abwärts. Der Hund schluckt die eingeflösste Milch nur schwer. Die nächsten Tage vermag er sich schon auf den auseinander gespreizten Beinen zu exhalten, sohwankt aber dabei stark mit dern Körper und. 
geht häufig zwangsmässig nach rückwärts, besonders beim Erfassen von Nahrung. Die Kniesehnenreflexe sind sehr lebhaft und beiderseits gleich. Die vordere Extremität wird mit dem Dorsum die ersten 'Tage aufgestellt.

In der zweiten Woche treten die Schwankungen des Körpers und das Schütteln des Kopfes in den Hintergrund, er geht wieder gut, nimmt selbst die Nahrung, vermag sich auf die Hinterbeine zu stellen. Die Schwankungen des Körpers sind ganz geringfügig geworden. Nur wenn man ibn auf den Hinterbeinen allein stehen lässt und ihm dabei Nahrung vorgehalten wird, machen sich noch Schwankungen des Körpers geltend. In der Folgezeit schwinden aber alle atactischen Bewegungen, so dass der Hund kaum von einem nicht operirten zu unterscheiden ist.

Bei der Obduction warde die Entfernung des ganzen Oberwarmes constatirt.

\section{Rindenabtragung des rechten Kleinhirnseitenlappens mit Schonung des oberwurmes.}

Bei einer erwachsenen Katze wurde die Rinde des hinteren Antheils des rechten Kleinhirnseitenlappens entfernt, wobei der Oberwurm geschont blieb. Beim Auslöffeln erfolgt conjugirte Ablenkung der Bulbi nach rechts und oben, in welcher Stellung die Bulbi lange bleiken. Ausserdem erfolgt Zusammenzwinkern der Augenlider, geringe Zuckungen im rechten Facialisgebiete, in der rechten vorderen Extremität, Bewegungen der Zunge, der Schnauze. Es tritt Nystagmus verticalis auf, welcher auch nach der Operation andauert. Der Kopf des Thieres wird während der Operation krampfhaft nach rückwärts gezogen.

Tach der Operation liegt die Katze ruhig und ganz schlaff da. Beide rechtsseitigen Extremitäten sind schlaff, während die linksseitigen tonisch weggestreckt werden. Die Katze vermag nicht zu sitzen, da sie sich auf die rechtsseitigen, wie paretisch erscheinenden Extremitäten nicht stützen kann. Passiv aufgerichtet, setat sie die rechte Vorderpfote mitdem Dorsum auf und fällt freigelassen zur Seite. Die Bulbi sind noch nach der rechten Seite etwas abgelenkt. Die Papillen sind sehr weit und gleich. Eine kurze Zeit hindurch waren die Pupillen ungleich. Die Katze muss künstlich mit der Pipette ernährt werden.

Einige Stunden nach der Operation sind kurz dauernde Wälzbewegungen im entgegengesetzten Sinne des Uhrzeigers aufgetreten.

Der Kopf wurde in der Folgezeit krampfhaft nach links gedreht. Beim passiven Aufstellen exscheinen die rechtsseitigen Extremitäten schlaff wie paretisch, wie nach Entfernung der motorischen Rindenzone des Grosshirns.

Die Katze vermochte sich später aufzusetzen und schrittweise vorsichtig za gehen, doch fällt sie dabei zur Seite. Es trat eine starke Abmagerung ein und das Thier ging bald zu Grunde.

Wie anatomischen Resultate bei diesen Versuchen waren ganz entsprechend den Ergebnissen der schon früher genauestens geschilderten Versuche. 
Ich habe in den oben gesehilderten Versuchen absichtlich nur jene Kleinhirnläsionen ausführlich in den anatomischen Folgen geschildert, welche klein und circumscript sind, da grosse Kleinbirnläsionen viel leichter unrichtige anatomische Resultate liefern.

Manche Autoren (Biedl, Bechterew) haben bei ihren halb= seitigen Kleinhirnabtragungen Faserbündel degenerirt gefunden, die mit dem Kleinhirn gar keine Gemeinschaft haben. Bei den grossen Läsionen des Kleinhirns werden leicht andere Gebiete mit verletzt und in der Folge degeneriren dann secundär Bündel, die gar nicht vom Kleinhirn abhängig sind. Namentlich wurde von verschiedenen Autoren das von mir genauer geschilderte Monakow'sche Bündel bei grossen Kleinhirnläsionen verletżt, wenn das Instrument zu tief kam. In der Folge wurde dann der Ursprung des Monakow'schen Bündels fälschlich im Kleinhirn angenommen, während es thatsächlich nach meinen Untersuchungen von den Ganglienzellen des rothen Kernes abgeht. Im Folgenden will ich nun genauer eine solche Kleinhirnläsion schildern, bei der auch das Monakow'sche Bündel verletzt wurde und ausserdem auch ein Theil des Deiters'schen Kernes und die Acusticuswurzeln. Die Degeneration des Monakow'schen Bündels und der centralen Hörbahn sind von der Kleinhirnläsion unabhängig. Ausserdem will ich den folgenden Fall zur anatomischen Darstellung der centralen Hörbahn herbeiziehen.

\section{Zerstörung der rechten Kleinhirnhemisphäre und des rechtsseitigen Mittellappens.}

Bei einer erwachsenen Katze wurde die rechte Kleinhirnhemisphäre und der rechtsseitige Oberwurm ausgelöffelt. Dabei wurden auch der Strickkörper, der Brückenarm und der Bindearm bei seinem Ursprunge und der Deiters'sche Kern zerstört; ausserdem war neben dem Strickkörper noch die aufsteigende Trigeminuswurzel und der Nervus acusticus zerstört worden.

Während der Auslöffelung der rechten Kleinhirnhemisphäre geschehen conjugirte Blickablenkungen nach rechts, Raddrehungen des rechten Augès. Kein Nystagmus. Nach der Operation fand sich eine Lähmung und Anästhesie der rechten Gesichtshälfte. Bewegungsstörungen machten sich in Form von Wälzbewegungen im entgegengesetzten Sinne des Uhrzeigers geltend.

Drei Stunden nach der Operation werden Wälzbewegungen von der gesunden zur verletzten Seite im entgegengesetzten Sinne des Uhrzeigers beobachtet, ferner Nystagmus rotatorius. Die rechte Pupille ist um die Hälfte weiter als die linke. In den rechtsseitigen Extremitäten ist der Tonus bedeutend erhöht gegenüber links. Der Kniesennenreflex ist beiderseits gesteigert.

Fünf Tage nach der Operation hört der Nystagmus auf. Die Wälzbewegungen waren die ersten Tage hindurch zu beobachten. 
Die Katze, die bisher nicht sitzen konnte, versucht sich am 5. Tage aufzurichten, dabei dreht sich der Kopf und Rumpf (Wirbelsäule) stark nach links.

Die Bewegungen der vorderen Extremität geschehen hastig, übereilt, dabei zittert und wackelt die Extremität atactisch. Ein Stück Fleisch, das vor ibr liegt und das sie fassen will, sucht sie mit der Vorderpfote zu erlangen, dabei ist aber die Bewegung so atactisch, dass sie daneben fährt, die Katze beisst in das Fleisch, vermag aber nicht zu kauen und zu schlucken; flüssige Nahrung schluckt sie gut. Die Katze wird mühsam mit der Pipette ernährt.

Die Katze empfindet Nadelstiche in den rechtsseitigen Extremitäten. Die Pupillen sind gleich und reagiren. Die rechtsseitigen Extremitäten werden spastisch gehalten, flectirt sowio in den übrigen Kleinhirnversuchen und zeigt MuskeIsinnsstörungen, so dass die Katze auch mit der Dorsalfläche der Zehen auftritt, wenn man sie passiv aufstellt. Die Katze gebraucht nur die linksseitigen Extremitäten, wenn man sie passiv aufstellt wird die rechte vordere Extremität mit der Dorsalseite der Zehen aufgestellt, wie nach Exstirpation der motorischen Rindenzone des Grosshirns.

Die Katze vermag nicht zu sitzen. Eine ebensolche Ataxie, wie bei Bewegungen in der vorderen Extremität, macht sich bei Bewegungen des Kopfes geltend. Beständig wenn die Katze eine Bewegung machen will, wackelt sie mit dem Kopfe.

Am sechsten Tage nach der Operation liegt die Katze ruhig auf ihrem Lager. Am rechten Auge, entsprechend dem verletzten austretenden Trigeminus, zeigt sich eine Keratitis mit Conusbildung. Das rechte $\mathrm{Ohr}$ und die rechte Gesichtshälfte empfinden aber jetzt.

Die Katze vermag nicht zu sitzen und fällt passiv aufgestellt zur Seite und macht daranschliessend Wälzbewegungen im umgekehrten Sinne des Uhrzeigers. Nystagmus ist nur zeitweise vorhanden. Die rechte Gesichtshälfte ist noch gelähmt. Das rechte Vorderbein wird eingezogen, flectirt gehalten wie bei einer Contractur and wird nicht in Gebrauch gesetzt, und sieht wie paretisch aus, während die linke, vordere Extremität gut gebrauchsfähig ist.

Sobald die Katze intendirte Bewegungen mit dem Kopfe macht, wackelt sie heftig mit dem Kopfe; sie macht nickende, wackelnde Bewegungen wie bei den oben genauer geschilderten Fällen mit Abtragnng einer Kleinhirnhälfte.

Das Thier muss künstlich gefüttert werden. Die Kniesehnenreflexe sind sehr lebhaft.

Am 12. Tage vermag die Katze noch jmmer nicht zu sitzen, wird sie aufgesetzt, so fällt sie zur Seite, es ist ihr das Gleichgewicht, sowie der Gebrauch der rechten vorderen Extremität vollständig vernichtet. Es treten mitunter leichte Wälzbewegungen auf. Der Nystagmus tritt noch zeitweise auf.

Am 17. Tage entstand eine Iridocychitis des rechten Auges durch die mechanisohen Verletzungen und am 19. Tage erfolgt der Durchbruch der 
Hornhaut an der Conusstelle. In der folgenden Zeit vernarbte die grosse Wunde.

An 19. Tage vermag die Katze schrittweise, vorsichtig durch die ganze Länge des Zimmers zu gehen, fällt aber dabei oft nach rechts um. Der Kopf wackelt heftig dabei.

Die Katze geht in den folgenden Tagen sehr mühsam, als ob sie eine Last am Rücken tragen möchte und fällt oft nach rechts und oft nach der Verletzungsseite um, dann soheint sie von der übergrossen Anstrengung des Gehens auszuruhen. Das Wackeln mit dem Kopfe hält beständig an. Die rechtsseitigen Extremitäten versagen und erscheinen paretisch. Am 20 . Tage nimmt die Katze selbst Nahrung.

Auch in der Folgezeit geht die Katze sehr müheselig. Der rechte Facialis und Trigeminus erscheint noch gelähmt. Die Katze beisst sich beim Kauen in die rechte Zungenhälfte. Ob die Katze rechts hört oder nicht hört, war bei dem Thiere nicht mit Sicherheit zu entscheiden.

Die Katze geht beständig schwerfällig und fällt dabei nach rechts um, die rechte vordere Extremität wird etwas besser auf den Boden gesetzt. Die Katze ermüdet sehr rasch.

Am 27. Tage nach der Operation werden beide motorischen Centren der Grosshirnrinde freigelegt und faradisch gereizt. Von beiden motorischen Centren sind sowohl. Zuckungen, als epileptische Anfälle auszulösen' Am linken motorischen Centrum mussten aber für die gleichen Wirkungen stärkere Ströme angewendet werden.

Sowie die Gehirne der übrigen Versuchsthiere so wurde auch dieses auf lückenlosen Serienschnitten nach Osmiumsäurefärbung genauestens anatomisch studirt.

Ich will in diesen Falle die aufgetretenen secundären Degenerationen genauer schildern.

Die Verletzung betraf die rechte Hälfte des Oberwurmes, (wobei die inneren und ventralen Ganglienzellen des rechten Dachkerns verschont blieben), ferner die rechte Kleinhirnhemisphäre, die austretenden Wurzeln des Nervus facialis, Nervus acusticus und Nervus trigeminus. Ausserdem war die aufsteigende Trigeminuswurzel und der rechte ventrale Acusticuskern zerstört, ohne dass die obere Olive dabei gelitten hatte.

Von dieser Verletzung degenerirte nun vom Deiters'schen Kern abwärts die Kleinhirn-Vorderstrangbahn und die Kleinhirn-Vorderseitenstrangbahn, die bis ins Sacralmark verfolgbar waren. In dem Photogramme dieses Falles sehen wir in Figur 14 im obersten Halsmarke die degenerirte Kleinhirn-Vorderstrangbahn (K V) und die KleinhirnVorderseitenstrangbahn (K V S). Im Photogramme Figur 15 sehen wir im K V S die vom unteren Halsmark an als vereinigtes Bündel ( $\mathrm{KV}+$ K V S) absteigende Kleinhirnbahn (Kleinhirn-Vorderseitenstrangbahn). Im 
Photogramm Figur 12 sehen wir im K V S den Verlauf der KleinhirnVorderseitenstrangbahn durch die Substantia reticularis. Die spinale Trigeminuswurzel, die medial vom Nervus acusticus zerstört war, zeigte absteigend degenerirende Fasern die wäbrend ihres Verlaufes zum Halsmark beständig feine Fäserchen in die Substantia gelatinosa Rolandi entsenden, die sich dort bei den Ganglienzellen aufsplittern. Im obersteu Halsmarke liegen diese (eigentlich absteigenden) Fasern der sogenannten "aufsteigenden" Trigeminuswurzel an der Aussenseite der kolbigen Hinterhörner (Substantia gelatinosa) und entsenden dort Fäserchen in diese hinein. Dort, wo die Hinterhörner die kolbige Anschwellung der Substantia gelatinosa verlieren, enden auch die Fasern der aufsteigenden oder besser gesagt, der caudalen oder spinalen Trigeminuswurzel.

Ausserdem konnten Fäserchen caudal von der Verletzungsstelle degenerirt verfolgt werden, die durch den Deiters'schen Kern abwärts ziehen beiderseits zwischen Strickkörper und Fasciculus solitarius biø zu den Burdach'schen Kernen. (Inneres Strickkörperbündel.) Während ihres Verlaufes entsenden sie beständig innere Bogenfasern in die Substantia reticularis. Aehnliche Fasern werden zum Acusticuskern beiderseits entsendet. Alle diese Fasern sind identisch mit den in der früberen Versuchsreibe (Seite 705) gesehilderten Fasern der ausstrahlenden Kleinhimbahn $\mathrm{z}$ und $\mathrm{z}$ Figur $1-3$, die zum grossen Theile vom Dachkern kommen. Zur gegenüberliegenden unteren Olive werden höchst spärliche Fäserchen entsendet.

Die gesunde Kleinhirnhälfte ist erfüllt von degenerirten feinen Fasern, die in der Rinde mit Aufsplitterungen endigen. (Figur 12.) Im Dachkern und gezahnten Kern der unversehrten Kleinhirnhälfte waren degenerirte Fäserchen, die hier endigten, zu sehen, namentlich im mittleren Abschnitte.

Vom zerstörten Areale des Monakow'schen Bündels degenerirten die Fasern abwärts bis ins Sacralmark mit denselben Eigenthümlichkeiten, die ich anderweitig ${ }^{1}$ ) beschrieb. In den Seitenstrangkern giebt das Monakow'sche Bündel zahlreiche Collateralen ab, die mit Aufsplitterungen bier enden. Im Photogramme Figur 14 und Figur 15 habe ich das Monakow'sche Bündel im obersten Halsmark und im Sacralmark abgebildet.

Aufsteigend degenerirten vom zerstörten Areal des Monakow'-

1) Probst, Dieses Archiv, Bd. XXXIII, H. 1 und Deutsche Zeitschrift f. Nervenheilkunde Bd. 15 u. Archiv f. Anatomie a. Physiologie 1901 u. 1902 a. Monatssohr. f. Psych. 1902. 
schen Bündels, jene Fasern, die ich ebenfalls schon anderweitig' ${ }^{1}$ ) beschrieb und im rothen Kern der anderen Seite mit Aufsplitterungen endigen. Ich will hier besonders bemerken, dass diese aufsteigend degenerirten Fasern im Areal des Monakow'schen Bündel's nicht als retrograde Degeneration der Fasern des Monakow'schen Bündels zu deuten sind, sondern eine besondere aufsteigende Bahn im Areal des Monakow'schen Bündels bilden. Eine retrograde Degeneration, die genau so wie die secundüre Waller'sche Degeneration auftreten würde, konnte ich bei meinen Versuchen, im intramedullären Verlauf nicht beobachten, sondern diese Art der Degeneration ist in mancher Beziehung andersartig, doch kann ich mich hier nicht weiter darauf einlassen.

Vom ventralen oder vorderen Acusticuskern aus degenerirten die Fasern des Trapezkörpers auf die andere Seite, indem sie sowohl an die rechte Olive wie an die gegenüberliegende Olive die zahlreichsten Collateralen abgiebt. Namentlich an die Innenseite der gegenüberliegenden Olive geben die degenerirten Trapezkörperfasern die zahlreichsten Collateralen ab, die daselbst endigen. (Tr Figur 12 und Figur 13.)

Die Hanptmasse der degenerirten Trapezlsörperfasern zieht weiter lateral, und bildet den lateralsten Antheil der lateralen Schleife, der zum Theil mit Aufsplitterungen im Kern der lateralen Schleife endigt, zum Theil zum hinteren Zweihügel weiter zieht und mit Aufsplitterungen dort endigt. (Tr Figur 13). Der mediale Antheil der lateralen Schleife kommt von der lateralen Acusticuswurzel und von dem Tubereulum acusticum der gegenüberliegenden Seite her, wie wir noch sehen werden.

Auf einem Frontalschnitte, wie einen das Photogramm Figur 12 zeigt, finden wir zahlreiche degenerirte Fasern, die dem dorsalen Längsbündel zustreben, die vom Deiters'schen Kern kommen; die Mehrzahl der Fasern geht in die laterale Partie des gleichseitigen hinteren Längsbündels (H L Figur 12 und 13), die geringere Zahl in das gegenüberliegende hintere Längsbündel. Sowohl die Fasern, die zum gleichseitigen, als die zum gegenüberliegenden hinteren Längsbündel gehen, geben zahlreiche Collateralen in den Abducenskern, Trochleariskern und Oculomotoriuskern ab, die dort mit Aufsplitterungen endigen.

Dịe sensiblen Fasern der austretenden Trigeminuswurzel degenerirten aufwärts zum gleichseitigen sensiblen Trigeminuskern; die zum gegenüberliegenden sensiblen T'rigeminuskern ziehenden Fasern waren durch die Degeneration ebenfalls bis dorthin verfolgbar. 
Interessant waren die Degenerationen der austretenden Acusticuswurzel zu verfolgen. Der ventrale Acusticuskern war ebenfalls zerstört.

Die laterale Acusticuswurzel degenerirte im dorsalen Zug um den Stricklörper gegen den frontalen Antheil des dreieckigen Acusticuskerns (Bechterew'scher Kern) hin. Hier endigten diese degenerirten Fasern mit Aufsplitterungen. Die vom Tuberculum acusticum kommenden degenerirten Fasern zieben nach innen und unten in die Substantia reticularis in der Richtung zur gegenüberliegenden oberen Olive. (x Figur 12). In einem starken Znge, der die Substantia reticularis durchflicht, erreichen diese Fasern die dorsale Seite der oberen Olive, (x Figur 12) wo vielleicht einige Collateralen abgegeben werden. Der Hauptzug dieser Fasern gelangt in das Areal des Monakow'schen Bündels, von wo aus der ziemlich mächtige Faserzug zur lateralen Schleife zieht ( $x$ Figur 13) und deren schon oben erwähnte mediale Abtheilung ausmacht. Dieses Bündel hat Monakow offenbar verfolgt bei Beschreibung seines aberrirenden Bündels und für Fasern des von mir genauer geschilderten Monakow'schen Bündels gehalten. Das Bündel zieht dann weiter zum medial-ventralen Rand des hinteren Zweihügels, wo es mit feinen, zahlreichen Aufsplitterungen endigt. In dieser Weise hätten wir also sowohl den medialen als den lateralen Antheil der lateralen Schleife genau bestimmt. Der mediale Antheil der lateralen Schleife liegt also eine Zeit lang im Areal des Monakow'schen Bündels zwischen oberer Olive und motorischen Trigeminuskern. Diese vom ventralen Acusticuskern und vom Tuberculum acusticum kommenden Fasern bilden die centrale Hörbahn ${ }^{1}$ ).

Ausser diesen Fasern ziehen vom rechten Tuberculum acusticum und der aufsteigend degenerirten lateralen Acusticuswurzel und vom Deiters'schen Kern degenerirte innere Bogenfasern im dorsalen Theile der Substantia reticularis in den gegenüberliegenden Deiters'schen Kern und Acustikuskern. Degenerirte Fasern gelangen auch über den rechten Deiters'schen Kern in die linke laterale Acusticuswurzel. Degenerirte Fasern strahlen auch in den Flocculus der gesunden Seite ein.

Die vom Kleinhirn aus degenerirten Brückenarmfasern (BrA Fig. 13) gelangen im medialen Antheil, theils indem sie die Pyramidenbahn durchkreuzen in das gegenüberliegende Brückengrau, woselbst diese Fasern mit Aufsplitterungen endigen (e Figur 13). Ein Theil der Brückenarmfasern steigt in der Raphe aufwärts and gelangt in den

1) Probst, Zur Anatomie und Physiologie der Leitungsbahnen des Gehirnstammes. Arch. f. Anatomie u. Phys. anatom. Abth. 1902. 
gegenüberliegenden Nucleus reticularis pontis, wo die Fasern endigen. Im Brückenarm giebt es keine rom Kleinhirn zum Rückenmark absteigende Bahnen, wie es Biedl u. A. annehmen.

Das ventrale Kleinhirn-Thalamusbündel (v K Th Figur 13) degenerirte proximalwärts, wie ich das in der ersten Versuchsreihe genauer schilderte. Die degenerirten Fasern ziehen durch den Deiters'schen Kern und überschreiten als innere Bogenfasern die Raphe und biegen in die Ecke zwischen Raphe und medialer Schleife und die sagittale Richtung um. Eine Menge Collateralen werden in den Nucleus reticularis pontis (Nr 4 Figur 13) entsendet. Das Bündel zieht ventral von der Vierhïgel-Vorderstrangbahn (v K Th Figur 13) und medial ventral vom rothen Kern in die innere Marklamelle des Sebhügels und in den Kern vent a, wo es mit Aufsplitterung endigt.

Die. Dachkernfasern kommen ganz so wie $\mathrm{c}$ in Figur 4 dorsal im Bindearm zu liegen (c Figur 13), indem sie vom rechten Dachkern in der Raphe des Oberwurmes auf die andere Seite ziehen und auf dem linken Bindearm aufliegen. Daselbst verlaufen sie dann ohne sich noch. einmal zu kreuzen in die linken Forel'schen Haubenfascikel, welche sie bilden (accessorisches Bindearmbündel). Von hier aus entsenden sie einzelne Fasern in die hintere Commissur, die bis zur medialen Grenze des caudalsten Antheils des gegenüberliegenden (rechten) Sebhügels zu verfolgen sind, wo sie mit Aufsplitterungen endigen. Der weitere Verlauf dieser Fasern, welche die Forel'sche Haubenfascikeln bilden, ist in die frontale Haubenstrahlung, das Kleinhirn-Thalamusbündel. Von hier aus werden Fasern theils in die innere Yarklamelle des Sehhügels entsendet, med $c$, theils zum Kern vent a, wo die Fasern mit Aufsplitterungen endigen. Auch in Ganglienzellen, die zwischen innerer Marklamelle des Sehhügels und dem Kern vent b gelegen sind, endigen viele dieser Fasern mit Aufsplitterungen; die proximaler verlaufenden Fasern gehen in der frontalen Haubenstrahlung weiter und entsenden später ihre Fasern in die innere Marklamelle, um in den caudalen Antheilen des Kerns med $\mathbf{c}$ und zwischen med $\mathrm{c}$ und vent a und der äusseren Marklamelle zu endigen.

Der degenerirte Bindearm verlief so, wie in der ersten Versuchsreihe geschildert. Die dorsal verlaufenden Dachkernfasern ( $c^{1}$ Fig. 13) verlaufen ebenso, wie die eben geschilderten Dachkernfasern der anderen Seite. Der Bindearm geht die gewöhnliche Kreuzung ein, nachdem er einen ventraleu Antheil vorher zum ventralen Kleinhirn-Thalamusbündel entsendet hat. In die hintere Commissur werden Fasern entsendet.

Das ventrale und dorsale Kleinhirnbündel verlänft dann zusammen als Kleinhirn-Thalamusbündel weiter in der frontalen Haubenstrahlung 
und im dorsalen Mark der Regio subthalamica. Von hier aus werden beständig Fasern in die innere Marklamelle entsendet, in deren Kernen die Fasern zum Theil mit Aufsplitterungen endigen. ${ }^{1}$ ) Die proximal verlaufenden Fasern werden am spätesten in die innere Marklamelle des Sehhügels entsendet und endigen alle mit Aufsplitterungen im Kerne vent a, so dass die feinsten Aufsplitterungen bis zur äusseren Marklamelle des Sehhügels reichen. (Figur 7 und 8).

Eine kleine Partie von Fasern, die als Bogenfasern mit den Fasern zum medialen Antheil der lateralen Schleife in der Brücke knapp über dem lateralen und mittleren Antheil der der Verletzungen gegenüberliegenden medialen Schleife zu liegen kommen, scheint bis zu den medialen grossen Ganglienzellen des gegenüberliegenden inneren Kniehöckers zu verfolgen zu sein, wo diese Fasern Verbindungen einzugehen scheinen.

Dieser Versuch zeigt uns in anatomischer Hinsicht bezüglich der centrifugalen Kleinhirnfasern ganz dieselben Resultate, wie die Experimente der früher geschilderten Versuchsreihen. Ausserdem sehen wir aber in diesem Falle anatomisch die centrale Hörbahn dargestellt und auch das Monakow'sche Bündel und die spinale Trigeminuswurzel ist degenerirt. Auf das Monakow'sche Bündel brauche ich mich hier nicht näher einzulassen, da ich dieses anderweitig geschildert habe.

Bezüglich der Striae acusticae konnte ich feststellen, dass diese vom Tuberculum acusticum ausgehen und gleichsam als Fortsetzung der lateralen Acusticuswurzel in Form von imeren Bogenfasern zur gegenüberliegenden oberen Olive, von hier in's Areal des Monakow'schen Bündels ziehen und dann in den inneren Antheil der lateralen Schleife übergehen und beim hinteren $Z$ weihügel mit Aufsplitterungen endigen.

Bezüglich der Trapezfasern konnte ich feststellen, dass diese vom ventralen Acusticuskern aus auf die andere Seite ziehen, nachdem sie zahlreiche Collateralen an die diesseitige und eine grössere Anzahl an die jenseitige obere Olive abgegeben haben. Von der ventralen Seite der gegenüberliegenden oberen Olive ziehen die Fasern in den äusseren Anthcil der lateralen Schleife und endigen zum grossen Theil im lateralen Schleifenkern, zum Theil auch beim hinteren $Z$ weihügel. Einzelne Fasern, die von der Verletzungsstelle kommen, ziehen an der dorsalen

1) Der Verlauf u. die Endigung des Kleinhirn-Sehhügelbündels (Bindearm) beim Mensehen ist ganz ännlich wie beim Hund und bei der Katze. Ich habe die Verhältnisse des Bindearmes beim Menschen in einer Arbeit: ,Zur Kenntniss des Bindearmes, der Haubenstrahlung u. der Regio subthalamica," Monatsschrift f. Psychiatrie u. Neurologie 1901, beschrieben und abgebildet. 
Seite der medialen Schleife an die Innenseite des inneren Kniehöckers, wo sie Verbindungen einzugehen scheinen, sie gehören aber nicht zu den Striae acusticae.

Ich kann die Ansicht Monakow's, dass die centrale Hörbahn im binteren Zweihügel unterbrochen wird, bestätigen. Auch fand ich gleich Monakow nach Abtragung eines Temporallappens eine degenerirte Bahn (nach Marebifärbung), die unter dem Linsenkern zum inneren Kniehöcker und Kern vent $c$ zog und dort endigte ${ }^{1}$ ). Wie sich die Verbindung des hinteren $Z$ weihügels, mit dem inneren Kniehöcker vollzieht, ist weder nach Abtragung eines Temporallappens, noch nach intracranieller Durschneidung der Hörnerven zu eruiren. Nach Verletzung des Tuberculum acusticum degeneriren einzelne Fasern auf die dorsale Seite der gegenüberliegenden medialen Schleife, die zum inneren Kniehöcker ziehen. Diese Faseru sind auf Mitverletzung des Monakow'schen Kerns zu beziehen. Die Hauptverbindung zwischen hinterem Zweibügel und innerem Kniehöcker geschieht durch den hinteren Zweihügelarm, wenigstens ist eine andere Verbindung nicht auffindbar ${ }^{2}$ ).

Auch nach intracranieller Durchschneidung der Hörnerven fand ich ähnliche Verhältnisse vor. Der Nervus cochlearis giebt Fasern zum ventralen Acusticuskern ab und endet mit Aufsplitterungen im dreieckigen Acusticuskern ${ }^{2}$ ). Vom ventralen Acusticuskern ziehen Fasern in den Trapezkörper, geben Collateralen an die oberen Oliven, besouders der gegenüberliegenden und dem Trapezkern $a b$ und ziehen zur lateralen Schleife, wo sie beim lateralen Schleifenkern und hinteren Zweihügel endigen. Verbindungen mit dem Facialiskern kounte ich nicht nachweisen. Nach Zerstörung des Tuberculum acusticum und des ventralen Acusticuskerns ist ihre Zahl bedeutend grösser. Der Nervus vestibularis geht zum vordersten Antheil des dreieckigen Acusticuskernes (Bechterew'scher Kern) und splittert sich hier und im dreieckigen Acusticuskern auf, einzelne spärliche Fasern scheinen gegen den Mittellappen hin aufzusteigen. Ein Theil des Nervus vestibularis und cochlearis geht in den inmeren Antheil des Strickkörpers über, woselbst die Fasern allmälig schwinden (spinale Acusticuswurzel) und sich im dreieckigen Acusticuskern aufsplittern.

1) Probst, Zur Kenntniss des Faserverlaufes des Temporallappens, des Bulbus olfactorius, der vorderen Commissur und des Fornix. Archiv f. Anatomie und Physiologie. 1901 und Archiv f. Psychiatrie Bd. 34, Heft 2, Ueber die Folgen der Arteriosklerose des Gehirns etc.

2). Prabst, Zur Anatomie und Physiologie, der Leitungsbahnen des Gehimstammes. Archiv f. Anat. und Phys. 1902. 
Der Deiters'sche Kern hat mit dem Acusticus nicht jenen Zusammenhang, der bisher angenommen wurde. Der Deiters'sche Kern giebt die oben beschriebenen Bahnen ab und steht nur in associativer Verbindung mit dem N. acusticus.

Meine Untersuchungen über die centrale Hörbahn stehen zumeist in Einklang mit den schönen Befunden von Ml onakow, Ramon y Cajal, Thomas, Baginsky, Onufrowitsch and Kirilzeff, die Abweichungen von diesen habe ich oben ausgeführt.

Bezüglich der im Rückenmark absteigenden Kleinhirnbahn, Kleinhirn-Vorderstrangbahn, Kleinhirn-Vorderseitenstrangbahn, welche sich im unteren Halsmark zu einem Randzonenbündel längs der Fissur und der ventralen Randzone vereinigen, Collateralen in die Vorderhörner abgeben und bis ins Sacralmark verfolgbar sind, giebt dieser Versuch ganz dieselben Resultate, wie die schon beschriebenen. (Figur $12 \mathrm{KVS}$; Figur $14 \mathrm{KV}$ und KVS; Figur $15 \mathrm{KVS}$.)

Die im äusseren Theil des Strickkörpers absteigend degenerirenden Fasern endigen beim Seitenstrangkern und entsenden feine innere Bogenfasern zur Substantia reticularis, von denen einige die Olive erreichen. Die im inneren Antheil des Strickkörpers (inneres Strickkörperbündel) absteigend degenerirenden Fasern können bis zum Burdach'schen Kern verfolgt werden und geben ebenfalls zahlreiche innere Bogenfasern zur Substantia reticularis ab. Einige ziehen gegen die gegenüberliegende Olive hin. Dass innere Strickkörperbündel degenerirt beiderseits nach einseitiger Läsion.

Die Fasern vom Wurm und dem Dachkerne sind in derselben Weise und ebenfalls lateral wie in den oben geschilderten Fällen zu verfolgen. Die oben fals ausstrahlendes Kleinhirnsystem bezeichneten Fasern bilden zugleich mit Fasern vom gezahnten Kern ein fächerförmiges Fasersystem welches caudal bis zum Burdach'sehen Kern (inneres Strickkörperbündel) proximal bis zum Sehhügel (KleinhirnSehhügelbündel:anndlaccessorischesKleinhirn-Sehhügelbündel und ventrales Kleinhirn-Sehhügelbündel) reicht und eine Menge innerer Bogenfasern zur Substantia reticularis entsendet. Dieses Fasersystem bildet auf der Dorsalseite der Bindearme und zwar nach halbseitiger Läsion beiderseits, das accessorische Bindearmbündel von dem aus ebenfalls im Verlaufe stets innere Bogenfasern entsendet werden und zum Theil die scheinbar ungekreuzten Bindearmfasern, allerdings in geringer AnzahJ, geliefert werden, welche die Bindearmkreuzung nicht eingehen, und im Sehhügel an den oben bezeichneten Kernen endigen.

Eine grosse Zahl von Fasern, die von dem Dachkern, von der Rinde 
des Mittellappens und rom gezahnten Kern kommen, endigen im Deiters'schen Kern.

Vom Deiters'schen Kern ziehen Bogenfasern in beide dorsale Längsbündel, die im Abducenskern, Trochlearis- und Oculomotoriuskern endigen.

Viele feine Bogenfasern treten zum dreieckigen Acusticuskern, andere gelangen knapp neben der Raphe in das Feld der VierhügelVorderstrangbahn und ziehen hier sagittal theils proximal bis in die Brücke, theils caudal in die Vorderstränge des Rückenmarkes.

Bezüglich des Bindearmes zeigt uns auch dieser Versuch die schon oben geschilderten Ergebnisse. Der Bindearm besteht aus centrifugalen Fasern aus dem gezahnten Kern und dom Dachkern und theilt sich in einen dorsalen Ast, (dorsales Kleinhirn-Thalamusbündel) und einen ventralen Ast, der das ventrale Kleinhirn-Thalamusbündel verstärkt. Die Bündel vereinigen sich dann als gemeinsames KleinhirnThalamusbündel, durchziehen das dorsale Mark der Regio subthalamica und enden in den schon oben geschilderten Kernen, hauptsächlich med $b$, med $c$ und zwischen med $c$, lat $b$ und vent $a$.

Von der verletzten Kleinhirnseite lassen sich degenerirte Fasern in die Dachkerne, den gegenüberliegenden gezahnten Keru, ferner in den Flocculus und in die Rinde des Seitenlappens verfolgen.

Der Brückenarm zeigt in seinem inneren Antheil centrifugale Kleinhirnbahnen, die theils um die Pyramidenbahn, theils durch die Pyramidenbahn zum gegenüberliegenden Brückengrau ziehen, woselbst sie endigen. Ein Theil dieser von der Rinde des Kleinhirns kommenden Brückenarmfasern steigt in der Raphe aufwärts und endigt beim gegenüberliegendem Nucleus reticularis pontis.

Das ventrale Kleinhirn-Thalamusbündel läuft rom Deiters'sche Kern durch innere Bogenfasern über die Raphe und biegt im Winkel zwischen medialer Schleife und Raphe sagittal um, giebt beim Nucleus reticularis pontis Collateralen ab und vereinigt sich dann mit dem ventralen Ast des Bindearmes und endigt in den Kernen der inneren Marklamelle und im central-ventralen Kern des Sehhügels.

Eigentliche Commissurenfasern zwischen beiden Kleinhirnhälften konnten nicht gefunden werden.

\section{IIorizontale Durchschneidung der rechten Kleinhirnhemisphäre.}

Die Membrana obturatoria zwischen Hinterhauptsknochen und Atlas wurde bei einer Katze durchtrennt und ein Stück des Hinterhauptknochens entfernt, der Mittellappen wurde mit einem stumpfen Haken emporgehalten und ein Gräfe'sches Messerchen in den rierten Ventrikel eingeführt und die rechte 
Kleinlsirnhälfte horizontal durchtrennt. Auf der lückenlosen Serienschnittreibe zeigte sich eine grosse Blutung in der rechten Kleinhirnhemisphäre und im rechtsseitigen Theile des Oberwurmes. Die secundär aufgetretenen Degenerationen bieten die schon in den früheren Versuchen beschriebenen Verhältnisse dar.

Sofort nach der Operation fällt die Katze auf die rechte Seite und liegt ganz schlaff da. Mit den linksseitigen Extremitäten führt sie glejch Bewegungen aus, während sie die rechtsseitigen Extremizaten nichi gebraucht. Beim Versuche sich aufzusetzen, fällt sie zur rechten Seite, sie vermag sich nicht zu erheben und kriecht liegend mit den linksseitigen Extremitäten weiter. Die rechtsseitigen Extremitäten werden wohl bewegt, aber intendirte, gewollte Bewegungen können nicht gut ausgeführt werden. Die Katze liegt auf der rechten Seite über der rechten vorderen Extremität. Auf die linke vordere Extremität vermag sich die Katze ganz gut zu stützen. Die Katze schiebt sich mit den linksseitigen Beinen weiter, so dass sie im Kreise nach rechts kommt. Die Katze vermag die rechte vordere Extremitat nicht unter dem Körper hervoszubringen, sondern macht mit dieser nur reflectorische Bewegungen.

Die Lidspalten sind gleich, die Pupillen gleich und reagiren, es besteht. kein Nystagmus. Die Kniesehnenreflexe sind sehr lechaft.

Das Thier muss künstlich mit der Pipette ernährt werden und schluckt schlecht. Die Katze vermag auch die folgenden Tage nicht zu stehen and fällt passiv aufgestellt sofort nach rechts um. Sie liegt beständig auf der reohten Seite, ist zahm, ruhig, ohne Bewegungsdrang. Die Katze magert in der Folge stark ab. Die linksseitigen Extremitäten können ganz gut zu intendirten Bewegungen gebraucht werden, nicht aber die rechtsseitigen, obwohl sie reflectorisch gut bewegt werden.

In der Folgezeit magert die Katze stärlier ab, sie vermag weder zu sitzen, noch sich aufzurichten und liegt stets auf der rechten Seite. Nach zwei Wochen ging das Thier zu Grunde.

Bei einer anderen Katze, die auf ähnliche Weise operirt wurde, indem vom vierten Ventrikel ans die rechte Kleinhirnhemisphäre horizontal durohschnitten wurde, fiel der Horizontalschnitt etwas ventraler und durchschnitt die gesammte Kleinhínhemisphäre.

Gleich nach der Operation wurde der Kopf des Thiexes stark zurückgezogen (Opisthotonus) die Vorderbeine zeigten tonische Streckungen. Die tonischen Streckungen in der Nacken- und Rückenmuskulatur hielt den ersten Tag an und die Katze springt durch Streckbewegungen oft wie ein Fisch empor und beschädigt sich, so dass sie in eine eigene Hängematte gelegt werden muss. Die nächsten Tage hörten die tonischen Streckirämpfe auf, aber die Katze vermochte nicht zu sitzen. Wird die Katze passiv aufgerichtet, so wird der Kopf und der Vorderkörper zurückgezogen, als ob sie sich sträuben wollte, vorwärts zu gehen; die Katze fällt dann zur Seite und vermag sich nicht aufzurichten. Die Pupillen sind gleich und reagiren. Es besteht Nystagmus verticalis. Der Kniesehnenreflex ist sehr lebhaft gesteigert. Bei der Rückenhaut emporgehalten, gebraucht die Katze nur die linksseitigen Extre- 
mitäten und setzt die rechtsseitige vordere Extremität mit der Dorsalseite der Zehen auf.

In der Folgezeit tritt der Nystagmus nur zeitweilig auf, die Beine werden links steif weggespreizt. Das Thier liegt meist ganz ruhig da und magert zusehends $a b$.

Nach zwei Wochen vermag das Thier sich zu setzen und selbstständig etwas Nahrung zu nehmen, nachdem es bisher künstlieh mit der Pipette ernährt wurde. Nun traten die atactischen Erscheinungen, wie bei Halbseitenabtragung des Kleinhirnes auf. Wackeln des Kopfes, Zittern, erschwerte Nahrungsaufnahme, grosse Ermüdbarkeit. In der folgenden Zeit tritt taumelnder, mühevoller Gang auf, wobẹi die Katze oft zur Seite fällt. Keine gröbere Sensibilitätsstörung, keine Lähmung.

Nach sechs Wochen waren alle Erscheinungen grösstentheils wieder zurückgegangen, nur bei schwierigen Bewegungen traten noch atactische Störungen auf.

\section{Durchschneidnng des Strickkörpers.}

Bei einer Katze wurde das Corpus restiforme durch einen sagittalen Schnitt dort, wo es in's Kleinhirn einstrahlt, mit der Hakencanüle durchtrennt. Nachdem das rechte Corpus restiforme in dieser Weise durchschnitten war, wurde der Kopf des Thieres stark nach rechts gezogen durch tonische Spannung der rechtsseitigen Hals- und Rückenmuskeln und gleich daraut traten heftige Wälzbewegungen im umgekehrten Sinne des Uhrzeigers auf. Das Thier liegt dann am Rücken, macht mit der linken vorderen Extremitüt Greifbewegungen, der Kopf wird nach rechts in den Körper gleichsam hineingedreht gehalten. Ausser dem Corpus restiforme wurden durch den Schnitt auch die austretenden Wurzeln des Facialis und Trigeminus lädirt und machten sich durch Lähmung and Anästhesie im rechten Facialisgebiete geltend.

Die linksseitigen Extremitäten werden heftig bewegt, während die rechtsseitigen schlaffer sind und wenig bewegt werden.

Die heftigen Wälzbewegungen dauern in der Folgezeit an, so dass die Katze in die Hängematte gebracht werden muss. Nach zwei Wochen gingen alle Erscheinungen wieder zurück.

Eine andere Katze, die ganz ähnlich operirt wurde, bei der aber der Nervus facialis und trigeminus verschont blieben, zeigte gleich nach Durchschneidung des rechten Corpus restiforme, wobei theilweise der Deiters'sche Kern zerstört warde, so dass die Kleinhirn-Vorderstrangbabn und die Kleinhirn-Vorderseitenstrangbahn caudalwärts degenerirte, tonische Streckungen in der linken vorderen Extremität auf. Der Kopf wurde tonisch zur rechten Soite gezogen und das Thier bleibt in dieser Stellung erst ruhig liegen. Die rechtsseitigen Extremitäten werden stark spastisch gebeugt gehalten. Dann erfolgen sehr lebhafte Wälzbewegungen im umgekehrten Sinne des Uhrzeigers. Die Katze vermag die linksseitigen Extremiten zu intendirten Bewegungen zu gebrauchen, während die rechte vordere Extremität stark flectirt gehalten wird. Anfallsweise rasche Athembewegungen. 
Die heftigen Wälzbewegungen danern an. Der Kopf wird dahei tief zum Boden und nach rechts zum Körper gezogen. Wird die Katze, wenn sie beruhigt ist, berührt, so erfolgen sofort furibunde Wälzbewegungen. Am ruhigsten verhält sich noch das Thier, wenn man die Rotationsstellung übertreibt und den Kopf nach rechts zum Schwanze hindrüclit.

Die Katze muss künstlich nit der Pipette ernährt werden. Sie vermag die eingeflösste Milch zu schlucken. Am dritten Tage nach der Operation vermag sje bereits selbst za fressen und die Wälzbewegungen haben nachgelassen. Aber jedes Mal, wenn man sie berührt, erfolgen Wälabewegungen, welche durch drei Wochen, so lange das Thier lebte, andauernd noch auszulösen waren.

Das Thier vermochte sich nicht aufzusetzen und liegt gewöhnlich in der Hängematte auf der Seite. Die Pupillen sind gleich und reagiren. Beim Blick zur Seite erfolgen nystagmusartige Zuckungen. Die Sehnenreflexe sind gesteigert.

In der Folgezeit magert das Thier stark ab und wird wegen Osmiumsäurefärbung nach drei Wochen Lebzeit mittelst Chloroform getödtet.

In diesem letzterwähnten Falle waren, wie es die lückenlosen Serienschnitte (Frontalschnitte) erwiesen, ausser dem Corpus restiforme noch der Deiters'sche Kern, ein Theil des gezahnten Kerns, die laterale Acusticuswurzel and die spinale Trigeminuswurzel zerstört worden. Die Osmiumsäurefärbung brachte die Degenerationscerhältnisse klar zum Ausdruck.

Im Strickkörper giebt es, wie ich es schon anderweitig ausführte, nur wenige absteigende Degenerationen einiger spärlichei äusserer Bogenfasern, welche um das Corpus restiforme herumziehen, gegen den Seitenstrangkern zu. Sie geben innere Bogenfasern in die Substantia reticularis ab.

Caudalwärts degenerirte in diesem Falle die Kleinhirn-Vorderstrangbahn, indem die Fasern vom Deiters'schen als innere Bogenfasern gegen die Raphe hinziehen und neben dieser sagittal in die caudale Richtung umbiegen und auf diesem Wege in das Fissurenrandbündel des Rückenmarkes gelangen.

Caudalwärts degenerirte ferner die Kleinhirn-Vorderseitenstrangbahn, indem die Fasern vom Deiters'schen und gezahnten Kern in medial ventraler Richtung gegen den Facialiskern und gegen die laterale Seite der unteren Olive hinziehen und ron hier in die ventrale Randzone (Austrittszone der volderen Wurzeln) des Rückenmarkes gelangen, und hier abwärts bis ins Sacralmark verfolgbar sird mit Einstrahlungen in die Vorderhörner. Die KleinhirnVorderseitenstrangbahn reicht im obersten Halsmark nicht bis in das Fissurenrandbündel, sondern ist hier noch von den Fasern der Kleinhim-Vorderstrangbahn getrennt. Frst in tieferen Partien des Halsmarkes stossen die Fasern der Kleinhirn-Vorderstrangbahn und der Kleinhirn-Vorderseitenstrang an der Ecke zwischen Fissurenrandzone und ventraler Randzone zusammen, so dass die Kleinkirn-Vorderstrangbahn und die Kleinhirn-Vorderseitenstrangbahn einen fortgesetzten Saum in der Randzone der vorderen Fissur and in der ventralen Randzone des Rückenmarks (unteres Hals- und Brustmark) bilden. 
Zu den unteren Oliven sehe ich von der Verletzungsstelle nur sehr spärliche degenerirte Fasern ziehen.

Von der Verletzungsstelle degenerirten auch Fasern zum Acusticuskern und sensiblen Trigeminuskern.

Das Kleinhirn war erfüllt von zahlreichen feincalibrigen degenerirten Fasern, die der. Rinde der Kleinhirnhemisphäre und des Oberwurmes zustrebten. Andere stärker calibrige Fasern waren von der Verletzungsstelle über den Dachkernen auf die andere Hemisphärenseite za verfolgen, die in der Rinde endigen. Diese Fasern sind identisch mit dem Faserbuindel a Figur 1.

Proximalwärts degenerirten vom Deiters'schen Kern. Fasern zu beiden hinteren Längsbündeln, welche die laterale Partie in der hinteren Längsbündelformation einnehmen und zahlreiche Collateralen an den Abducens-, Trochlearis- und Oculomotoriuskern abgeben.

Gegen den Sehhügel zu degenerirten ausserdem der Bindearm, der nach seiner Kreuzung, im dorsalen Mark der Regio subthalamica als WleinhirnThalamusbündel bis zum Kern med $\mathrm{c}$ und den lateral davon liegenden Zellen des Kerns vent a zu verfolgen war, wo die Fasern mit Aufsplitterungen endigen. Im gegenüberliegenden Bindearm, also im linken, (die Verletzung war rechtsseitig) war in diesem Falle keine Faser degenerirt, da der rechte Dachkern und die davon abgehenden Fasern bei der Operation intact blieben.

Von der lateralen Acusticuswurzel, Tuberculum acusticumaus ist in diesem Falle der schon oben beschriebene Faserzug (centrale Hörbahn) degenerirt zu verfolgen. Die Fasern ziehen gleichsam als Fortsetzung der lateralen Acusticuswurzel medial ventral in dte Substantia reticularis der Brücke und überschreiten in der Richtung zur oberen Olive die Raphe. Bei der gegenüberliegenden (linken) oberen Olive ziehen die Fasern lateral ins Feld des Monakow'schen Bündels und ziehen von hier in die laterale Schleife, deren mediale Partie sie bilden. Dieser degenerirte Faserzug der Acusticusbahn degenerirt an die innere und untere Seite des hinteren (linken) Zweihügels, wo die Fasern mit feinen Aufsplitterungen endigen. Vielleicht werden von diesem Faserzug Collateralen an die linke obere Olive abgegeben.

Vom ventralen Acusticuskern degeneriren im starken Zuge die Fasern des Trapezkörpers, indem sie feine Fäserchen sowohl in die rechte, als hauptsächlich in die gegenüberliegende (linke) obere Olive abgeben. Das Vliess der linken oberen Olive ist erfüllt von feinsten Einstrahlungen. Während die oben beschriebene Acusticusbahn gegen die dorsale Seite der linken oberen Olive gezogen ist und von hier zur lateralen Schleife, zieht der Faserzug, der den Trapezkörper bildet an die ventrale Seite der gegenüberliegenden (linken) oberen Olive. Von hier aus zieht der Trapezfaserzug nach Abgabe der zahlreichsten Collateralen an die linke obere Olive und dem Trapezkern in die laterale Schleife, deren seitlichsten Antheil er bildet und ron da aus gegen den linken hinteren Zweihügel und endigt hier. In den Kern der lateralen Schleife werden feine Einstrablungen von diesen Fasern gesehen. 
Die Fasern der spinalen Trigeminuswurzel degeneriren absteigend und geben im Verlaufe feinste Einstrablungen in die Substantia gelatinosa ab. Die Fasein sind bis ins oberste Halsmark za verfolgen, wo sie feine Einstrahlungen in die Substantia gelatinosa der kolbigen Hinterhörner abgeben und sich so aufsplittern. Die spinale Trigeminuswurzel enthält also absteigende Fasern, die in der Substantia gelatinosa endigen. Dieselben Ergebnisse bezüglich der spinalen Trigeminuswurzel hatte der oben geschilderte Versuch auf Seite 722. Auch die Ergebnisse über die centrale Hörbahn sind in diesem versuche gleich dem auf Seite 726 geschilderten.

Nachdem ich in den bisher geschilderten Versuchen nur die centrifugalen Kleinhimbahnen näher nach Kleinhirnverstümmlungen ausführte, will ich im Folgenden auf die anatomischen und physiologischen Ergebnisse eingehen, welche die Durchschneidung der zum Kleinhirn ziehenden Bahnen zeigt. Ich will die anatomischen und physiologischen Folgen nach Zerstörung der unteren Oliven, der Hinterstrangkerne, des Brücken- und Bindearmes, und des Rückenmarkes zeigen.

\section{Durchtrennungen des Brückenarmes und des Bindearmes.}

In mehreren Fällen, Katzen, Hunden und Igeln, habe ich die Bindearmfas sern knapp vor ihrer Kreuzung im hinteren $Z$ weihügelgebiete durchschnitten. Die secundäre Degeneration der Bindearmfasern zeigte denselben Verlauf, wie wir sie nach Läsion des gezahnten Kernes constatiren konnten. Ich erwähne diese Versuche hier, um zu constatiren, dass ich im Bindearm keine Fasern nachweisen konnte, die etwa im rothen Kern oder im Sehhügel entspringen würden und durch den Bindearm zum Kleinhirn rerlaufen würden. Alle Fasern des Bindearmes entspringen in den Ganglienzellen des gezahnten Kernes und des Dachkerns und verlaufen gegen den Sehhügel hin.

Nach Durchschneidungen des Brückenarmes konnte ich die dogenerirten Brückenarmfasern in das Kleinhirn verfolgen. Diese Fasern sind feincalibrig und steigen im Brückenarm gegen das Kleinhirn aufwärts und lrommen zwischen gezahnten Kern und Kleinhirnrinde zu liegen. Sie umziehen lateral den gezahnten Kern und ziehen von hier, Fasern an die Kleinbirnrinde abgebend, gegen den Oberwurm, wo die Fasern ebenso wie im Seitenlappen in der Rinde enden.

Nach Rindenabtragungen des Oberwurmes und der Kleinhirnhemisphäre konnten wir auch absteigende Fasern im Brückeaarm constatiren, welche von den Ganglienzellen der Kleinhirnrinde ausgehen und im gegenüberliegenden Brückengrau mit Aufsplitterungen endigen. Die vom Kleinhirn absteigenden Brückenarmfasern haben ebenfalls ein dünnes Caliber und ziehen in den medialen Antheilen des Brückenarmes abwärts zum gegenüberliegenden Brückengran. Die von der Kleinhirnrinde im Brückenarm absteigenden Fasern sind bedeutend geringer an Zahl, dio Hauptmasse machen die von den Ganglienzellen des Brückengraues zur Kleinhirnrinde aufsteigend degenerirenden Fasern aus. 
Die im Brückenarm absteigenden Kleinhirnfasern gehen aber nicht nur zum gegenüberliegenden Brückengrau, das um die Pyramidenbahn angehäuft ist, sondern es steigen solche Fasern auch in der Raphe der Brücke aufwärts und endigen beim gegenüberliegenden Nucleus reticularis pontis, wohin auch das ventrale Kleinhirn-Thalamusbündel zahlreiche Collateralen mit Aufsplitterungen entsendet.

Einzelne wenige centrifugale Brückenarmfasern scheinen nach meinen Untersuchungen auch im gleichseitigen Brückengrau zu endigen.

Der Brückenarm enthält somit sowohl centrifugale als centripetale Kleinhirnfasern, die das Brückengrau mit der Rinde des Mittel- und Seitenlappens des Kleinhirns auf mannigfache Weise verbinden. In Figur 4 und Figur 13 ist der Verlauf der Brückenarmfasern deutlich zu sehen. Ausser der gegenseitigen Verbindung des Brückengraues mit der Kleinhirnrinde, obliegt dem Brückenarme zum Theil noch die Verbindung der Kleinhirnrinde mit dem gegenüberliegenden Nucleus reticularis tegmenti ${ }^{1}$ ).

\section{Zerstörung der unteren Olive.}

Bei Hunden und Katzen ${ }^{1}$ ), denen ich das Gebiet der unteren Olive zerstört hatte,konnte ich degenerirte Fasern von diesem Gebiete aus in's Kleinhirn verfolgen. Zahlreiche äussere Bogenfasern, die von hier aus degenerirt waren, zogen an die laterale Seite der spinalen. Trigeminuswurzel und kamen ventral und ventrallateral an den Strickkörpern anstossend zu liegen. Mit dem Strickkörper zogen diese degenerirten Fasern an die Aussenseite des gezahnten Kerns und weiter im Bogen in die caudalen und frontalen Theile des Oberwurmes, wo dieseFasern in derRinde endigen. Innere degenerirte Bogenfasern ziehen von der Verletzungsstelle (mediale Schleife und innerer Abschnitt der unteren Olive) zu den vordersten Antheilen des Burdach'schen Kerns. Nur wenige Fasern ziehen von der gleichseitigen Olive zum Stricklörper.

Der Hund mit Zerstörung der linken unteren Olive zeigte am ersten Tage Wälzbewegungen nach links, im Sinne des Uhrzeigers, am zweiten Tage überkugelt er sich häufig nach rechts, der Gang der Beine ist atactisch, die Vorderbeine werden überkreuzt, die Bewegungen sind ungeschickt, der Hund tritt oft mit der Dorsalseite der Zehen auf, das Stehen ist nur mit seitlich gespreizten Beinen möglich. Die Sehnenreflexe des Hundes sind sehr lebhaft. Der Hund liegt die meiste Zeit in der Ruhlage. Die Wälzbewegungen nach rechts dauern nur die ersten drei Tage an. Der Kopf wird meist nach links gehalten und die linke vordere Extremität wird abnorm hoch gehoben und am vierten Tage läuft der Hund bereits gut, doch fällt er häufig beim Stiegensteigen und überrollt sich dabei. In der Folgezeit überkreuzt er noch die Beine beim Laufen, läuft schwer die Stiege hinauf und ist dabei unsicher. Nach fünf Wochen waren alle gröberen Gehstörungen geschwunden.

Nach Rindenläsionen des Kleinhirns konnte ich eine Atrophie der gegen-

1) Probst, Zur Anatomie u. Phys. der Leitungsbahnen des Gehirnstammes. Arch. f. Anat. u. Physiol. 1902. 
ïberliegenden unteren Olive constatiren. Nach meinen Versuchen mit balbseitigen Rindenabtragungen des Kleinhirns degenerirt nur eine verschwiadend kleine Zahl von Kleinhirnfasern zur gegenüberliegenden Olive. Im Gegensatz zu den Versuchen mit Kleinhimrindenabtragungen ergeben die Versuche mit Zerstörung der unteren Olive zahlreiche Fasern, welche zum gegenüberliegen Strickkörper und von da zur Kleinhirnrinde ziehen, und zwar sind es hauptsächlich äussere Bogenfasern, welche dem Strickkörper seinen Olivenantheil zuführen.

Der oben geschilderte Versuch beweist, dass die grosse Ueberzahl des Olivenantheils des Stricklörpers seine Ursprungsganglienzellen in der Olive besitzt, während eine versehwindend kleine Anzahl von Fasern von Ganglienzellen der Kleinhirnsinde entspringen und durch den Strickkörper zur gegenüberliegenden Olive zieht.

Die Versuche zeigen auch, dass die untere Olive nur wenige Fasern zum gleichseitigen Strickkörper, dagegen eine stattliche Anzahl zum gegenüberliegenden. Strickkörper entsenden. Ausserdem beweist der Fall mit Zerstörung der unteren Olive, dass die Olive Fasern zu den Hinterstrangkernen, hauptsächlich dem gegenüberliegenden Burdach'schen Kern entsendet. Einzelne Fasern gelangen bis in die ausstrahlende Kleinhirnbahn.

Ebenso interessant wie die anatomischen Ergebnisse, waren die physiologischen, indem ich nach Zerstörung der unteren Olive viele ähnliche Erscheinungen constatiren konnte, wie sie nach Kleinhirnverstümmelungen aufzutreten pflegen. Die physiologischen Ergebnisse will ich aber zum Schluss mit den Kleinhirnläsionen zusammenfassend wiedergeben.

Im Folgenden will ich nun auf die Darstellung der rom Rückenmark in's Kleinhirn ziehenden Bahmen eingehen.

\section{Zerstörung der ventralen Randzone des obersten Halsmarkes.}

Die Gegend der ventralen Randzone der vorderen Grundbündel wurde mittelst eines eigens dazu gemachten Häkọens isolirt zerstört, nachdem ein Dornfortsatz abgetragen war, indem mit dem Häkchen seitlich rom Rückenmark eingegangen wurden und dann das Häkchen umgewendet wurde. Von der ventralen Randzone des Halsmarkes können degenerirte Fasern verfolgt werden, die aufwärts an die lateral-ventrale Seite der unteren Olive zieben, die dann von der lateralen Seite der Olive direct im lateral-dorsalen Zug zum Deitersschen Kern ziehen, wo sie mit Aufsplitterungen enden. Es ist also die ventrale Randzone auch durch Fasern mit dem Deiters'schen Kern verbunden, die im Rückenmark (wahrscheinlich in den gekreuzten Hinterhörnern) ihre Ursprungszellen haben.

Zugleich mit diesen Fasern degeneriren andere in die Substantia reticu- 
laris alba knapp neben der Raphe aufwärts. Diese Fasern wenden sich dann seitlich in die Substantia reticularis und und verschwinden hier. Sie sind bis in die proximale Brücliengegend verfolgbar und geben Collateralen seitljch ab.

Ausserdem degenerirt yon der ventraien Randzono des Haismarkes ein Bündel an die lateral-ventrale Partie der unteren Olive, das weiter proximal in den lateralsten Antheil der medialen Schleife, welcher an die mediale Seite der oberen Olive stösst, gelangt und weiter proximal stets die lateralste Partie der medialen Schleife bildet und im Kern vent a mit Aufsplitterungen endigt. Es sind das vom Rückenmark aufsteigende. Schleifenfasern (Hinterhorn), was die schönen Befunde Edinger's bestätigt.

Ausserdem sind auch spärliche Fasern aus der ventralen kandzone des Halsmarkes in den Strickkorper und das Kleinhim yerfolgbar.

Bei einem anderen Hunde, dem ich mittelst eines Häkchens die ventrale Randzone im obersten Halsmarke zerstörte, war auf den Serienschnitten die secundäre Degeneration leicht zu verfolgen. Nach abwärts degenerirte die ventrale Randzone des Vorderstranges und das Fissurenrandbündel. Es jst das jene Zone, welche von den Faseln der Kleinhirn-Vorderstrangbahn, der Kleinhirn-Vorderseitenstrangbahn, der Vierhügel-Vorderstrangbahn und den Fasern des hinteren Längsbündels eingenommen wird. Die ventrale Randzone und das Fissurenrandbündel degenerirten bis in's Sacralmark. Im IJalsmarts, im Brustmark und im Lenden- und Sacralmark werden von dieser Degenerationszone stets feine Fäserchen in die Vorderhörner entsendet, die dort endigen.

Aufsteigend degenerirten viererlei Faserzüge, die ich schon oben erwähnte. Die Hauptmasse des aufsteigenden Degenerationszuges kommt auf die laterale und dorsale Seite der unteren Olive zu liegen.

Dort, wo die Pyramidenkreuzung beginnt und die caudalen Ganglienzellen des Seitenstrangkernes auftreten, werden von der ventralen Randzone Fasern gegen den Seitenstrangkern hin abgegeben, welche auf proximaleren Schnituen als aussere vordere Bogenfasem in die Innenseite des Strickhöpers zu liegen kommen und mit den Fasern dieses zur Rinde des Wurmes ziehen, waselbst sie frei endigen. Es existirt also ein Faserzug, der die ventrale Randzone des Halsmarkes durch äussere Bogenfasern mit dem gleichseitigen Strickkörper und mit dem Wurm des Kleinbirnes verbinden.

Der zweite Faserzug, der von der ventralen Randzone des Halsmarkes. aus aufsteigend durch dje secundäre Degeneration verfolgt werden kann, bildet dje Hauptmasse und den längsten Faserzug. Dieses Bündel gelangt yon der ventralen Randzone an die Aussenseite der Pyramide und wo die untere Olive auftritt an die lateral-ventrale Seite der unteren Olive und bildet dann den seitlichsten Antheil der medialen Schleife. Während das Bündel lateral-ventral von der unteren Olive liegt, liegt es medial-ventral von der oberen Olive. In der Brücke und in dem hinteren Zweihügel liegt das Bündel ventral vom Monakow'schen Bündel, immer die seitlichste Partie der medialen Schleife innehabend. In der Trochlearisgegend bilden diese Rückenmarksfasern der medialen Schleife die lateralsten Fasern der medialen Schleife, welche in einem dorsalen Bogen aufwärts streben. Beim inneren Kniehöcker 
kommen die Fasẹn dieser Rückenmarkschleife zwischen die grossen medial gelegenen Zellen des inneren Kniehöckers zu liegen. Von hier aus ziehen die Fasern zum ventralen Sehhügelkern vent a, woselbst sie sich aufsplittern.

Ein dritter Faserzug; der von der ventralen Randzone des Halsmarkes ausgeht, der aber aus zahlreichen Fasern besteht, gelangt von der ventralen Randzone ebenfalls an die laterale Seite der unteren Olive und zieht von hier aus durch die Substantia reticularis in der kürzesten Verbindung zum Dejters'schen Kern. Zwischen unterer Olive und Innenseite des Facialiskernes steigen die Fasern dorsalwärts empor und gelangen auf Frontalschnitten, wo der Abducenskern erscheint in den Deiters'schen Kern, zwischen dessen Ganglienzellen sich die Fasern aufsplittern.

Ein vierter Faserzug, der von der ventralen Randzone des obersten Halsmarkes aufwärts degenerirt, gelangt an die dorsolaterale Seite der Pyramide und ziebt von hier aus lnapp gegen die Raphe unter dem hinteren Längsbündel in sagittaler: Richtung weiter. Dieser Faserzug besteht aus wenig zahlreichen Fasern dickeren Calibers, dis im Areal der Vierhügel-Vorderstrangbahn liegen. Diese Fasern sind neben der Raphe unter dem hinteren Längsbündel bis in die Gegend, wo der Trigeminusliorn auftritt zu verfolgen. In der Trochlearisgegend sind diese Fasern bereits vollständig geschwunden. Dieser vierte Faserzug, der von der ventralen Randzone des obersten Halsmarkes proximal bis in die Trigeminuskerngegend verfolgbar ist, giebt während seines Verlaufes seitlich Fasern in die Substantia reticularis ab, die bei den grossen zerstreut liegenden Ganglienzellen der Substantia reticularis endigen. In der Quintusgegend sind nur wenige Fasern rorhanden, die alle in der Substantia reticularis daselbst verschwinden. Zum Deiters'schen Kern werden von diesem Faserzuge ebenfalls Fasern entsendet.

Das Gowers'sche Bündel war in meinen Versuchen mit Zerstörung der ventralen Randzone nicht verletzt worden, weshalb auch eine störende Degeneration dieses nicht eintrat und die oben beschriebenen Bahnen gut isolirt verfolgt werden konnten. In jenen Fällen, wo ich die ventrale Randzone nur wenig verletzte gegen das Fissurenrandbündel zu, konnte jch keine Fasern verfolgen die ron der ventralen Randzone direct zum Innenrand des Striekkörpers ziehen.

Die Thiere, denen auf diese. Weise die vordere (ventrale) Randzone des obersten Halsmarkes zerstört war, boten keine groben Ausfallserscheinungen dar.

Die anatomischen Ergebnisse dieser Versuche sind, wie wir gesehen haben, äusserst lehrreich, indem dadurch die vier oben dargestellten Bahnen, die bisher unbekannt waren, ganz isolirt dargestellt werden konnten.

Ich habe die oben beschriebenen Faserzüge näher in der Monatsschrift für Psychiatrie und Neurologie Januar 1902 erörtert und abgebildet. 


\section{Zerstörmng der Hinterstrangkerne.}

Bei Hunden und Katzen, denen ich einseitig die Hinterstranglierne zerstörte, konnte ich degenerirte Fasern constatiren, die von der Verletzung mit den Fasern des Strickkörpers, seitlich rom gezahnten Kern gegen den Oberwurm hinzogen, wo sie in der Rinde endigten. Ausserdem konnte ich degenerirte Fasern von der Verletzungsstelle gegen den gleichseitigen Deiters'schen. Kern hinziehen sehen. Zur gegenüberliegenden unteren Olive ziehen von der Verletzung aus innere Bogenfasern.

Die Folgen der Entfernung der Hinterstrangkerne äussern sich ähnlich wie Kleinhirnläsionen in Gleichgewichtsstörungen und atactischen Symptomen. Wenn ich einem Hunde die rechte Hinterstrangkerne zerstörte, so vermochte dieser nicht mehr zu gehen, das Thier will sich erheben, fällt aber sofort schleudernd zur Seite. Er fällt bei Läsion der rechten Hinterstrangkerne zur linken Seite, oder gar nach rückwärts indem er auf den Hinterbeinen sich erhebt und sich nach rückwärts überschlägt.

Am zweiten Tage nach der Operation vermag er sich zu erheben, kann aber kaum ein bis zwei Schritte machen, sofort wirft es ihn atactisch, schlendernd zur Seite. Der Hund nimmt selbst Nahrung zu sich. Die rechte Vorderpfote wird stark tonisch gebeugt (contracturirt) gehalten, auch bei den Gehversuchen. Er setzt die rechte Vorderpfote mit der Dorsalseite der Zehen auf, gradeso wie die Thiere mit Rindenabtragungen des Kleinhirns.

Die Kniesehnenreflexe sind beiderseits äusserst lebhaft. Beim Versuche zu geben fälit der Hund schleudernd zur Seite. Mit der Nadel gestochen reagirt der Find nicht. Bei Gehversuchen kommt das rechte Vorderbein durch die tonische Beugung und Adduction mit dem linken Vorderbein über Kreuz zu stehen, dabei balancirt der Hund lange, um nicht zu fallen und schwankt hin and her.

Am vierten Tage nach der Operation sind die Pupillen, die anfangs träge reagirten, gleich und reagiren prompt. Das rechte Vorderbein scheint paretisch und wird mit der Dorsalseite der Zehen aufgesetzt wie bei Abtragung der motorischen Zone des Grosshirnes(Sensibilitäts-Muskelsinnstörungen).

Am fünften Tage nach der Operation geht der Hund schon besser; auf den Hinterbeinen ist er nicht atactisch, wohl aber mit den Vorderbeinen. Die Vorderbeine werden oft überkreuzt beim Stehen und Gehen. Gewöhnlich fällt der Hund beim Gehen klatschend auf die linke Seite.

Beim Gehen wackelt der Hund stark, tänzelt umher; am siekenten Tage geht er schon besser, schwankt aber noch stairk. Die rechte Vorderpfote wird wenig gebraucht und ist tonisch etwas gebeugt und wird mit der Dorsalseite der Zehen aufgesetzt. Der Hand überkreuzt beim Stehen und Gehen häufig die Vorderbeine. Am linken Vorderfusse gestochen, zieht der Hund rasch das Bein zurück, rechts lässt er sich ruhig stechen ohne zu reagiren. Die Pupillen sind gleich und reagiren.

Am zwölften Tage läuft der Hund bereits umher, überkreuzt aber noch immer dabei die Vorderbeine; die rechte Vorderpfote erscheint wie paretisch, 
er vermag sich nicht darauf zu siützen. Beim Gehen schwankt er, schaukelt hin und her. Der Hund bellt seit der Operation nicht, während er früher sehr viel Lärm schlug.

Am 14. Tage ist der Hund wieder munter bellt und knurrt, er läuft bedentend besser, aber die Vorderbeine überkreuzen sich noch, er fällt beim Springen leiclıt auf den Rücken.

Am 15. Tage wurde die Kleinhirnrinde electrisch gereizt. Am hinteren Ende des Oberwurmes erfolgte ein Zurückziehen der Halses, weiter vorne entstanden Schüttelbewegungen des Kopfes, Angenzwinkern. Die vordere Partie des Oberwurmes brachte keine besonderen Erscheinungen auf die electrische Reizung. Reizung der rechten Kleinhirnhemisphäre bewirkte conjugirte Augenablenkungen, leichte Adduction in der vorderen rechten Extremität. Bewegungen im Unterkiefer und im gleichseitigen Facialisgebiet konnten ebenfalls beobachtet werden. Bei der Controlllosigkeit der faradischen Reizung ist es schwer zu entscheiden, ob nicht da oder dort Stromschleifen mitwirkten.

Vom freigelegten rechten Hinterhauptslappen konnten bei starken Strömen epileptische Anfälle ausgelöst werden, was beweist, dass die Abtragung der Hinterstrangkerne einer Seite für den Ablauf der von der Grosshirnrinde ausgelösten epileptischen Anfälle belanglos ist.

Wir sehen aus diesem Versuche die grosse Aehnlichkeit der Erscheinungen bei Kleinhirnläsionen und Läsionen der Hinterstrangkerne, wenngleich die Kleinhirnläsion viele schwerere Symptome darbietet, unter denen die Thiere stark herunterkommen oder gar zu Grunde gehen. Wir sehen aus unseren Versuchen, dass Kleinhirnläsionen, Zerstörung der unteren Olive, Zerstörung der Hinterstrangkerne in mancher Beziehung ähnliche Erscheinungen darbieten, die alle atactische Störungen bedingen.

Nach meinen Untersuchungen mit Zerstörung der Hinterstrangkerne gehen also von den Hinterstrangkernen Fasern als bintere Bogenfasern zum gleichseitigen Strickkörper und ziehen mit den Fasern dieses zur Rinde des Mittellappens, woselbst sie endigen. Die Fasern ziehen seitlich vom gezabnten Kern gegen die Rinde des Oberwurmes.

Zahlreiche Fasern ziehen selbstrerständlich von den Hinterstrangkernen zur gegenüberliegenden medialen Schleife und endigen im Sehhügel hauptsächlich im Kern vent $a^{l}$ ). Mit diesen inneren Bogenfasern ziehen auch Fasern zur gegenüberliegenden unteren Olive, so dass die Oliven und Hinterstrangkerne gegenseitig miteinander verbunden sind.

Von einem Hinterstrangkern ziehen vielleicht einzelne Fasern auch zur gleichseitigen medialen Schleife.

1) Ein directes Hinterstrangkern-Grosshirnsystem (Tschermak) existirt nicht. 
Ebenso wie von den Hinterstrangkemen und den gekreuzten Oliven ziehen auch Fasern aus den Hinter- und Seitensträngen und aus der ventralen Randzone in den Strickkörper derselben Seite mittelst hinterer äusserer Bogenfasern ein und steigen mit der Kleinhirnseitenstrangbahn zur Rinde des Wurmes auf, wie es die folgenden Versuche zeigen.

\section{Partielle Durchschneidnngen des mittleren und unteren Brust- markes und des Lendenmarkes.}

Um den genauen Verlauf der vom Rückenmark kommenden und in's Kleinhirn einstrahlenden Fasern festzustellen, habe ich Halbseitendurchschneidungen in verschiedenen Höhen des Rückenmarkes durchgefübrt, sowie auch einzelıe Randpartien einer Rückenmarkshälfte isolirt zerstört.

Nach einer Durchschneidung eines vorderen Quadranten nebst den Randpartien der Seitenstränge im mittleren Brustmarke degenerirt absteigend die ganze Randzone der vorderen Fissur und die ventrale vordere Randzone und zwar stärker auf der Verletzungsseite, schwächer auf der nicht verletzten Seite. Diese absteigenden Fasern sind bis ins unterste Sacralmark zu verfolgen, indem sie stets Fasern in die Vorderhörner entsenden, wo diese sich aufsplittern. Ausserdem werden Fäserehen in die vordere Commissur entsendet. Ausser diesen beiderseits in der Fissurenrandzone und der ventralen Randzone absteigenden dicken Fasern, degeneriren viele in den Seitensträngen zerstreute Fasern abwärts, die im weiteren Verlauf in die laterale Randzone gelangen und dort bis in das Gebiet der Kleinhirnseitenstrangbahn ausgebreitet sind; viel weniger solche Fasern verlaufen in der nicht verletzten Hälfte des Rückenmarkes degenerirt abwärts. Auch diese gelreuzten Fasern entsenden Fäserchen in die Vorderbörner, wo sie sich aufsplittern. Die Einstrahlungen in die Vorderhörner der Lendenanschwellung bilden ein vielverzweigtes Netzwerk in den Vorderhörnern. Einzelne Fäserchen gelangen durch die vordere Commissur in das gegenüberliegende Vorderhorn.

Der Bur'ach'sche Strang war nicht verletzt worden, sondern nur der Goll'sche Strang, der aufwärts bis zum Goll'schen Kern degenerirt war. In den Hintersträngen konnte ich keine weitere absteigende Degeneration nachweisen.

Aufsteigend degenerirte die Kleinhirn-Seitenstrangbahn und das Gowers'sche Bündel stark auf der Verletzungsseite, schwächer auf der unversehrten Seite; ausserdem degenerirten aufwärts Fasern in der Randzone der vorderen Fissur und in der ventralen and lateralen Randzone des Rückenmarkes. Diese im Fissurenrandbündel und in der ventralen Randzone aufsteigenden Fasern, geben im weiteren aufsteigenden Verlauf stets Fäserchen ab in die Vorderhörner, bis sie im obersten Halsmark durch ihre Faserabgabe an ihre Endigungsstelle in den Vorderhörnern ganz verschwinden.

In das verlängerte Mark gelangen von den aufsteigend degenerirenden Fasern nur das Gowers'sche Bündel und die Klënhirnseitenstrangbahn. 
Die Kleinhirnseitenstrangbahn liegt im unteren Halsmarke zwischen der Pyramidenseitenstrangbahn und der austretenden hinteren Wurzel and bildet lateral am Rande einen schwächeren Saum, um die laterale Partie des Pyramidenseitenstrangbündels. Die Hauptmasse der Fasern des Gowers'schen Bündels liegen in der seitlichen Randzone dort, wo eine Linie durch die vor- dere Commissur gelegt die seitliche Randzone trifft und vorne davor. Fier sind die Fasern am dichtesten angehäuft. Von hier aus weiter nach vorue und rückwärts verjüngt sich das Bündel. Ijie hintersten (dorsalsten) Fasern des Gowers'schen Bündels stossen an die vordersten (frontalsten) Fasern der Kleinhirnseitenstrangbahn. Die Hauptmasse der Fasern der Kleinhirnseitenstrangbahn liegen zwischen Pyramidenbahn und austretender hinterer Wurzel; von hier aus verjüngt sich das Bündel in die laterale seitliche Randzone.

In der Halsansohwellung des Rückenmarkes bilden die beiden Bündel einen mehr continuirlichen Saum von der austretenden hinteren Wurzel, wo die Kleinhirnseitenstrangbahn einen grösseren Umfang hat, bis gegen die Austrittsstelle der vorderen Wurzein.

Im obersten Halsmark (Figur 9) sind die beiden Bündel wieder mehr von einander geschieden, indem die Kleinhirn-Seitenstrangbahn (KS S Fig. 9) hier einen dicken dorsalen und lateralen Randsaum um die Pyramidenseitenstrangbabn bildet und das Gowers'sohe Bündel (g Fig. 9) wieder seine charalkteristische Form angenommen hat, indem die Hauptmasse der Fasern in der Randzone liegt, welcher van einer Linio durch die vordere Commissur getroffen wird. Von dieser Stelle aus verjüngt sich das Bündel nach vorn und hintev.

In der Pyramidenkreuzung sind die beiden Bündel mehr von einander getrennt. Die Kleinhirnseitenstrangbahn bleibt hier massig an der lateralen ventralen Seite des Hinterhornes, während das Gowers'sche Bündel etwas ventraler in der seitlichen Randzone zu liegen kommt.

Dort, wo die untere Olive und der Hypoglossuskern auftritt, rommt das Gowers'sohe Bündel ventral vom Seitenstrangkern zu liegen und werden hier seine Fasern auf Frontalschnitten etwas sohief getroffen. Die Fasern des Gowers'schen Bündels werten hier ventral rom Seitenstrangkern ron den aussersten Bogontasern durchzogen. Die Kheinhin-Seitenstrangbahn hommt hier schon dorsaler gegen den Strickkörper zu liegen.

Das Gowers'sche Bündel behält diesen Platz yentral vom Seitenstrangkern im weiteren Verlaufe inne und liegt weiter proximalwärts, wo der Seitenstrangkern geschwunden ist zwischen der Kleinhirn-Vorderseitenstrangbahn und dem Monakow'schen Bündel, indem es hier ganz am Rande gelegen ist. Das Gowers'sche Bündel liegt auch im weiteren proximalen Verlaufe medialventral rom Monakow'schen Bündel.

Wakrend das Gower's'sehe Bundel an die rentrale Seite des Tacialiskerns zu liegen kommt, gelangt die Kleinhirn-Seitenstrangbaln in den Strickkörper an die Aussenseite des proximalen äusseren Burdach'schen Kerns.

Die Fasern des Gowers'schen Bündels ventral vom Facialiskern und medial vom Monakow' schen Bündel sind hier von den candalsten Fasern des 
Trapezkörpers durchzogen. Gerade senkrecht auf die Trapezkörperfasern verlaufen in den $Z$ wischenräumen, welche die Trapezkörperfasern lassen, die Fasern des Gowers'schen Bündels.

Die Fasern der Kieinhinseitenstrangbahn bilden den medialen Antheil des Strickkörpers und ziehen gegen das Kleinhirn hin. Den äusseren Antheil des Strickkörpers bilden, wie wir aus den früheren Versuchen ersehen, äussere Bogenfasern, die von den unteren Oliven herkommen.

Das Gowers'sche Bündel gelangt proximalwärts zwischen den Trapezkörperfasern an die ventrale Seite der oberen Oliven, medial-ventral vom Monakow'schen Bündel, lateral von den seitlichsten Antheilen der medialen Schleife. Dort, wo der Abducenskern auftritt, kommt das Gowers'sche Bündel ein klein wenig lateraler gegen das Monakow'sche Bündel zu liegen und ist dann lateral-ventral von der oberen Olive, zwischen dieser und der austretenden Facialiswurzel situirt.

Die Kleinhirnseitenstrangbahn gelangt als innerer Antheil des Strickkörkörpers, an die Aussenseite des Deiters'schen Kerns zu liegen (KSS Fig. 10).

Im weiteren proximalen Verlauf beschreiben sowohl das Gowers'sche Bündel, als die Kleinhirnseitenstrangbahn einen Bogen nach rorne, um dann von vorne nach rückwärts in den Oberwurm zu gelangen. Deshalb sehen wir bei den oben beschriebenen Sohnitten, wo das Gowers'sche Bündel an der Innenseite der austretenden Facialiswurzel ventral vom Monakow'schen Bündel liegt, bereits auf den caudaleren Schnitten durchs Kleinhirn degenerirte Fasern im Wurm, die sich theilweise knapp unter den Dachkernen krenzen. Auch an der.dorsalen Seite des gezahnter Kerns sehen wir degenerirte Fasern bereits auftreten. Diese Fasern kommen als Bestandtheile des Gowers'schen Bündels, wie wir sehen werden, über dem Bindearm (g Fig. 11) von vorn nach rückwärts in's Kleinhirn, während die Fasern der Kleinhirnseitenstrangbahn als innerer Antheil des Strickkörpers (KSS Fjg. 10) einen Bogen um den gezahnten Trern machen, um vor diesem (proximal) in den Pittellappen zu kommen, wo sich die Fasern in der Rinde aufsplittern (KSS Fig. 10 und 11).

Die Fasern der Kleinhirnseitenstrangbahn gehen schon viel caudaler aufwärts zum Oberwurm, während das Gowers'sche Bündel noch eine Weile proximal in sagittaler Richtung weiter läuft.

Bei der austretenden motorischen Trigeminuswurzel liegt das Gowerssche Bündel ebenfalls am Rande, lateral-ventral vom Monakow'schen Bündel (g Fig. 10), welches hier dorsaler zu liegen kommt, zwischen oberer Olive und und austretender motorischer Trigeminuswarzel. Auf dieson Schnitten durch das Kleinhirn sind die gezahnten Kerne und Dachlerne theilweise geschwunden und hier nun kreuzen sich in der Mittellinie des Wurmes die Fasern der Kleinhirnseitenstrangbahn (KSS und KSS' Fig. 10) und des Gowers'schen Bündels ( $g$ und $g^{\prime}$ Fig. 10), welches inzwischen noch seinen Bogen nach vorne (proximal) beschreibt. Die Fasern der Kleinhirnseitenstrangbahn ziehen hier bereits vor dem gezahnten Kern zum Oberwarm und endigen nach theilweiser Kreuzung über die Raphe in der Rinde des Oberwurms (a Fig. 10). 
Das Gowers'sche Bündel zieht inzwischen von der ventralen. Seite des Monakow'schen Bündels an die lateral-ventrale Seite dieses (g Fig. 10), proximaler an die laterale Seite des Monakow'schen Bündels (M Fig. 10): und zieht nun zwischen Monakow'schem Bündel and innerem Rande des Brückenarmes aufwärts (dorsalwärts) und gelangt in dieser Weise auf die laterale und dorsale Seite des Bindearmes (g Fig. 11). Die Fasern des Gowersschen Bündels liegen hier über den Dachkernfasern (accessorisches Bindearmbündel) des Bindearmes.

Während der Bindearm rom gezahnten Kerne nach innen, unten und vorwärts zieht, umschlingen die Fasern des Gowers'schen Bündels, die hier ventro-dorsal verlaufen ( $\mathrm{g}$ Fig. 11), von unten und vorne den Bindearm und gelangen dorsal und lateral und dorsomedial vom Bindearm ron rorne nach rückwärts (caudal) in das untere Mark des Wurmes (g Fig. 10), um sich hier zu lireuzen und in der Rinde des Wurmes mit Aufsplitterungen (d Fig. 10) zu endigen. Fasern des Bindearnes und die Fasern des Gowers'schen Bündels sind in einander eingehängt, wie zwei Ame, ganz ähnlich wie das innere Strickkörperbündel und der Bindearm.

Die Katze mit dieser Verletzung im Rückenmarke, welche die ventrale, laterale und dorsale Randzonenpartie des Brustmarkes verletzt hacte, schien etwas paretisch am rechten Hinterbein. Die Sensibilität, soweit sie bei einer gewissen Skepsis beim Thiere zu prüfẹ ist, war nicht grob gestört, der grösste Antheil der Hinterstränge war intact geblieben und nur die caudalsten Fasern des Goll'schen Stranges waren eben aufwärts degenerirt. Die Katze vermochte gleich nach der Operation zu gehen und bot in der Folgezeit keine gröberen Störungen dar, bis auf einen Magen-Darmkatarrh.

In weiteren Fällen habe ich die vorderen und seitlichen Grundbündel des Lendenmarkes in ihrer Randzone durchtrennt. Auch in diesen Fällen boten sich keine gröberen Lähmungserscheinungen dar.

Die Thiere vermochten gloich nach der Operation zu gehen. Die Katze setzte bei rechtsseitiger Läsion des obersten Lendenmarkes die rechte vordere Extremität umgekehrt mit der Dorsalseite der Zehen auf (Muskelsinnstörung), springt abel ganz gut vom Tisch herunter. Sie stolpert öfters mit dem rechten Vorderbein; sichere tactile Sensibilitätsstörungen sind nicht zu constatiren. Die Katze frisst gleich nach der Operation, beleckt und putzt sich. Das rechto Vorderbein wird oft umgekehrt aufgesetzt, aber auch dieses Symptom scbwindet in der Folgezeit.

Am 15. Tage nach der Operation wurden die motorischen Zonen des Grosshirnes freigelegt and versucht, $o b$ epileptische Anfälle erzielbar sind. Von der linken motorischen Zone liessen sich typische epileptische Anfälle auslösen. Von der rechten motorichen Zone (die Verletzung betraf die rechte Rückenmarkshälfte) liess sich Jein epileptischer Anfall auslösen, doch liessen sich Einzelzuckungen auslösen, sowohl von der linken wie rechten motorischen Zone.

Auch in diesem Falle degenerirten die Kleinhirnseitenstrangbahn und das Gowers'sche Bündel in der oben beschriebenen Art und Weise 
aufwärts in's Kleinhirn. Zum Unterschiede von dem früher beschriebenen Versuche degenerirten hier nur spärliche Fasern im Fissurenrandbündel und in der ventralen Randzone aufwärts und verschwanden bald.

Abwärts degenerirten eine Menge Fasern im Fissurenrandbündel und in der ventralen Randzone, welche die zahlreichsten Aestchen in die Vorderhörner entsendeten und hier mit zahlreichen Aufsplitterungen endigten. Die ganze ventrale und laterale Randzone des Sacralmarkes ist von degenerirten Fasern erfüllt, welche ein zahlreiches Fasernetzwerk in die Vorderhörner entsenden.

Aufsteigend waren ausser dem Gowers'schen Bündel und der Kleinhirnseitenstrangbahn, die stark auf der Verletzungsseite degenerirt waren und schwächer auf der unversehrten Rückenmarksseite, noch einzelne Fasern: des Goll'schen Stranges degenerirt, die bei den Goll'schen Kernen endigten. Das Gowers'sche Bündel und die Kleinhirnseitenstrangbahn haben nach meinen Untersuchungen einen theilweise gekreuzten Ursprung im Rückenmark und fübren dem Kleinhirn sensible Erregungen zu.

Bei Verletzung der ventralen Randzone im mittleren Brustmarke degenerirten bedeutend mehr Fasern abwärts, als nach Verletzung der ventralen Randzone im oberen Halsmarke. Es spricht dies dafür, dass im Rückenmark neue Fasern der ventralen Randzone zuwachsen, die wahrscheinlich von den Vorderhörnern des Rückenmarkes ausgehen.

Eine Fortsetzung der Fasern des Gowers'schen Bündels zum Sehhügel, wie es einige Autoren annehmen, kann beim Hund und bei der Katze und auch beim Menschen nach meinen Ergebnissen nicht gefunden werden.

Was nun noch die übrigen Fasersysteme betrifft, die im Rückenmarke aufsteigend degeneriren, so müssen wir in Betracht ziehen, ob von den Hintersträngen direct Fasern in's Kleinhirn einstrahlen.

Edinger beschrieb eine doppelte Verbindung des Hinterstranges mit dem Strickkörper, eine directe Verbindung durch äussere hintere Bogenfasern an der hinteren äusseren Peripherie des verlängerten Markes und eine gekreuzte Verbindung durch vordere äussere Bogenfasern, welche vom Hinterstrang gegen die Mittellinie ziehen, sich dann kreuzen und durch die Oliven-Zwischenschichte und um die Pyramiden zum Strickkörper ziehen.

Darkschewitsch und Freud geben solche äussere bintere Bogenfasern zu, die direct zum Strickkörper ziehen, die meisten Fasern entbält jedoch derselbe von den Hinterstrangkernen. Auch Obersteiner berichtet gleich Edinger über directe und gekreuzte Verbindungen des Strickkörpers mit den Hintersträngen. Die Endigung der Fasern der 
Hinterstränge im Kleinhirn soll nach Edinger zugleich mit den Fasern der Kleinhirnseitenstrangbahn im Wurm des Kleinhirnes sein.

Thomas fand hintere äussere Bogenfasern, welche nach aussen direct zum Strickkörper ziehen und sich den Fasern der Kleinhirnseitenstrangbahn zugesellen.

Hoche fand in seinen beiden Fällen Fasern der Goll'schen Stränge in der Gegend der Pyramidenkreuzung zu den Fasern der Kleinhirnseitenstrangbahn stossen als äussere hintere Bogenfasern und einige äussere vordere Bogenfasern, die nach Umkreisung der Pyramide in den Strickkörper übergehen.

Pellizzi fand nach experimentellen Rückenmarksläsionen eine Menge Fasern der Hinterstränge in die innerste Partie des Strickkörpers übergehen, die Fasern vom Keilstrang gehen direct und die vom zarten Strang gehen an der dorsalen Peripherie dahin ab.

Mott und Sherrington sowie Tooth sahen keine Fasern von den hinteren Wurzeln der Cervicalgegend zum Strickkörper ziehen und fanden, dass die Fasern, welche die Wurzeln der Lendengegend dahin lieferten, sehr wenig zahlreich sind.

Schaffer fand in einem Falle totaler Zerstörung des Rückenmarkes in der Höhe der 11. Dorsalwurzel die Degeneration der Hinterstränge in die Strickkörper übergehen.

Auf Grund meiner Untersuchungen mit Degeneration der Hinterstränge konnte ich nur eine geringe Zahl von Fasern feststellen, die als äussere hintere Bogenfasern zum Strickkörper ziehen. Eine gekreuzte Verbindung mit dem Strickkörper konnte ich nicht deutlich nachweisen. Von der ventralen Randzone des oberen Halsmarkes ziehen äussere, vordere Bogenfasern zum Strickkörper, die wahrscheinlich von den gegenüberliegenden Hinterhörnern kommen.

Nachdem ich die verschiedenen centrifugalen und centripetalen Leitungsbahnen des Kleinhirns genau erörtert und dargestellt habe, will ich auf die Erscheinungen, welche in den Kleinhirnverstümmelungen auftraten, näher eingehen.

Nach den von mir gefundenen Resultaten nach Kleinhirnabtragungen kann ich zum grossen Theile die Befunde von Luciani, Russel und Thomas bestätigen und Neues hinzufügen.

1. Nach halbseitiger Rindenabtragung des Kleinhirns mit partieller Verletzung des gezahnten Kernes und des Dachkernes erfolgten während der Auslöffelung der linken Rindenpartie lebhafte Ablenkung beider Bulbi nach rechts und wenn mit dem Löffelchen gegen den Mittellappen hin mechanisch gereizt wurde, erfolgte vorübergehend eine Blickablen- 
kung nach links. Wurde mit dem Löffelchen seitlich tiefer eingegangen, ohne Verletzung des Deiters'schen Kerns oder des Nervus trochlearis, so erfolgen Raddrebungen der Bulbi.

Unmittelbar nach der Operation des Thieres erfolgte Opisthotonus und Gehbewegungen nach rückwärts, gleich darauf machte sich eine allgemeine Schlaffheit geltend, Der Kopf des Thieres wird wiederholt krampfhaft nach rückwärts gezogen, die vorderen Extremitäten werden tonisch gestreckt, anfallsweise tritt ein wilder stürmischer Bewegungsdrang ein, verbunden mit krampfhafter Streckung der Vorderbeine, dann tritt wieder allgemeine Erschlaffung ein. Der Kopf wird tonisch zur operirten Seite gezogen und gedreht und es treten dann heftige Wälzbewegungen auf, die wenn die Operation links war, im Sinne des Uhrzeigers stattfinden, wenn die Uhr mit dem Zifferblatt capitalwärts gehalten wird; betrifft die Operation die rechte Seite, so erfolgen die Wälzbewegungen im umgekehrten Sinne. Während der Wälzbewegungen sind die Pupillen maximal weit, nahher werden sie wieder eng. Die Thiere müssen künstlich ernäh!'t werden. Am zweiten Tage wird der Kopf des Thieres noch zur verletzten Seite gezogen, die Extremitäten der verletzten Seite sind meist spastisch, schwächer und es wird beim passiven Aufrichten des Thieres die Vorderpfote der verletzten Seite mit der Dorsalfläche auf den Boden aufgestellt, wie bei Thieren mit Entfernung der motorischen Zone. Es treten kurz dauernde Muskelsinnstörungen in der gleichseitigen Extremität auf, ganz ähnlich wie nach Sehhügelzerstörung ${ }^{1}$ ) und nach Abtragung der motorischen Zone des Grosshirnes. Die Wirbelsäule ist nach der Verletzungsseite verkrümmt.

Wenn die Rindenabtragung nicht tief war und der Dachkern und gezahnte Kern nur aussen partiell lädirt ist, wird der Kopf des Thieres schon am 3. und 4. Tage ganz ordentlich gehalten; die Extremitäten der Verletzungsseite werden tonisch weggespreizt und das Thier fällt auf die Seite. Das Thier vermag sich nur für Augenblicke zu erheben; die Pupillen sind gleich und reagiren lebhaft, es sind weder Seh-noch Hörstörungen zu constatiren. Die Kniesehnenreflexe sind beiderseits lebhaft gesteigert. Am vierten Tage nimmt das Thier spontan etwas Nahrung, versucht zu gehen, schwankt aber zur Seite und fullt. Die linksseitigen Extremitäten werden weggespreizt und der Körper des Thieres fällt nach rechts. Die ersten acht Tage vermag das Thier nicht zu gehen

1) Probst, Ueber die Leitungsbahnen des Grosshirnes mit besonderer Berücksichtigung der Anatomie und Physiologie des Sehhügels. Jahrb. f.a Psych. Bd. XXI. ferner dieses Archiv Bd. 33, H. 3. 
und das Gleichgewicht za erhalten. In der zweiten Woche geht das Thier mühsam, Schritt für Schritt, taumelt und fällt zur Seite, dabei ermüdet das Thier sehr schuell. Bei gewollten Bewegungen macht sich Wackeln des Kopfes geltend und Schwanken des Körpers, so dass die spontane Nahrungsaufnahme sehr erschwert ist. Nur mit grosser Anstrengung und Mühe bringt das Thier für kurze Zeit den Kopf zur Nahrung, stets schwankt es atactisch mit dem Körper und wackelt. Das Schwanken des Körpers, das Wackeln des Kopfes, die atactischen Bewegungen der Extremitäten, das Aufsetzen der Dorsalfläche der Vorderpfote dauern lange an; in der fünften Woche verschwinden alle Erscheinungen und in der Folgezeit sind nur mehr bei schwierigeren Bewegungen atactische Erscheinungen zu sehen.

Wird bei einem auf diese Weise operirten Thiere die Kleinhirnrinde freigelegt und faradisch gereizt, so beobachten wir bei schwacher Reizung des hintersten Antheils des Oberwurmes ein heftiges Zurückfahren des Kopfes.

Wenn die Elektroden an der Grenze zwischen gesunder Hemisphäre und Mittellappen aufgesetzt werden, so erfolgt eine Drehung der Bulbi nach der gesunden Seite und unten. An verschiedenen Stellen des Oberwurmes erhält man auf faradische Reizung Benteln des Kopfes, Zwinkern der Augen, Bewegung der Obren und Kieferbewegungen..

Wenn nun nach Reizung der Kleinhirnrinde die der Terletzungsseite gegenüberliegende motorische Zone des Grosshirnes freigelegt und faradisch gereizt wird, so erfolgte in vielen Fällen kein epileptischer Anfall bei starken Strömen, doch konnten stets Bewegungen der Extremitäten und des Kopfes ausgelöst werden. Die Erregbarkeit der Rinde dieser motorischen Zone, war bald gesteigert, bald verringert.

Bei schwacher faradischer Reizung der Rinde des Seitenlappens konnte ich öfters in der gleichseitigen vorderen Extremität leichte Adductionsbewegungen sehen und auch leicht Zuckungen im gleichseitigen Facialisgebiet. Bei stärkeren Strömen wurde divergirende Stellung der Bulbi beobachtet.

Bei Abtragung der linken Kleinhirnrinde konnten bei Reizung des hinteren Theiles des Mittellappens Kieferbewegungen, bei Reizung rechts vorne seitlich an der rechten Kleinhirnhemisphäre Raddrehungen der Bulbi beobachtet werden.

Ich möchte aber auch hier betonen, dass die Erfolge der faradischen Reizung der Rinde immer sehr skeptisch betrachtet werden müssen, da wir den faradischen Reizversuchen (Stromschleifen) gegenüber nur eine geringe Controlle ausüben können.

2. Bei leichter Verletzung des hinteren Abschnittes des Mittellap- 
pens mit Verletzung eines Dachkernes, waren die Erscheinungen gering. Die Thiere sinken beim Sitzen auf der Verletzungsseite mebr ein, können aber gleich nach der Operation vom Boden auf den Tisch springen. Unmittelhar nach der Operation sind Gleichgewichtsstörungen beim Gehen zu beobachten und tonische Streckungen der vorderen Extremitäten. Der Kopf wird auch in der folgenden Zeit gesenkt gehalten. Die Sehnenreflexe sind gesteigert, die Hautreflexe vorhanden. In den Pupillenbewegungen ist keine Störung. Das Thier ermüdet leicht. Nach einigen Tagen ist keine Störung mehr zu bemerken, nur der Kopf wird gesenkt gehalten und kann schwer gehoben werden.

3. Wurde ausser einem Dachkern und der darüberliegenden Rinde des Mittellappens noch die Rinde eines Seitenlappens entfernt, machten sich während der Auslöffelung Kieferbewegungen, Bewegungen im Facialisgebiet geltend, der Kopf wurde nach rückwärts gebeugt und es erfolgten conjugirte Blickablenkungen nach der entgegengesetzten Seite. Gleich nach der Operation wird die vordere Extremität der Verletzungsseite mit der Dorsalfläche der Zehen auf den Boden gestellt. Das Thier sucht sich aufzurichten, fällt aber dabei zur Seite. Der Kopf des Thieres wird zur Seite gezogen. Die hinteren Extremitäten können gut bewegt werden, während unmittelbar nach der Operation die vorderen Extremitäten nicht zum Aufstellen verwendet werden können. Die vorderen Extremitäten werden ruhig gehalten und der ganze Körper wird durch dje Bewegungen der hinteren Extremitäten vorwärts geschoben. In der vorderen Extremität der Verletzungsseite machen sich atactische Bewegungen geltend. Das Thier vermag sich kurze Zeit nach der Operation auch auf diese Vorderpfote aufzustützen, aber diese Pfote wird mit der Dorsalfäche der Zehen aufgesetzt. Beim Gehen schwankt das Thier stark. Der Kopf wird nach rüekwärts in den Nacken gezogen, das Thier geht dann nach rückwärts. Die Bulbi stehen nicht abnorm, die Pupillen sind gleich und reagiren. Der Kopf wird wiederholt nach rückwärts gezogen, die Vorderpfote der Verletzungsseite wird stets mit der Dorsalseite der Zehen auf den Boden gesetzt.

Einige Stunden nach der Operation werden lebhafte Wälzbewegungen beobachtet, welche, wenn die Operation linksseitig war, im Sinne des Uhrzeigers vollführt werden.

Das Thier vermag nicht zu sitzen und fällt auf die Seite. Am Tage nach der Operation ist das Thier ruhig; beim passiven Aufstellen wird die Vorderpfote der Verletzungsseite mit der Dorsalseite der Zehen auf den Boden gestallt, der Kopf wird aufrecht gehalten, die Pupillen sind weit und gleich gross. Das Thier macht nur mehr geringe $W_{a ̈ l z-}$ 
bewegungen beim Untersuchen und liegt beständig auf der Seite und muss künstlich mit der Pipette ernährt werden.

Der Kopf des Thieres wird häufig nach der gesunden Seite hin verdreht. Nach einigen Tagen macht das Thier Gehversuche, fällt aber dabei taumelnd, atactisch zur Seite; die Vorderpfote der Verletzungsseite wird stets mit der Dorsalseite der Zehen aufgesetzt, ganz so wie nach Rindenabtragung der motorischen Zone. Das Thier ermüdet sehr rasch. Am dritten Tage nach der Operation vermag das Thier zu sitzen, am fünften etwas zu gehen, wobei es zur Seite fällt. Der Kopf wird häufig zur Seite gezogen. Die Pupillen sind gleich und reagiren. Die Sehnenreflexe sind gesteigert. Am sechsten Tage vermag das Thier bei grosser Vorsicht schrittweise $z u$ gehen, dabei balancirt es mühselig und schwankt und taumelt. Die vordere Extremität der Verletzungsstelle wird mit der Dorsalseite der Zehen aufgestellt. Die Bulbi stehen nicht abnorm, es besteht kein Nystagmus. Das Thier magert rasch ab.

In der zweiten Woche nimmt das Thier selbst Nahrung zu sich, schwankt stark beim Gehen, setzt noch immer die Vorderpfote der Verletzungsseite mit der Dorsalfläche der Zehen auf den Boden. In der folgenden Zeit bessern sich die atactischen Gebstörungen zusehends, doch ist die Ermüdbarkeit des Thieres gross.

Wird die unverletzte Kleinhirnrinde eines in dieser Weise operirten Thieres freigelegt und faradisch gereizt, so erfolgen conjugirte Blickablenkungen nach derselben Seite, auch Rotationsbewegungen der Bulbi und Nystagmus kann beobachtet werden. Nach faradischer Reizung der linken Hälfte des Mittellappens wurden bei stärkeren Strömen auch Bewegungen im linken Facialis und ganz leichte Bewegungen (Adduction) in der linken vorderen Extremität festgestellt. Der Kopf wurde dabei nach links und binten gezogen.

Nach Abtragung einer Kleinhirnhälfte wobei der vordere Theil des Mittellappens verschont blieb, machen sich schwere Allgemeinerscheinungen geltend. Bei Auslöffelung des rechten Seitenlappens machte sich dauernd conjugirte Ablenkung der Bulbi nach links geltend, wenn die Auslöffelung nahe dem Mittellappen geschah, nach rechts wenn die Auslöffelung lateral gemacht wurde. Ausserdem wurden conjugirte Ablenkung der Bulbi nach oben, Raddrehung der Bulbi, Zuckungen im Facialisgebiet derselben Seite, leichte Adductionsbewegungen der rechten vorderen Extremität beobachtet. Es erfolgten auch Bewegungen des Kopfes nach aufwärts und rückwärts und Augenzwinkern. Gleich nach der Operation liegt das Thier ganz schlaff da in passiver Seitenlage. Dann wird der Kopf nach der verletzten Seite gedreht gehalten, das 
Vorderbein der Verletzungsseite ist stark spastisch flectirt. In der Zunge werden oft Krämpfe beobachtet, die Zunge wird herausgestreckt und vermag erst später wieder zurückgebracht zu werden und bleibt während des tonischen Krampfes zwischen den Zahnreihen. In der vorderen Extremität der Verletzungsseite wechselt tonische Muskelspannung mit folgender Erschlaffung. Wird der Hund passiv aufgesetzt so wird die Vorderpfote der Verletzungsseite umgekehrt aufgesetzt, der Kopf und die Wirbelsäule wird nach der Verletzungsseite gedreht. Die Pupillen sind gleich und reagiren.

Später machten sich Wälzbewegungen von der gesunden zur kranken Seite geltend, d. h. bei Abtragung der rechten Kleinhirnhälfte im umgekehrten Sinne des Uhrzeigers.

Während der Wälzbewegungen sind die Pupillen maximal weit und die Bulbi werden conjugirt zur gesunden Seite abgelenkt. Die Vorderpfote der Verletzungsseite bleibt contracturirt. Zumeist wird der Kopf des Thieres lebhaft nach rückwärts gezogen und die vorderen Extremitäten gestreckt. Die Sehnenreflexe sind gesteigert. Das Thier muss künstlich mit der Pipette ernäbrt werden. Die Wälzbewegungen hören am vierten Tage auf, die abnorme Stellang des Kopfes und die Verkrümmung der Wirbelsäule lässt Ende der ersten Woche nach. Nach zwei Wochen vermag das Thier zu stehen, wobei die Beine stark weggespreizt werden, um eine grössere Unterstützungsfläche zu haben. In der dritten Woche macht das Thier die ersten Gehversuche, die mit vieler Anstrengung und Ermüdung vor sich gehen; dabei fällt es oft schleudernd atactisch zur Seite. Kaum ist es einige Schritte taumelnd gegangen, balancirt es mühsam herum uud fällt schliesslich. Der Kopf wackelt beständigt, der Körper schwankt hin und ber, besonders bei der Nahrungsaufnahme und bei gewollten Bewegungen. Beim Gehen spreizt der Hund die Beine weg, um nicht so leicht zu fallen. Alle diese Störungen besserten sich in der 5. -6 . Woche, nur das Wackeln des Kopfes und eine gewisse Schwäche und leichte Ermüdbarkeit bleibt bestehen, welche Erscheinungen die ersten zehn Wochen andauern. Störungen im Hören und Sehen konnte ich nicht constatiren. Die Muskelsinnstörnngen sind rasch vorübergehend.

4. Nach Abtragung des ganzen Mittellappens des Kleinhirns fand ich unmittelbar nach der Operation Streckbewegungen in den Vorderbeinen, während der Kopf beftig in den Nacken zurückgeworfen wird. Es besteht dabei conjugirte Blickablenkung nach unten und Nystagmus. Der Hund muss künstlich, genährt werden und schluckt schlecht. Die folgenden Tage vermag sich der Hund schon ziemlich auf den Beinen 
zu erhalten, schwankt aber dabei stark mit dem Körper und geht bäufig zwangsmässig nach rückwärts, besonders wenn er die Nahrung erfassen will. Die Kniesebnenreflexe sind sebr lebhaft. In der zweiten Woche treten die Schwankungen des Körpers und das Schütteln und Wackeln des Kopfes, die in der ersten Woche bestanden, in den Hintergrund, die Lokomotion geht besser vor sich, der Hund nimmt selbst Nahrung und vermag sich auch auf die Hinterbeine zu erheben. In der Folgezeit schwinden alle atactischen Schwankungen des Rurnpfes und des Kopfes und der Hund läuft fast wie ein nicht operirter.

5. Nach Abtragung einer ganzen Kleinhirnhälfłe liegt das Thier unmittelbar nach der Operation rubig, schlaff, völlig passiv am Boden. Nach einigen Stunden werden aber heftige Wälzbewegungen ausgeführt von der gesunden zur kranken Seite, oder mit anderen Worten, wenn die Läsion linksseitig ist, im Sinne des Uhrzeigers. Auf Schall und Berührung werden die Wälzbewegungen rapid ausgelöst. Der Hund liegt auf der operirten Seite mit nach der Verletzungsseite zurückgebeugtem Kopfe und gestreckten vorderen Extremitäten. Ausserdem besteht Nystagmus und conjugirte Augenablenkung nach der gesunden Seite. Der Hund muss künstlich mit der Pipette ernährt werden. Die Wälzbewegungen dauern die ersten Tage an. Am Ende der ersten Woche versucht sich der Hund aufzurichten, fällt aber sofort auf die operirte Seite. Kopf, Rumpf und Extremitäten zeigen ein Schwanken und Zittern. Der Hund vermag die erste Woche weder zu sitzen, noch zu stehen. Das Vorderbein der operirten Seite wird spastisch sebr steifgehalte und mit dem Dorsum aufgesetzt, die Vorderbeine sind meist gestreckt. Die Angenablenkung und der Nystagmus schwinden in den nächsten Tagen. Um das Schwanken und Schütteln des Kopfes zu verhindern, stützt sich der Hund gegen die Unterlage oder die Wand. Bei der Nahrungsaufnahme muss dem Hund der Kopf gehalten werden, damit das Schwanken dieses behoben wird. Nach 2 Wochen vermag sich der Hund zu erheben, spreizt dabei weit die Beine auseinander, făllt aber trotzdem zur Seite. Bei gewollten Bewegungen werden die Schwankungen des Körpers bedeutend stärker. - Die Kniesebuenreflexe sind scbr gesteigert. Das Vorderbein der operirten Seite wird die erste Zeit beständig mit der Dorsalseite der Zehen auf den Boden gestellt. Nach vier Wochèn geht der Hund bereits viel besser und schwankt nur mehr wenig. Nach Verlauf von 8 Wochen treten bereits die meisten Störungen wieder zurück, so dass sie nur mehr durch Kunstgriffe demonstrirt werden können. Die leichte Ermüdbarkeit des Hundes bleibt noch lange bestehen.

6. Nach vollständiger Abtragung des Kleinhirns treten gewöhnlich 
keine Wälzbewegungen ein. Der Hund liegt nach der Operation ganz schlaff und passiv da; einige Stunden später werden die Vorderbeine tonisch gestreckt und der Kopf wird nach rückwärts in den Nacken geworfen. Es besteht meist keine Ablenkung der Bulbi. Die Kniesebnenreflexe sind sehr lebhaft gesieigert. In der folgenden Zeit schwankt der Kopf beständig hin und her, so dass der Hund keine Nahrung erfassen kann. Bei gewollten Bewegungen wird das Schwanken ärger. Die erste Zeit muss das Thier künstilich genäbrt werden und magert dabei colossal ab. Der Hund stïtzt sich auf der Unterlage, um das Wackeln des Kopfes zu verhindern. Die Vorderpfoten werden mit dem Dorsum aufgesetzt. Nach zwei Wochen versucht der Hund die ersten Schritte zu thun, doch vermag er sich erst nach vier Wochen ein wenig zu stützen. Das Schwanken des Rumpfes und das Wackeln des Kopfes sind ebenso vorhanden, wie nach halbseitiger Abtragung des Kleinbirns. Meist liegt das Thier apathisch da, bellt nicht und nimmt keine Nahrung. In der fünften Woche geht der Hund etwas besser, schwankt aber noch stark. Die meisten Thiere gingen um diese Zeit $z u$ Grunde. Die Kniesehnenreflexe waren andauernd gesteigert, die Ermüdbarkeit des Thieres war eine sehr grosse. Der Intellect, das Sehen und Hören war nicht gestört.

7. Partielle Läsion der Rinde des Seitenlappens im caudalen Theile, bewirken während des Auslöffelns durch die mechanische Reizung eine conjugirte Ablenkung der Bulbi nach der operirten Seite und oben, in welcher Stellung die Bulbi längere Zeit verharrten. Ausserdem erfolgte während des Auslöffelos Zusammenzwinkern der Lider, geringe Zuckungen im Facialisgebiete der operirten Seite, in der vorderen Extremität, Bewegungen der Zunge und Schnauze und $\mathrm{Ny}$ stagmus verticalis, welch' letzterer auch nach der Operation andauert. Der Kopf dès Thieres wird während der Operation in den Nacken gezogen. Nach der Operation liegt das Thier ganz schlaff da, die Extremitäten der Verletzungsseite sind ganz schlaff, während die gegenüberliegenden weggespreizt werden. Das Thier vermag sich auf die Extremitäten der operirten Seite nicht zu stützen, passiy aufgerichtet wird die Vorderpfote der operirten Seite mit der Dorsalseite der Zehen aufgesetzt; freigelassen fällt das Thier um.

Die Bulbi werden nach der operirten Seite abgelenkt. Einige Stunden nach der Operation treten kurz dauernde Wälzbewegungen auf u. z. wenn die Läsion links war, im Sinne des Uhrzeigers. Der Kopf wird zur gesunden Seite gezogen. Beim passiven Aufsitzen wird auch in der Folgezeit die Vorderpfote der operirten Seite mit der Dorsalseite auf den Boden gesetzt, wịe bei einem Thiere nach Abtra- 
gung der motorischen Zone. Später in der zweiten Woche vermag das Thier sich zu erheben und schrittweise vorsichtig zu gehen, doch fällt es oft taumelnd zur Seite. In der Folgezeit schwinden die atactischen Symptome.

8. Nach Zerstörung des rechtsseitigen Mittel- und Seitenlappens, wobei der Dachkern zum grossen Theil erhalten blieb, der gezahnte Kern und Deiters'sche Kern aber vollständig zerstört war, machten sich während des Auslöffelns conjugirte Blickablenkungen nach der operirten Seite hin geltend, Raddrehungen der Bulbi aber kein Nystagmus. Drei Stunden nach der Operation werden lebbafteste Wälzbewegungen von der gesunden zur kranken Seite $d$. h h bei linksseitiger Operation im Sinne des Uhrzeigers vollführt. Der Tonus der Muskeln der operirten Seite ist ein erhöhter, die Kniesehnenreflexe sind beiderseits gesteigert. Am 5. Tage haben die Wälabewegungen nachgelassen und das Thier versucht sich aufurichten, dabei dreht sich Kopf und Wirbelsäule stark nach der gesunden Seite. Die Bewegungen der vorderen Extremität sind ataktisch, das Thier zittert und wackelt. Auch das Kaugeschäft ist ganz ataktisch und durch tonische Spannungen bald der Kaumuskeln bald der Zunge gestört. Das Thier muss künstlich gefüttert werden. Eine tactile Sensibilitätsstörung ist nicht mit Sicherheit zu eruiren, wohl aber kurz dauerude Muskelsinnstörungen der Verletzungsseite. Die Extremitäten der Operationsseite werden tonisch, flectirt eingezogen gehalten; es werden anfangs nur die Extremitäten der gesunden Seite gebraucht. Wenn das Thier passiv aufgestellt wird, wird die Vorderpfote der operirten Seite mit der Dorsalseite aufgestellt, wie nach Exstirpation der motorischen Grosshirnzone. Das Thier vermag nicht zu sitzen und macht stets wackelnde Bewegungen des Kopfes. Nystagmus tritt nur vorübergehend auf. Das rechteVorderbein wird eingezogen, flectirt gehalten, contracturirt und wird nicht in Gebrauch gesetzt und sieht scheinbar ganz paretisch aus, während die Extremitäten der unversehrten Seite gut gebrauchsfähig sind. Sobald das Thier gewollte Bewegungen mit dem Kopfe und Rumpfe macht, tritt Wackeln und Schwanken auf. Die Kniesehnenreflexe sind sehr lebhaft. Auch in der zweiten Woche vermag das Thier noch nicht zu sitzen, passiv aufgesetzt fällt es zur Seite, es ist der geschickte Gebranch der Extremitäten der Verletzungsseite völlig abhanden gekommen. Das Thier vermag erst in der 3. Woche vorsichtig Schritt für Schritt zu gehen und fällt dabei oft um. Das Gehen macht viele Ermüdung, das Thier geht dann in der Folge so, als ob es eine schwere Last tragen wollte. Oft fällt es auf die Verletzungsseite um, das Thier muss infolge der Ermüdung oft ansruhen. Erst in der 
5. und 6. Woche gehen solche Thiere besser und erst nach 8 Wochen verschwinden alle Störungen.

Bei so operirten Thieren habe ich die motorische Rindenzone desGrosshirns beiderseits freigelegt und konnte beiderseits sowiohl Einzelzuckungen als epileptische Anfälle auslösen. An der motorischen Zone des Grosshirnes, welche der lädirten Kleinhirnhälfte gegenüberliegt, mussten aber für dieselben Zuckungen, die von den anderen motorischen Zone ausgelöst wurden, bedeutend Istärkere Ströme verwendet werden. Epileptische Anfälle können auch ohne Kleinhirn ausgelöst werden.

9. Nach horizontaler Durchschneidung der einen Kleinhimbälfte, so dass diese ganz vom verlängerten Mark und der Brücke getrennt ist, liegt das Thier ganz schlaff da und vermag nur die Extremitäten der gesunden Seite richtig zu gebrauchen. Beim Versuche sich aufzusetzen fällt das Thier auf die verletzte Seite und vermag sich nicht zu erheben und kriecht liegend mit den Extremitäten der unversehrten Seite weiter. Die Extremitäten der verletzten Seite werden wohl bewegt, aber intendirte gewollte Bewegungungen können nur mit Schwanken ausgefübrt werden. Das Thier liegt über den Extremităten der Verletzungsseite und vermag sich nur auf die Extremitäten der unverletzten Seite zu stïtzen. Das Thier schiebt sich mit den letzterwähnten Extremitäten, wie mit einem einseitigen Ruder im Kreise herum. Die Vorderpfote der Verletzungsseite vermag nicht unter dem Körper hervorgebracht werden, und es werden anfangs nur reflectorische Bewegungen mit dieser gut ausgeführt. Die Lidspalten sind dabei gleich gross, die Pupillen sind gleich und reagiren. Es besteht nicht regelmässig ein Nystagmus. Die Kniesehnenreflexe sind gesteigert. Das Thier liegt ruhig auf der Verletzungsseite, muss künstlich gefüttert werden und magert infolge dessen stark ab. Ist der Horizontalschnitt etwas tiefer angelegt in der Höhe des Deiters'schen Kerns, so wird sofort nach dem Schnitte der Kopf des Thieres stark opisthotonisch zurückgezogen, die Vorderbeine zeigen dabei tonische Streckungen. Die opisthotonischen Streckungen des Kopfes und der Wirbelsäule dauern die ersten Tage an. Das Thier vermag weder zu sitzen noch zu stehen. Wird das Thier passiv aufgerichtet, so erfolgen Bewegungen, als ob das Thier sich sträuben wollte nach vorwärts zu gehen und weicht zurück. Die Vorderpfote der Verletzungsseite wird mit dem Dorsum aufgesetzt. Die Pupillen sind gleich und reagiren, es besteht Nystagmus verticalis. Die Kniesehnenreflexe sind gesteigert. In der Folge werden die Extremitäten der unversehrten Seite stark weggespreizt. Das Thier liegt meist ruhig da und magert infolge der künstlichen Ernährung zusehends ab. In der zweiten Woche vermag das Thier sich zu setzen, 
und selbstständig etwas Nabruvg zu nehmen. Es traten dann die atactischen Erscheinungen, Wackeln des Kopfes, Zittern und Schwanken des Körpers, grosse Ermüdbarkeit, erschwerte Nahrungsaufnahme ein. In der Folge tritt taumelnder, mühevoller Gang auf, wobei das Thier oft zur Seite fällt. Der Muskelsiun ist gestört, die tactile Sensibilität zeigt keine ganz sicheren Störungen. Nach 6 Wochen sind alle Erscheinungen wieder zurückgegangen und es treten nur mehr bei schwierigen Bewegungen ataktische Störungen auf.

10. Nach Durchschneidung eines Strickkörpers entstehen ebenfalls tonische Rückwärtsbewegungen des Kopfes mit tonischer Streckung der Vorderbeine. Gleich darauf treten heftige Wälzbewegungen ein, die, wenn die Verletzung den linken Strickkörper betraf, im Sinne des Uhrzeigers vor sich gingen. Das Thier liegt dann am Rücken, der Kopf wird in den Rumpt an der Verletzungsseite hineingebohrt. Die Extremitäten der Verletzungsseite sind baid schlaff, bald spastisch und werden wenig bewegt. Die Wälzbewegungen dauern die ersten zwei Wochen an, in manchen Fällen büren sie in einigen Tagen auf. Die Sehnenreflexe sind sehr lebhaft. Das Thier muss künstlich ernährt werden nnd magert sichtlich ab.

11. Bezüglich der Halbseitendurchschneidung im verlängerten Mark und in der Brücken- und Vierhügelgegend verweise ich auf meine früheren Arbeiten, in welchen ich die abnormen Stellungen und Haltungen beschrieb.1)

12. In mancher Beziehung ähnlich wie nach Kleinhirnläsionen sind die Erscheinungen nach Zerstörung der unteren Olive. Der Hund bietet darnach leichte Wälzbewegungen dar, welche die ersten drei Tage andauern. Das Gehen ist erst nur schwer möglich, der Hund überkugelt sich oft, geht nach der Quere, ganz atactisch, mit gespreizten Beinen um seine Unterstützungsfläche zu vergrössern. Die Vorderbeine werden beim gehen überkreuzt, die Bewegungen sind ungesebickt ataktisch, er taumelt die ersten Tage und tritt mit der Dorsalseite der Zehen auf. Das Stehen ist nur mit gespreizten Beinen möglich. Die Sehnenreflexe sind dabei sebr lebhaft. Die meiste Zeit liegt der Hund ruhig auf seinem Lager, der Kopf wird meist nach der Verletzungsseite gezogen, das Vorderbein der Verletzungsseite wird abnorm hoch gehoben. Am 4. Tage läuft der Hund bereits gut, nur überrollt er sich leicht. In den folgenden Tagen überkreuzt er noch die Vorderbeine und läuft nur schwer über die Stiege. Nach 5 Wochen gehen alle Störungen

1) Dieses Archiv Bd. 33 und Jahrbücher f. Psych. Bd. 20 und Archiv f. Anat. 1902 und Jahrb. f. Psych. Bd. 21. 
wieder zurück. Bei Zerstörung der unteren Olive sind allerdings auch die hier zerstörten Kleinhirnbahnen zu berücksichtigen, ebenso wie die verletzte mediale Schleife.

13. Sehr ähnlich wie die Störungen, welche nach Kleinhirnläsionen und welche nach Zerstörung der unteren Olive eintreten, sind die Erscheinungen, welche nach Zerstörung der Hinterstrangkerne auftreten. Es treten hauptsächlich ataktische Symptome und Gleichgewichtsstörungen auf. Nach Zerstörung der Hinterstrangkerne vermag der Hund nicht mehr zu gehen, er will sich erheben, fällt aber sofort schleudernd zur Seite, oder indem er sich auf den Hinterbeinen etwas erhebt balancirt er nach rückwärts. Am zweiten Tage versucht das Thier sich zu erheben, es fällt aber sofort, ataktisch schleudernd zur Seite. Der Hund nimmt selbst Nahrung zu sich. Die Vorderpfote der Verletzungsseite wird stark contracturirt gehalten, auch bei den Gehversuchen und wird mit der Dorsalseite der Zehen auf den Boden aufgesetzt, ganz so wie Thiere mit Abtragung der motorischen Zone des Grosshirnes, oder nach Zerstörung des Schleifenkerns des Sehhügels oder nach Kleinhirn-Läsionen oder nach Zerstörung der unteren Olive. Die Kniesehnenreflexe sind beiderseits sehr lebhaft. Beim Versuche durch das Zimmer zu gehen fällt der Hund schlendernd zur Seite. Nit der Nadel gestochen reagirt der Hund die ersten Tage nicht. Bei Gehversuchen kommt das rechte Vorderbein durch die tonische Beugung und Adduction mit dem linken Vorderbein über Kreuz zu stehen, dabei balancirt der Hund hin und her und fällt gelegentlich schleudernd zur Seite. Am 5. Tage geht der Hund schon besser. die Pupillen sind gleich und reagiren; die Hinterbeine gehen ziemlich gut, dagegen sind die Vorderbeine ataktisch und überkrenzen sich; dabei wackelt der Hund stark und schwankt taumelnd herum. Die Vorderpfote der Verletzungsseite ist beständig flectirt, contracturirt und wird mit der Dorsalseite der Zehen auf den Boden gestellt. In der zweiten Woche läuft der Hund bereits umher, doch schwankt und schaukelt er stark beim Gehen, der Hund hat seine Beine nicht in der Gewalt. Seit der Operation bellt der Hund nicht, während er früher viel Lärm schlug. In der dritten Woche bessern sich die Gehstörungen, doch sind diese erst nach 6-8 Wochen völlig geschwunden. Lange Zeit noch bis zur 5. Woche wird die Vorderpfote der Verletzungsseite mit der Dorsalfäche der Zehen auf den Boden aufgesetzt.

Wird̀ bei einem Hunde mit Zerstörung der Hinterstrangkerne einige Wochen nach der Operation die Kleinhirnrinde freigelegt und faradisch gereizt, so finden wir bei Reizung des' hinteren Endes des Mittellappens ein Zurückziehen des Halses und Kopfes, weiter vorne Schüttelbewe- 
gungen des Kopfes, Zwinkern der Lider. Reizung der vorderen Partie des Mittellappens bringt keine besonderen Erscheinungen hervor. Reizung der rechten Kleinhirnhälfte bewirkt conjugirte Augenablenkung nach rechts und leichte Adduction der gleichnamigen vorderen Extremität. Ausserdem können Bewegungen im Unterkiefer und im gleichseitigen Facialisgebiete beobachtet werden, wenn die Reizung nahe dem Mittellappen geschieht. Von der Grosshirnrinde können bei Zerstörung der Hinterstrangkerne noch epileptische Anfälle ausgelöst werden. Der Ausfall der Hinterstrangkerne biudert ebensowenig, wie der Ausfall des Kleinhirns die Auslösung epileptischer Anfälle von der Grosshirnrinde. $\left.{ }^{1}\right)$

Es liegt mir bei meinen Versuchen hauptsäshlich daran, genau die Erscheinungen, welche die betreffende Kleinhirnläsion erzeugt, festgestellt zu haben und diese Thatsachen zu sammelu, ohne mich in Hypothesen weiter einzulassen.

Wir haben gesehen, dass die Kleinhirnläsionen mit schweren Allgemeinerscheinungen einhergehen, die für die Lokomotion des Thieres viel eingreifendere Störungen herbeiführt als etwa die Abtragung der motorischen Rindenzone des Grosshirns. Die Thiere mit Kleinhirnverstümmelungen müssen die erste Zeit mühsam mit der Pipette gefüttert werden und später ist die spontane Nahrungsaufnabme eine gestörte und geringe, so dass die Thiere zusehends abmagern und schwer am Leben zu erhalten sind. Die manchmal beobacbteten trophischen Störungen sind vielleicht alle auf die geringe Nahrungsaufnahme zu beziehen.

Der Einfluss des Kleinhirns auf die Extremitäten ist wie wir gesehen baben ein gleichseitiger. Der Einfluss einer Kleinhimhälfte auf die gegenüberliegenden Extremitäten ist nur ein geringer. Diese gefundene Thatsache stimmf sehr gut auch mit den anatomischen Thatsachen. Wir haben nämlich gefunden, dass die Kleinhirn-Vorderstrangbahn und Kleinhirn-Vorderseitenstrangbahn von einer Kleinhirnhälfte resp. Deiters'schen Kern zur gleichnamigen Rückenmarkshälfte gehen und nur ein kleiner Theil von Fasern auch in die gegenüberliegende Rückenmarkshälfte gelangt. Wir sehen unmittelbar nach Abtragung einer Kleinhirnhemisphäre die gleichseitigen Extremitäten unbehülflich geworden, Muskelschlaff heit wechselt mit tonischer Muskelspannung, Contractur in Flexions und Adductionsstellung und eine gewisse Muskelschwäche ein-

1) Probst, Ueber den Hirnmechanismus der Motilität, über Rindenabtragungen, Sohweifkernverletzungen, Sehhügelversetzungen eto. Jahrbücher für Psychiatrie. Bd. XX. 1901. 
treten und später ataktisches, ungeordnetes Zusammenspiel der Muskeln der Verletzungsseite und Muskelsinnstörungen. Die Muskeln der Extremitäten der Verletzungsseite sind zwar nicht gelähmt, eine Katze mit halbseitiger Abtragung des Kleinhirns konnte in der zweiten Woche nach der Operation, trotz des ataktischen, taumelnden Ganges, bis auf die höchste Spitze eines Baumes entfliehen, doch ist die Muskelermüdbarkeit eine rasche bei solchen Thieren, so dass sie rasch erlahmen so fiel die auf den Baum gekletterte Katze wieder herab, da sie nach kurzer Zeit nicht mehr die Kraft hatte sich festzuhalten.

Neben der leichten Ermüdbarkeit der Muskeln ist namentlich in der 2.-4. Woche nach der halbseitigen Kleinhiruläsion das ungeordnete, atactische Zusammenspielen der Muskeln der Verletzungsseite auffallend. Das Thier erkennt seinen Mangel und sucht mühsam diese Ataxie mit Hülfe der gesunden Extremitäten richtig zu stellen, das Thier geht sehr vorsichtig Schritt für Schritt und lernt auch im Laufe der Zeit nach 8--10 Wochen wieder ganz ordentlich zu gehen und zu laufen. Dadureh, dass die Muskeln der Verletzungsseite nicht mehr in der richtigen Gewalt des Thieres sich befinden, taumelt das Thier während dieser Zeit stark beim Gehen, ja es vermag sich in der ersten Woche nach der Operation kaum zu erheben. In der Folgezeit werden aber alle Bewegungen wieder erlernt. Nur nach vollständer Abtragung des Kleinhirns bleibt eine gewisse Schwäche und Ataxie dauernd bestehen. Die Sehnenreflexe sind namentlich in der ersten Zeit lebhaft gesteigert.

Die Nahrungsaufnahme nach gröberen Kleinhirnläsionen ist durchaus in der ersten Zeit eine erschwerte, die Thiere müssen mit der Pipette genährt werden. Dabei schlackt das Thier schlecht. Oefters werden auch tonische Krämpfe in den Kaumuskeln und in der Zunge beobachtet, die mit folgender Erschlaffung abwechseln. In der späteren Zeit, der 2.-4. Woche, ist die spontane Nahrungsaufnahme durch das Wackeln des Kopfes und das Schwanken des Körpers, das bei allen Bewegungen, namentlich beabsichtigten Bewegungen auftritt, sehr erscbwert.

Die unmittelbar und mittelbar der Operation folgenden Erscheinungen sind hauptsächlich Ausfallserscheinungen; an diese schliessen sich dann mittelbar die Erscheinungen der Compensation an.

Von den unmittelbar der Operation. folgenden Störungen sind hauptsächlich das opithotonische Zurückbeugen des Kopfes, das Verziehen desselben nach der Seite, die tonischen Streckungen der Vorderbeine, die Verkrümmung der Wirbelsäule und die Wälzbewegungen 
hervorzuheben. Charakteristisch ist das Zurückbeugen des Kopfes mit Rückwärtsbewegung.

Die Wälzbewegungen dauern nur die ersten Tage an, bei reinen Durchschneidungen des Strickkörper: mit Verletzung des Deiters'schen Kernes dauern diese meist länger, zwei Wochen, an. Wälzbewegungen kommen aber auch durch andere Hirnverletzungen zustande, wie ich das in früheren Arbeiten ausführte. Namentlich beobachtete ich Wälzbewegungen, wenn der vordere Kern eines Sehhügels isolirt zerstört war. Die Wälzbewegungen an und für sich sind also nicht charakteristisch für die Kleinhirnläsion. Ebenșo beobachtete ich auch Wälzbewegungen, bei Hunden, denen die untere Olive einseitig zerstört worden war und Hunden, denen ein Nervus acusticus durchschnitten war, doch sind diese Wälzbewegungen nicht furibund wie nach Kleinhiruläsionen.

Das Verziehen des Kopfes zur Seite beobachtete ich stets nach Halbseitendurchschneidungen des verlängerten Markes, der Brücke und der binteren Zweihügelgegend wobei der Kopf des Thieres zur gesunden Seite abgelenkt wird. Auch bei Läsionen der caudalen Thalamuskerne wird der Kopf zur Seite abgelenkt und ist mit Drehung des Kopfes rerbunden.

Auch Nystagmus ist für die Kleinhirnläsion nicht allein charakteristisch, ich konnte Nystagmus auch nach Halbseitendurchschneidungen der Brücke und hinteren Zweihügelgegend, sowie auch nach isolirtes Sehbügelverletzungen beobachten ${ }^{1}$ ). Es sind dies aber lauter Organe, in die Kleinhirnfasem einstrahlen und bei deren Zerstörung auch der Kleinhirneinfluss unterbrochen wird.

Auch nach Halbseitendurchschneidung durch die hinteren Zweihügel werden tonische Streckungen der Vorderbeine gesehen, Ablenkung des Kopfes zur gesunden Seite und Verkrümmung der Wirbelsäale.

Wenn wir dann noch auf die ataktischen Störungen des Hundes mit Halbseitenabtragung des Kleinhirns eingehen, so muss ich bemerken, dass diese auch bei Hunden mit Zerstörung der unteren Olive auftreten, und auch bei Hunden mit zerstörten Hinterstrangkernen einer Seite. Es sind also auch die ataktisehen Symptome, die in der 2. 1. 3. Woche nach Halbseitenabtragung des Kleinhirns auftreten, nicht nur nach Läsion des Kleinhirns, sondern auch nach Zerstörung der unteren Olive, und auch nach Zerstörung der Hinterstrangkerne zu beobachten; auch bei diesen Zerstörungen vermag der Hund eine Zeit hindurch nur

1) Probst, Physiologische, anatomische u. pathol.-anat. Untersuchungen d. Sehhügels. Arch. f. Psych. Bd. XXXIII. 1900, Zeitschr. f. Nervenheilkunde Bd. XV. u. XVII. u. Monatsschr. f. Psych. 1900 und Jahrb. f. Psych. Bd. 21. 
müheselig, unter beständigem Taumeln, wobei er oft zur Seite fällt, zu gehen. Wenn wir dann noch anf die Versuche von Ewald und Goltz hinweisen, so treten auch nach Labyrinthabtragungen Gleichgewichtsstörungen ein, ähnlich wie bei Kleinhirnläsionen. Es müssen also die Erscheinungen, welche die Läsion anderer Hirntheile darbieten genau mit den Erscheinungen nach Kleinhirnläsion verglichen werden, weil sonst falsche theoretische Schlüsse über die Function des Kleinhirnes unterlaufen. Die Hauptsache der experimentellen Forschung ist, die Erscheinungen gleicher Kleinhirnläsionen genau festzusetzen, bei genauer anatomischer Durchforschung der daran sich schliessenden secundüren Degenerationen und sie mit den Erscheinungen anderer ebenso studirter Hirntheile zu vergleichen. In dieser Weise finden wir dann Erscheinungen, die wohl nach Zerstörung dieses auftreten, aber auch nach Zerstörung anderer Hirntheile (untere Olive, Hinterstrangkerne, Labyrinth, Brücke, hinterer Zweihügel, Sehhügel) zu beobachten sind.

Nach Halbseitenabtragung des Kleinhirns ist das Vorderbein der Verletzungsseite contracturirt und wird bei den ersten Gehversuchen mit der Dorsalseite der Zehen auf dem Boden gesetzt, ganz ähnlich wie wir sie nach Abtragung der motorischen Zone des Grosshirns oder nach Durchschneidung der inneren Kapsel oder des Hirnstammes finden und wie ich es auch nach Zerstörung der ventralen Sehhügelkerne sah. Die bestehende Contractur des gleichseitigen Vorderbeines mag wohl dazu beitragen, dass das Thier mit dem Dorsum auftritt, aller Wahrscheinlichkeit nach handelt es sich hier aber auch um Huskelsinnstörungen.

Was nun die electrischen Reizversuche der Kleinhirnrinde betrifft, so stehen wir dieser nur mit wenigen Controllmitteln gegenüber und müssea dieselben skeptisch betrachtet werden. Im Verein mit den Lüsionserscheinungen unserer Versuche und im Verein mit den mechanischen Reizversuchen, die ich ausführte, haben sie aber einigen Werth 1).

Reizung des hinteren Theiles des Mittellappens bewirkte ein rasches Zurückfahren des Kopfes und Halses, während die Reizung des vorderen Theiles des Oberwurmes wenig Erscheinungen machte. In der Mitte des Oberwurmes, mehr nach hinten, bewirkte die faradische Reizung lebhaftes Zwinkern der Augenlider, Schüttelbewegungen des Kopfes, Nystagmus und conjugirte Augenablenkungen.

Reizung eines Seitenlappens nahe dem Mittellappen bewirkte ein Zurückziehen des Kopfes nach hinten und zur Reizungsseite mit ent-

1) Probst, Zur Kenntniss d. Pyramidenbahn u. Reizversuche d. Kleinhirnrinde. Monatsschr. f. Psych, 1900. Bd. VI. 
sprechenden conjugirten Augenablenkungen. Es konnten auch leichte Zuckungen im Facialisgebiete und Kaubewegungen beobachtet werden und leichte Adductionsbewegungen der gleichnamigen Vorderpfote. In der lateralen Partie des Seitenlappens wurden Raddrehungen des Bulbus constatirt.

Nach halbseitiger Abtragung einer Kleinhimhälfte kömnen von beiden motorischen Zonen des Grosshirnes noch Einzelzuckungen sowie epileptische Anfälle erzielt werden, doch sind in einem solchen Falle an der motorischen Zone, welche der abgetragenen Kleinhirnhälfte gegenüberliegt, für dieselben Zuckungen bald schwächere, bald stärkere Ströme nöthig. Epileptische Anfälle können auch ohne Kleinhirn von der motorischen Zone des Grosshirns ausgelöst werden ${ }^{1}$ ).

Nach kleineren halbseitigen Läsionen des Kleinhirns fand ich die Erregbarkeit der gegenüberliegenden motorischen Zone des Grosshirns bald mehr bald minder erregbar. Die Zuckungen, die durch Reizung der Kleinhirnrinde ausgelöst werden, sind viel prompter und rascher und clonischer als die von der motorischen Zone des Grosshirns ausgelösten Zuckungen, die mehr einen verlangsamten, tonischen Charakter haben.

Sowohl nach den Reizversuchen der Kleinhirnrinde ${ }^{1}$ ), als nach dem anatomischen Verlaufe der Kleinhirnfasern durch das hintere Längsbündel zu den Augenmuskelnervenkernen ist zu schliessen, dass die Function der Kleinhirnrinde sicher auch mit der conjugirten Blickrichtung zusammenhängt und diese regulirt. Es arbeitet diesbezüglich das Kleinhirn zugleich mit den Rinden-Zweihügelfasem der Sehsphäre, welche letztere wieder durch den occipitalen Hirnschenkelfussantheil und das Brückengrau mit der Kleinhirnrinde verbunden ist.

Das Kleinhirn steht dem geordneten Spiels der willkürlichen Muskeln als Regulator vor; fällt nach Halbseitenabtragung der Einfluss einer Kleinhirnhälfte weg, so folgt nach den unmittelbaren Erscheinungen das wichtigste Kleinhirnsymptom die cerebellare Ataxie. Es tritt eine ungeordnete Function der Muskeln bei allen willkürlichen Bewegungen auf, weshalb das Thier die taumelnden Bewegungen beim Gehen macht and das Wackeln des Kopfes und das Schwanken des Körpers eintritt, welche Störungen durch die Function des Grosshirnes $n$ unterdrücken versucht werden. Das Thier muss die exacten Bewegungen erst wieder erlernen. Selbst nach Entfernung des ganzen Klein-

1) Probst, Ueber den Hirnmechanismus der Motilität. Jahrbücher für Psychiatrie. Bd. XX. 1901. 
hirnes werden die atactischen Erscheinungen im Laufe der Zeit bedeutend gebessert.

Wenn wir die Störungen betrachten, welche die Zerstörung der unteren Olive und der Hinterstrangkerne eines Acusticus oder des Labyrinthes und die sagittale Durchschneidung eines Brückenarmes erzeugen, so findẹn wir, dass sie ganz ähnliche Gleichgewichtsstörungen (taumelnder atactischer Gang etc.) erzeugen, wie Halbseitenlasionen des Kleinhirns. Wir wissen aber auf Grund unserer anatomischen Untersuchungen, dass sowohl die untere Olive, als die Hinterstrangkerne als das Labyrinth in mannigfachen im ersten Theile meiner Arbeit geschilderten Verbindungen mit dem Kleinhirn stehen. Auffallend ist es, dass sowohl die untere Olive, als die Hinterstrangkerne, eine grosse Zahl von Fasem dem Kleinhirne zuführel und dagegen nur wenig Kleinhirnfasern erhalten.

Bei Halbseitenabtragung des Kleinhirns werden auch die von der unteren Olive, dem Nervus acusticus und den Hinterstrangkernen zum Kleinhirn aufsteigenden Fasersysteme abgetragen, woraus die ähnlichen Erscheinungen resultiren.

Es scheinen also die taumeinden atactischen Bewegungen beim Gehen zu einem grossen Theile auf dem Ausfall sensibler Fasersysteme zu beruhen, durch welche normaliter beständig sensible Eindrücke dem Kleinhirn zugeführt werden, weshalb auch die zweckentsprechenden Impulse vom Kleinhirn zur Peripherie nicht entsendet werden können. Bei Durchschneidung des Gowers'schen Bündel, der sensiblen Kleinhirnseitenstrangbahn und der Hinterstränge erfolgen aber nicht auffallende atactische Symptome.

Die untere Olive, die Hinterstrangkerne und die Ursprungszellen des Nervus acusticus sind Zellenlager, welche Neurone zum Kleinhirn senden, und welche Neurone durch Zerstörung, sei es nun, dass ihre Ursprungszellen in der unteren Olive, im Gehörorgan oder in den Hinterstrangkernen zerstört werden, oder ihr Verlauf im Kleinhirn durch Halbseitenabtragung des Kleinhirns verletzt wird, zum Theil die unmittelbaren Erscheinungen und die atactischen Gleichgewichtsstörungen bedingen. Mit Verletzung dieser Theile sind offenbar starke Schwindelgefühle verbunden, die zu den Wälzbewegungen beitragen.

Andererseits steht das Kleinhirn zugleich mit dem Grosshirn den Blickrichtungen vor, die den jeweiligen Körperstellungen angemessen sein müssen. In dieser Weise functionirt dann, Acusticus, untere Olive und Hinterstrangkerne zusammen mit den Augenmuskelnervenkernen. Mittelbar durch die centrale Hörbahn functionirt das Kleinbirn zusammen mit den oberen Oliven, dem hinteren $Z$ weihügel und durch Neu- 
rone weiterer Ordnnng mit dem inneren Kniehöcker und dem Temporallappen. Durch den Bindearm functionirt das Kleinhirn zusammen mit der manuigfaltigen Thätigkeit des Sehhügels, wo Kleinhirnreize zur Grosshirnrinde übergeben werden können. Durch die Verbindung mit dem rothen Kern können auf dem Wege des Monakow'schen Bündels vom Kleinbirn kommende Reize peripherwärts vermittelt werden. Durch den Brückenarm steht das Kleinhirn in directer Verbindung mit dem gegenüberliegenden Brückengrau, woselbst sich auch Fasern aus dem Stirn-, Temporal-, Parietal- und Occipitalhirn aufsplittern; dadurch tritt die Grosshirnrinde in Verbindung zum Kleinhirn. Nach meinen Untersuchungen kommt vom Parietallappen und Occipitallappen zugleich mit der bekannten Bahn aus dem Temporallappen ein Bündel in den seitlichen Antheil des Hirnschenkelfusses ${ }^{1}$, welches sich ebenfalls im Brückengrau aufsplittert. Die Reize einer Kleinhimhälfte begegnen sich also im gegenüberliegenden Brückengrau mit Reizen aus der gegenüberliegenden Grosshirnhemisphäre, die vom Stirnhirn, Parietalhirn, Occipitalhirn und Temporalhirn kommen. In dieser Weise kann also das Kleinhirn mit der gegenüberliegenden Grosshirnhemisphäre gemeinsam arbeiten, sowie es vermittelst des Bindearmes gemeinsam mit dem gegenüberliegenden Sehhügel und der gegenüberliegenden Grosshirnhemisphäre arbeitet. Durch die Kleinhirn-Vorderstrangbahn werden Kleinhirnreize durch den Deiters'schen Kern hauptsächlich auf die gleichseitigen, zu einem geringen Theil auch auf die gegenüberliegenden Vorderhörner übergeben; durch die Kleinhirn-Vorderseitenstrangbabn werden Kleinhirnreize den gleichseitigen Vorderhornsäulen übergeben.

Im rothen Kern, sowie im Seitenstrangkem können durch daselbst einstrahlende Kleinhirnfasern Contacte mit dem Ml onakow'schen Bündel geschehen, welches ebenfalls Collateralen im Seitenstrangkern abgiebt. Jadurch, dass der Bindearm im gegenüberliegenden Sehhügel endigt und die centrifugalen Brückenarmfasern im gegenüberliegenden Brückengran, arbeitet eine Kleinhirnhälfte mit der gegenüberliegenden Grosshirnhemisphäre; das Kleinhirn entsendet durch die absteigenden Kleinbirnbahnen seine Reize zur g.eichen Rückenmarkshälfte und auf eben diese Rückenmarkshälfte wirkt wieder die gegenüberliegende Grossbirnhemisphäre, mit welcher diese Kleinhirnhemisphäre gemeinsam arbeitet; dadurch ist auch in Folge der Verbindung mit dem gegenüberliegenden Sehhügel und durch dessen Vermittlung mit der gegenuiberliegenden Grosshirnrinde, der Einfluss einer Kleinhirnhemisphäre ein hauptsächlich directer,

1) Archiv für Psych. Bd. 35. H. 1 und Archiv f. Anat. 1901 und Jahrb. f. Psych. 1902. 
gleichseitiger. Es gehen also hier sowohl die anatomischen wie die physiologischen Ergebnisse Hand in Hand.

Vermittelst der inneren Bogenfasern, welche yom sogenannten accessorischen Bindearmbündel, inneren Strickkörperbündel und vom D ei ters'schen Kern zur Substantia reticularis abgegeben werden, könmen Kleinhirnreize auf die Vierhügel-Vorderstrangbahn und die Brückenseitenstrangbahn einwirken. Die Vierhügel-Vorderstrangbahn erhält nach meinen Untersuchungen einen Zuschuss von Faseru von den grossen zerstreuten Ganglienzellen in der Substantia reticularis der Brücke, wo auch Bogenfasern vom Kleinhirn enden. Ebenso geht die Brückenseitenstrangbahn von daselbst lateraler liegenden Ganglienzellen aus, wo ebenfalls Kleinhirnfasern endigen. Durch diese zahlreichen Verbindungen sind die mannigfaltigsten Einwirkungen des Kleinhirns möglich.

Ich muss nach meinen Ergebnissen das Kleinhirn als einen Regulirapparat für die Muskelactionen anseben, die für die Körperhaltung und für die Locomotion, für willkürliche, automatische und reflectorische Bewegungen in Betracht kommen. Von beiden Gehirnstammhälften werden die Muskeln jeder Körperhälfte stets beim Sitzen, beim Stehen und bei Locomotion, bei willkürlichen, reflectorischen und automatischen Bewegungen in einen gewissen der jeweiligen Haltung oder Bewegung des Körpers entsprechenden Spannungszustand versetzt, wobei für das Kleinhirn unter anderem jene Muskelgruppen in Betracht kommen, die im Sinne Schiff's, die Fixation der verschiedenen Gelenke jeweilig besorgen, so dass die von der Grosshirnrinde intendirte Bewegung präcise und exact vor sich gehen kann. Dieser Touns, der von jeder Kleinbirnhälfte ausgeht, entsteht ganz automatisch ohne Zuthun des Willens. Durch diese beständige automatische Regulirung des Muskeltonus wird unter anderen auch das Körpergleichgewicht erhalten, ohne dass aber gesagt werden darf, dass das Kleinhirn das Organ des Gleichgewichtes ist. Bei dieser Erhaltung des Gleichgewichtes ist aber auch der Sehhügel and der übrige Gehirnstamm in den oben näher auseinandergesetzten Theilen thätig. Bei jeder Bewegung, die wir machen, verschiebt sich der Schwerpunkt des Körpers, dabej müssen verschiedene Muskelgruppen mitthuen, um dem Körper das Gleichgewicht zu erhalten. Es muss also in gewissen Muskelgruppen der Tonus vermehrt werden, um das Gleichgewicht zu erhalten. Wenn z. B. das rechte Bein seitwärts gespreizt wird, müssen die Muskeln, welche den Kopf und den Rumpf zur linken Seite ziehen, in einen stïrkeren Tonus versetzt werden, um das Gleichgewicht zu erhalten und gewisse Gelenke fixirt werden, um die Bewegungen exact auszuführen. Das Kleinhirn regulirt num, indem es durch seine sensiblen Babnen (Olivenfasern, Gowers- 
sches Bündel, Kleinhirnseitenstrangbahn, Fasem aus der ventralen Randzone des Rüekenmarkes, Fasern aus den Hintersträngen und Hinterstrangkernen) die Empfindungen über die Körperhaltung erhält, automatisch diesen Tonus auf dem Wege des Deiters'schen Kernes und der Kleinhirnvorderseitenstrangbahn, auf dem Wege des Dachkerns und gezahnten Kerns, der ausstrahlenden Kleinhirnbahn, des inneren Strickörperbündels, des accessorischen Bindearmbündels, der Fasern zum Seitenstrangkern (M o nak o w'sches Bündel), des Kleinhirn-Sehhügelbündel (einerseits rother Kern, Monakow'sches Bündel andererseits ventraler Sehhügelkern-Körperfühlsphäre).

Jede Hirnstammbälfte, Sehhïgel, Vierhügel, Brücke und verlängertes Mark, erhalten durch ihre motorischẹn Haubenbahnen die Muskeln in einem gewissen Tonus. Fällt nun durch Halbseitendurchschneidung, z. B. der Brücke diese Wirkung einer Seite fort, so wirken die motorischen Bahnen der anderen Haube noch fort und bewirken eine $\mathrm{Ab}$ lenkung und Verdrehung des Körpers, die erst im Laufe der Zeit vom Grosshirn theilweise überwunden wird; Kopf und Rumpf werden in dem Falle zur gesunden Seite abgelenkt.

Das Kleinhirn übt nun diesen regulirenden Tonus unter anderem vor allem auf die Nackenmuskeln und Rückenmuskeln aus, wie ich das durch die Reizersuche nachweisen konnte. Wird nun eine Kleinhirnhälfte abgetragen, so wirkt die andere Kleinhirnhälfte noch fort auf die gleichseitige Muskulatur des Nackens etc., welche die Wälzbewegungen bervorbringen und die ebenfalls erst im Laufe der Zeit überwunden werden. In der gleichen Weise ist die conjugirte Blickablenkung und der Nystagmes bei halbseitiger Kleinhirnläsion zu erklären.

Unter anderen regulirenden Einflüssen übt das Kleinhirn bei Bewegungen auf jene Muskeln tonisirend ein, welche die Gelenke fixiren. Wenn z. B. der Unterarm gebeugt werden soll, muss für eine solche exacte Bewegung das Schultergelenk fixirt sein. Fällt dieser Kleinhirneinfluss fort, so entstehen die schleudernden, atactischen Bewegungen, die wir beim Versuchsthiere wohl als das wichtigste Symptom hinstellen (cerebellare Ataxie). Ganz ein ähnlicher Zustand, wie er beim Thiere durch Halbseitenläsion des Kleinhirns entsteht, bestebt auch beim Venschen in Fällen von multipler Sklerose mit starkem Intentionstremor. Sowie bei einem solchen Kranken schleudernde, atactische Bewegungen entstehen, ebenso bewegt sich das Thier mit Halbseitenläsionen des Kleinhirns, besonders bei intendirten Bewegungen. Der Kopf des Thieres wackelt ïber der Nahrung hin und her, ohne dass das Thier die Nahrung erfassen könnte, wird aber der Kopf fixirt, so geht das Erfassen der Nahrung gut. 
Die anatomischen und physiologischen Ergebnisse zeigen, dass jede Grosshirnhälfte zugleich mit der gegenüberliegenden Kleinhirnhälfte auf dieselbe Körperhälfte Einfluss nimmt. Wir sehen nach Grosshirndefecten Atrophien der gegenüberliegenden Kleinhirnbälfte, wir kennen nun auch diese Verbindungswege und die Leitungsrichtung dieser Bahnen, wir sehen aus den Reizversuchen, dass das rechte Grosshirn und das linke Kleinbirn, die linke Körpermuskulatur beherrscht.

Auch auf einen anderen Punkt kann ich hier noch hinweisen. Wir sehen nach Abtragung des rechten Stirnhirnes eine Ablenkung des Kopfes nach rechts, ebenso nach isolirter Zerstörung des rechten Sehhügels; bei Halbseitendurchschneidungen im Vierhügel, der Brücke sehen wir diese Kopf- und Rumpfablenkung nach rechts bei linksseitiger Halbseitendurchschneidung. In allen diesen Fällen können von Thieren auch Kreisbewegungen nach rechts ausgeführt werden, die auch in seltenen Fällen, wo der Radius der Kreisbewegung ein kleiner ist, in leichte Wälzbewegungen übergehen. Bei Abtragung der linken Kleinhirnhälfte entstehen nun Wälzbewegungen im Sinne des Ohrzeigers. Wir sehen also auch aus diesen $Z$ wangshaltungen und Zwangsbewegungen das Zusammenspiel der Grosshirnrinde mit dem gegenüberliegenden Kleinhirn. Die Gegend der Bindearmkreuzung, der Meyner't'schen und Forel'schen Kreuzung zeigt die Kueuzungsstelle der physiologischen Verknüpfung der Grosshirnrinde mit dem gegenüberliegenden Kleinhirn.

Wie vollzieht sich nun der Hirnmechanismus des Kleinhirnes nach meinen anatomischen und physiologischen Ergebnissen? Das Primitive, von dem wir ausgehen müssen, ist der spinale Reflexbogen. Das Hinterhorn erhält durch seine hintere Wurzel die sensiblen peripheren Eindrücke und die Ganglienzellen wirken nun auf die Vorderhornzellen regulirend ein. Bei Verletzung der hinteren Wurzeln können keine exacten motorischen Leistungen mehr erfolgen, ja es kann sogar mit dem Wegfall der hinteren sensiblen Wurzeln eine reflectorische Lähmung eintreten. Auch nach Zerstörung eines Hinterstrangkemes können die oben erwähnten motorischen Störungen in der Haltung und Locomotion des Thieres auftreten (Contractur, Ataxie, Muskelgefühlsstörung). Ganz ähnlich verhält es sich mit dem Kleinhirn, wenngleich der Mechanismus complicirter ist. Auch das Kleinhirn erhält von der Peripherie seine sensiblen Eindrücke und wirkt dann regulirend auf die motorischen Apparate in dem oben genannten Sinne.

Wir haben oben die Bahmen genau erörtert, auf welchen centripetalen Kleinhirnbahnen dem Kleinhirn Reizwellen zuströmen. Wir fanden am Rückenmarke das Gowers'sche Bündel und die Klein- 
hirnseitenstrangbahn, welche Erregungen aus dem Rückenmarke der Kleinhirurinde zuführen. Diese Verbindungen sind theilweise gekreuzte. Ausserdem fanden wir sensible Fasern aus der ventralen Randzone des Rückenmarkes durch den Strickkörper zur Kleinhirnrinde ziehen, und andere Fasern von hier zum Deiters'schen Kerne ziehen, der seinerseits wieder durch Fasern mit der Kleinhirnrinde verbunden ist. Ebenso gehen auch sensible Fasern aus den Hinterstrangkernen durch den Strickkörper der Kleinhirnrinde zu.

Durch alle diese Bahnen werden Erregungen aus dem Rückenmarke der Kleinhirnainde, hauptsächlich dem Mittellappen, zugeführt.

In dem verlängerten Marke fanden wir als zuführende Kleinhirnfasern, ein mächtiges Bündel, das von der gegenüberliegenden unteren Olive ausgeht und durch den Strickkörper zur Kleinhirnrinde (Mittellappen) führt, ausserdem giebt auch der gleichseitige Seitenstrangkern Fasern in den Strickkörper ab. Der Acusticuskern und die Ganglienzellen im inneren Abschnitt des Strickkörpers entsenden ebenfalls Fasern zur Kleinhirnrinde.

In der Brücke fanden wir eine mächtige centripetale Kleinhirnbahn in den Fasern des Brückenarmes. Dieser sendet nach meinen Befunden die Grosshirnimpulse, die dem gegenüberliegenden Brückengrau übermittelt werden, in die Rinde des Kleinhirnes und zwar hauptsächlich nur in die Rinde des Seitenlappens.

Damit wären die zuführenden Kleinhirnbahnen erschöpft. Wir sahen demnach, dass die aus dem Rückenmark und dem verlängerten larke kommenden Reize hauptsächlich der Rinde des Kleinhirnmittellappens übergeben werden, während die vom Grosshirn kommenden Reize hauptsächlich der Rinde des Kleinhirnseitenlappens übergeben werden.

Sehen wir nun wie es mit den centrifugalen Kleiuhimbahnen steht. Von der Kleinhirnrinde können weder Fasern in das Rückenmark, noch zum Sehhügel verfolgt werden. Die Kleinhirnrinde entsendet alle ihre centrifugalen Fasern zu ihren Kernen, dem gezahnten Kern, dem Dachkern und dem Deiters'schen Kern. Directe Rindenfasern können nur durch den Brückenarm zum Brückengrau und zum gegenüberliegenden Nucleus reticularis pontis (Umschaltung auf die Pyramidenbahn) verfolgt werden; weitere centrifugale Rindenfasern des Kleinhirns werden in dem äussersten Abschnitte des Strickkörpers zum Seitenstrangkern (Umschaltung zum Monakow'schen Bündel) entsendet. Anderweitige centrifugale Rindenfasern des Kleinhirnes kann ich nicht nachweisen.

Das Kleinhirn entsendet also seine Reize hauptsächlich durch die 
Schaltstationen des gezahnten Kernes, des Dachkernes und des Deiters schen Kernes. Vom gezahnten Kern gehen die Kleinhirnreize durch die Kleinhirn-Sehhügelstiele und das ventrale Kleinhirn-Sehhügelbündel zum rothen Keru (Umschaltung auf das Monakow'sche Bündel! und zum Sehhügelkern vent a (Umschaltung zur Körperfühlsphäre). Durch die ausstrahlende Kleinhirnbahn, dem accessorischen Bindearmbündel und dem inneren Strickkörperbündel werden Reize vom Dachkerne den Kernen der Medulla oblongata und der Brücke übergeben. Diese Fasern können auf die Brücken-Vorderstrang- und Brücken-Seitenstrangbahn einwirken.

Vom Deiters'schen Kern werden die Kleinbirnreize der KleinhirnVorderseitenstrangbahn für die Vorderhörner des Rückenmarkes übergeben und durch das hintere Längsbündel den Kernen der Augenmuskelnerven.

Es kann also das Kleinhirn durch den Deiters'schen Kern und die Kleinhirn-Vorderstrangbahn regulirend auf die Muskelactionen einwirken, ausserdem kann es durch den Bindearm auf den rothen Kern und das Monakow'sche Bündel tonisirend einwirken und weiterhin durch den Sehhügelkern vent a auf die Körperfühlsphäre wirken und diese von seinen Leistungen in Kenntniss setzen. Auch auf das Brïckengrau, wo die Pyramidenbahn Collateralen entsendet, kann es centrifugal mittelbar auf die Pyramidenbahn wirken und ebenso auch im Seitenstrangkern, wohin die Pyramidenbahn Fasern des accessorischen Pyramidenbündels entsendet und wo auch das Monakow'sche Bündel Collateralen abgiebt.

Das Kleinhirn kann offenbar auf sensible Erregungen, die es erhält, auf den Deiters'schen Kern etc. einwirken; es, kann aber auch in einer gewissen Artverarbeitet diese sensiblen Eindrücke durch den Bindearm zum Sehhügelkern vent a weiter befördern. Diese Endigungsstätte spricht sehr für die Weiterleitung sensibler Reize, da ja nach meinen Untersuchungen etwas lateral und caudal direct angrenzend (vent $\mathrm{c}+$ vent a) die mediale Schleife endigt. Es liegt also hier eine Schaltstation sensibler Reize aus dem Rückenmarke vor, die theils auf dem Wege der medialen Schleife, theils auf dem Umwege des Kleinhirns, gezahnten Kerns, Bindearmes hierher gelangen. Von hier aus werden diese Reize durch Sehhügel-Rindenfasern (Dieses Archiv Bd. 33 und Jahrb. f. Psych. 1902) der Körperfühlsphäre übergeben. Thatsächlich baben wir auch nach Zerstörung des Sehhügels und des Hinterstrangkernes Sensibilitätsstörungen besonders Muskelsinnstörungen gesehen. Auch bei Kleinhirnläsionen sahen wir vorübergehende Muskelsinnsstörnngen, die mit den oben geschilderten anatomischen Verhältnissen völlig übereinstimmen. 
Durch diese dem Kleinhirn zugeführten sensiblen Erregungen kann es tonisirend auf die Muskelactionen wirken einerseits durch das Monakow'sche Bündel und die Pyramidenbahn, andererseits durch die Kleinhirn-Vorderseitenstrangbahn.

Ich möchte hier noch auf die grosse Bedeutung des Brückengraues hinweisen. Hier giebt nicht nur die Pyramidenbahn Collateralen ab, sondern es enden hier auch Fasern aus dem Schläfelappen, Scheitellappen und Hinterhauptslappen. Es sind das jene Fasern, die ich im lateralen Theile des Hirnschenkelfusses nachweisen konnte und die hier mit Anfsplitterungen endigen. Dadurch können also Reize einer grossen Oberfläche der Grosshimrinde auf das Brückengrau und vermittelst dieses auf die gegenüberliegende Kleinhirnhälfte einwirken, die in ihrem Sinne dann auf die Muskelactionen einwirkt.

Wien, im Mai 1900.

\section{Exklärung der Abbildungen (Taf. XVI-XVII.).}

Figur 1. Photogramm eines Frontalschnittes durch das Gehirn einer Katze mit einseitiger Abtragung der Kleinhirnrinde und theilweiser Zerstörung des gezahnten Kerns und des Dachkerns.

Nt Dachkern, N d gezahnter Kern, a degenerirtes Bündel von der Verletzung in die gesunde Kleinhirnhemisphäre, VIII Nervus cochleae, Cr Strickkörper, $\mathrm{z}^{1}$ und $\mathrm{z}$ innere Abtheilung des Strickkörpers, inneres Strickkörperbündel, das bis zum Burdach'schen Kern verfolgbar ist; b absteigend degenerirende Kleinhirnfasern im äusseren Theil des Strickkörpers. Va spinale Trigeminuswurzel, 0 untere Olive, $y_{1}$ und $y_{2}$ innere Bogenfasern, die rom Kleinbirn kommend, knapp neben dor Raphe sagittal umbiegen. KVS Kleinhirn-Vorderseitenstrangbahn; vKTh ventrales Kleinhirn-Thalamusbündel. Py Pyramidenbahn.

Der Frontalschnitt geht durch die untere Olive, den Facialiskern und den Nervus acusticus. Färbung nach Marchi.

Figur 2. Frontalschnitt durch das Gehirn derselben Katze in der Höhe des Facialiskniees und der austretenden Facialiswurzel.

Die Verletzungsgrenze des Kleinhirns ist dureh die zahlreichen Degenerationen (roth) erkenntlich. c und $\mathrm{c}^{\prime}$ Dachkernfasern, die sich im Mittellappen eben kreuzen. BA degenerirter Bindearm, der aus dem verletzten gezahnten Kern hier abgeht. Nd gezahnter Kern, der Dachkern ist nur mehr im vordersten Antheil getroffen, bim äusseren Theii des Stricklkörpers absteigende Kleinhirnfasern, die bis zum Seitenstrangkern verlaufen. Cr Strickkörper. Va spinale Trigeminuswurzel, SgV Substantia gelatinosa der aufsteigenden Trigemiauswurzel. $\quad c, z$ und $c^{\prime} z^{\prime}$ ausstrahlende Kleinhirnbahn mit den abgehenden inneren Bogenfasern, die in $y$ und $y^{\prime}$ in die sagittale Richtung umbiegen und 
bis in die vordere Brücke verfolgbar sind, NVI Abducenskern, VII N. facialis, s mediale Schleife, vKTh ventrales Kleinhirn-Thalamusbündel, 0 Olive.

Figur 3. Photogramm eines Frontalschnittes durch das.Gehirn derselben Katze. Marchi'sche Färbung. Die Verletzung reicht in den gezahnten Kern Nd hinein. Cr Stricklörperfasern im Verlaufe zum Mittellappen. c und $\mathrm{c}^{\prime}$ accessorisches Bindearmbündel, BA degenerirter Bindearm, z innere Bogenfasern der ausstrahlenden Kleinhirnbahn zur Substantia reticularis, $y_{1}$ und $\mathrm{y}_{2}$ in die sagittale Richtung umgebogene, inwere Bogenfasern rom Kleinhirn, 0 Olive, Py Pyramidenbahn, vKTh ventrales Kleinhirn-Thalamusbündel.

Figur 4. Frontalschnitt durch das Gehirn derselben Katze. V Blutgerinnsel in der Verletzungsstelle, $c$ und $\mathrm{c}^{\prime}$ Dachkernfasern, scheinbar ungekreuzte Bindearmfasern, BA Bindearm, Vd abstejgende, cerebrale Trigeminuswurzel, BrA degenerirte centrifugale Brückenarmfasern, die im Brückengrau BrG gegenüber endigen, NRT Nucleus reticularis tegmenti, y Kleinhirnbogenfasern, die sagittal knapp neben der Raphe bis in die vordere Brücke verlaufen, NV Nervus trigeminus, vKTh ventrales Kleinhirn-Thalamusbündel, s medialo Schleite.

Figur 5. Frontalschnitt durch die hintere $Z$ weihügelgegend derselben Katze. C. qu. p. hinterer Zweihügel, $c$ und $\mathrm{c}^{\prime}$ scheinbar ungelireuzto Bindearmfasern, dKTh dorsales Kleinhirn-Thalamusbündel, BA Bindearm, BrA Brückenarm, x ventraler Ast des Bindearmes zum ventralen KleinhirnThalamusbündel vKTh, BrG Brückengrau, p Pyramidenbahn.

Figur 6. Photogramm eines Frontalschnittes durch den vorderen Zweihügel derselben Katze.

Aqu Aquaeductus Sylvii, c und c' scheinbar ungelireuzte Bindearmfasern vom gegenüberliegenden Dachkern, RK rother Kern, BM Meynert'sches Bündel, dKTh dorsales Kleinhirn-Thalamusbündel, vKTh ventrales KleinhirnThalamusbündel, p Hirnschenkelfuss, s mediale Schleife.

Figur 7. Photogramm eines FrontaIschnittes durch die hintere Commissur derselben Katze.

c p hintere Commissur, p Hirnschenkelfuss, L. m. e. änssere Marklamelle des Sehhügels, L. m. i. innere Marklamelle des Sehhügels. CL Luysscher Körper, BM Meynert'sches Bündel, f Fornix, BV Bündel von Vicq d'Azyr, o' Dachkernfaseru, anscheinend ungekreuzte Bindearmfasern, KTh vereinigtes Kleinhirn-Thalamusbündel, vent $\mathrm{b}$ medial-ventraler Thalamuskern, Cge äusserer Kniehöoker, II Tractus opticus.

Figur 8. Frontalschnitt durch das Chiasma Nervi optici derselben Katze (Photogramm).

B Balken, f Fornix. T. th. Taenia thalami, Cge äusserer Kniehöcker, med a medialer Kern des Sehhügels, vent a central-ventraler Sehhügelleern, Lm e änssere Marklamelle des Sehhügels, $c^{\prime}$ scheinbar ungekreuzte Bindearmfasern rom Dachkern, PK Pedunculuskern, BV Bündel von Vicq d'Azyr, II Chiasma Nervi optici, f Fornix, med c grosszelliger medialer Sehhügelkern, ca Commissura anterior, Li Linsenkern.

Die Endigungen des Kleinhirn-Thalamusbündels reichen auf den fronta- 
leren Schnitten seitlich bis zur äusseren Marklamelle des Sebhügels. Die Fasern $c^{\prime}$ sind äusserst spärlich und nicht in allen Fällen nachweisbar.

Figur 9. Pbotogramm eines Frontalschnittes durch das oberste Halsmark nach theilweiser Durchschneidung des Vorder- und Seitenstranges and zum Theil der Hinterstränge im mittleren Brustmark. GGowers'sches Bündel, KSS Kleinhirn-Seitenstrangbahn, Go Goll' scher Strang. G' Gowers' sches Bündel, KSS' Kleinhirnseitenstrangbahn auf der unverletzten Seite. Marchi'sche Färbung.

Figur 10. Photogramm eines Frontalschnittes durch die Brücke derselben Katze.

NV Trigeminuskern, V Nervus trigeminus, M Monakow'sches Bündel, Py, Pyramidenbahn, s mediale Schleife, G Gower'sches Bündel der Verletzungsseite, $d$ in der Rinde des Mittellappens endigende Fasern, $G^{*} G_{0}$ wers'sches Bündel der unverletzten Seite, KSS' Kleinhirn-Seitenstrangbahn der unverletzten Seite, BrA Brückenarm.

Figur 11. Photogramm eines Frontalschnnittes durch die Brücke derselben Katze.

Py Pyramidenbahn, s mediale Schleife, VNervus trigeminus, G Gowers sches Bündel der Verletzungsseite, KSS Kleinhirn-Seitenstrangbahn der Verletzungsseite. Vd cerebrale Trigeminuswurzel, BA Bindearm, G' Gowerssches Bündel der unverletzten Seite, KSSt Kleinhirn-Seitenstrangbahn der unverletzten Seite.

Figur 12. Photogramm eines Frontalschnittes durch das Gehirn einer Katze mit Abtragung eines Seitenlappens des Flocculus und theilweise halbseitiger Abtragung des Mittellappens mit Verletzung des Nervus acusticus, Facialis, Trigeminus und des Monakow'schen Bündels und der spinalen Trigeminuswurzel.

V Verletzungsstelle, N VIII laterale Acusticuswarzel, St Strickliörper, Va spinale Trigeminuswurzel, $\mathrm{x}$ centrale Hörbahn vom Tuberculum acnsticum zum gegenüberliegenden hinteren Zweihügel, KVSKleinhirn-Vorderseitenstrangbahn, N VII Facialisknie unterhalb der Abducenskern, HL hinteres Längsbündel, Tr Trapezkörperfasern vom ventralen Acusticuskern zur gegenüberliegenden lateralen Schleife mit Einstrahlungen bei $b$ in die gleichseitige und bei a in die gegenüberliegende obere Olive.

N VI Nervus abducens, 00 obere Olive, N VII Nervus facialis, Va spinale Trigeminuswurzel, N VIII Neryus acusticus, y N VIII ventraler Acusticuskern, z ausstrahlende Kleinhirnbahn mit abgehenden inneren Bogenfasern; D Deiters'scher Kern, St Stricklörper, Nd gezahnter Kern, Nt Dachkern, y degenerirtes Faserbündel von der Verletzung in die gesunde Kleinhirnbemisphäre.

Figur 13. Photogramm eines Frontalschnittes durch die Brücke derselben Katze.

V Verletzungsstelle, BrA Brückenarm, BA Bindearm, c Endigungen der centrifugalen Brückenarmfasern im gegenüberliegenden Brückengrau, $\mathrm{M}^{*}$ die im Areal des Monakow'schen Bündels liegenden, zum rothen Kern aufstei- 
gend degenerirenden Fasern, HL hinteres Längsbündel, VV Areal der Vierhügel-Vorderstrangbahn, NV Nervus trigeminus, Nrt Nucleus reticularis pontis, vKTh ventrales Kleinhirn-Thalamusbündel, M Areal des Monakow'schen Bündels, Tr Trapezkörperfasern im äusseren Antheil der lateren Sehleife, x centrale Hörbahn vom gegenüberliegenden Tuberculum acusticum im inneren Antheil der lateralen Schleife, w Dachkernfasern des Bindearmes vom gegenüberliegenden Dachkern, Vd cerebrale Trigeminuswurzel, NIV Nervas trochlearis, y degenerirtes Bündel von der Verletzungsstelle durch den Mittellappen in den gesunden Seitenlappen.

Figur 14. Photogramm eines Durchschnittes durch das oberste Halsmark dieser Katze.

KV Kleinhirn-Vorderstrangbahn, KVS Kleinhirn-Vorderseitenstrangbahn, M Monakow'sches Bündel.

Figur 15. Photogramm eines Durchsohnittes durch das Sacralmark derselben Katze.

KVS vereinigte Kleinhirn-Vorderstrangbahn und Kleinhirn-Vorderseitenstrangbahn, M Monakow'sches Bündel.

Die Figuren 1 bis 8 zeigen dieselbe Vergrösserung, ebenso die Figur 10 bis 13 , ebenso die Figuren 9, 14 und 15 . 
V
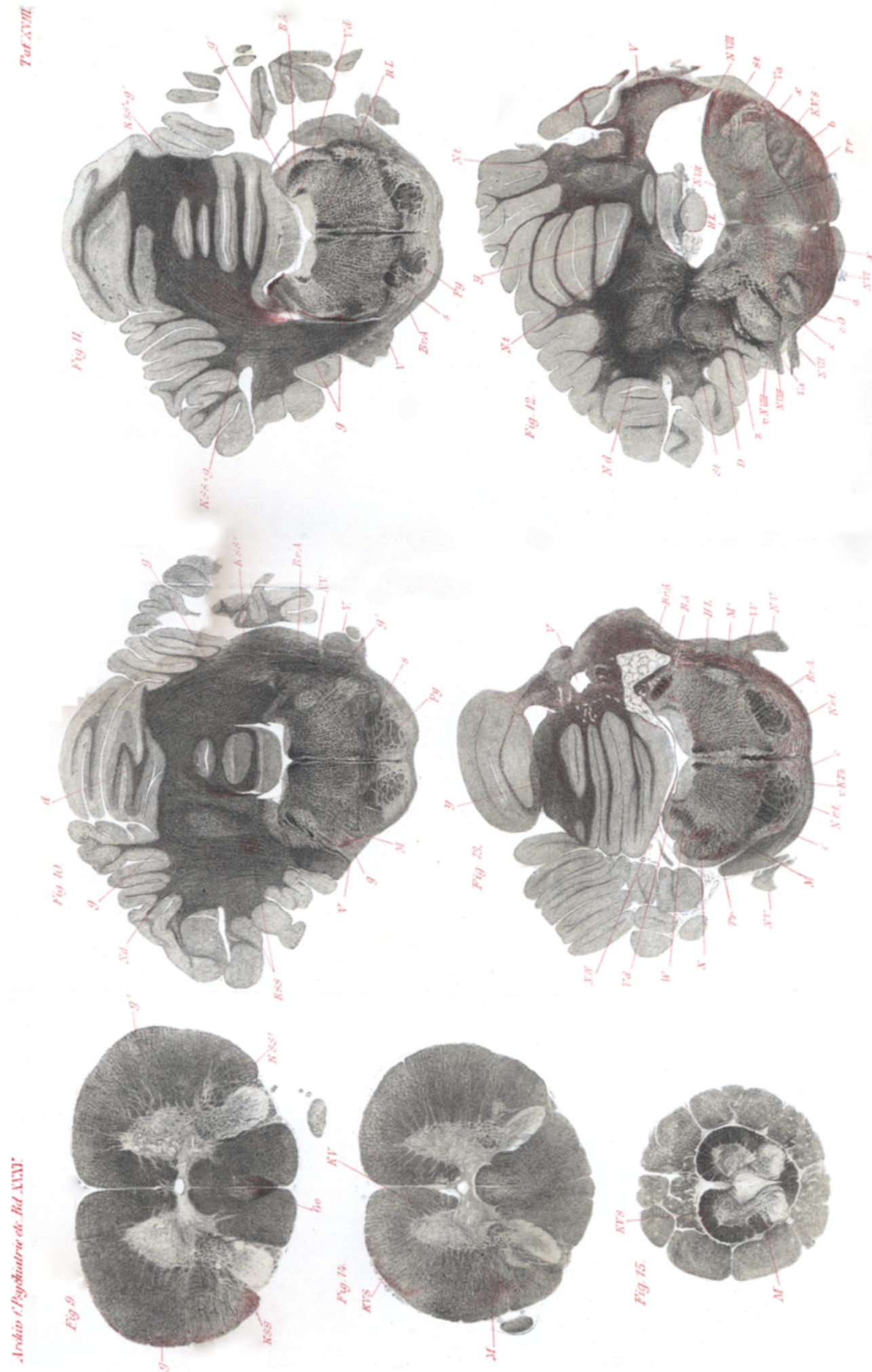